\title{
Electrical Resistivity Imaging and the Saline Water Interface in High-Quality Coastal Aquifers
}

\author{
A. Costall ${ }^{1}$ (D) B. Harris ${ }^{1} \cdot$ J. P. Pigois ${ }^{2}$
}

Received: 24 November 2017 / Accepted: 13 March 2018 / Published online: 14 May 2018

(C) The Author(s) 2018

\begin{abstract}
Population growth and changing climate continue to impact on the availability of natural resources. Urbanization of vulnerable coastal margins can place serious demands on shallow groundwater. Here, groundwater management requires definition of coastal hydrogeology, particularly the seawater interface. Electrical resistivity imaging (ERI) appears to be ideally suited for this purpose. We investigate challenges and drivers for successful electrical resistivity imaging with field and synthetic experiments. Two decades of seawater intrusion monitoring provide a basis for creating a geo-electrical model suitable for demonstrating the significance of acquisition and inversion parameters on resistivity imaging outcomes. A key observation is that resistivity imaging with combinations of electrode arrays that include dipole-dipole quadrupoles can be configured to illuminate consequential elements of coastal hydrogeology. We extend our analysis of ERI to include a diverse set of hydrogeological settings along more than $100 \mathrm{~km}$ of the coastal margin passing the city of Perth, Western Australia. Of particular importance are settings with: (1) a classic seawater wedge in an unconfined aquifer, (2) a shallow unconfined aquifer over an impermeable substrate, and (3) a shallow multi-tiered aquifer system over a conductive impermeable substrate. We also demonstrate a systematic increase in the landward extent of the seawater wedge at sites located progressively closer to the highly urbanized center of Perth. Based on field and synthetic ERI experiments from a broad range of hydrogeological settings, we tabulate current challenges and future directions for this technology. Our research contributes to resolving the globally significant challenge of managing seawater intrusion at vulnerable coastal margins.
\end{abstract}

\section{A. Costall}

alexander.costall@postgrad.curtin.edu.au

1 Department of Exploration Geophysics, Western Australian School of Mines: Minerals, Energy and Chemical Engineering, Curtin University, ARRC/CSIRO Building, H-Block Level 4, 26 Dick Perry Avenue, Kensington WA 6151, Australia

2 Department of Water and Environmental Regulation (DWER), Western Australia, The Atrium, level 4/168 St Georges Terrace, Perth, WA 6000, Australia 
Keywords Electrical resistivity imaging $\cdot$ Perth, Western Australia $\cdot$ Coastal hydrogeology $\cdot$ Seawater intrusion $\cdot$ Near-surface geophysics $\cdot$ Hydro-geophysics

\section{Introduction}

Of the world population in 2003, an estimated 1.2 billion people lived within $100 \mathrm{~km}$ of the coast (Small and Nicholls 2003). Population density along coastal margins, shown in Fig. 1, is higher than average population densities worldwide (Small and Nicholls 2003). As global population increases, the demand on accessible fresh groundwater from shallow coastal aquifers will increase, potentially resulting in the loss of potable water to seawater intrusion. This will have significant human impact (Vorosmarty et al. 2000). In 2001, an estimated $85 \%$ of the Australian population were living within $50 \mathrm{~km}$ of the coast (ABS 2006). Densely populated coastlines of Thailand, Vietnam, and Bangladesh are all at high risk of seawater intrusion (Imperial College London 2015). Populations with the greatest need to access readily available fresh water are often the ones at risk of losing this resource.

Management systems involving aquifer replenishment, such as the Groundwater Replenishment Schemes (GWRS) in Perth, Western Australia (Water Corporation 2016), and California, USA (Water-Technology 2016), can be designed to mitigate seawater intrusion. However, the infrastructure tends to be costly and out of reach for many developing countries.

Seawater intrusion monitoring with wells is a necessary and reliable method of recovering water chemistry above and below the seawater interface. However, wells cannot map

\section{UN-Adjusted Global Population Density, 2015}

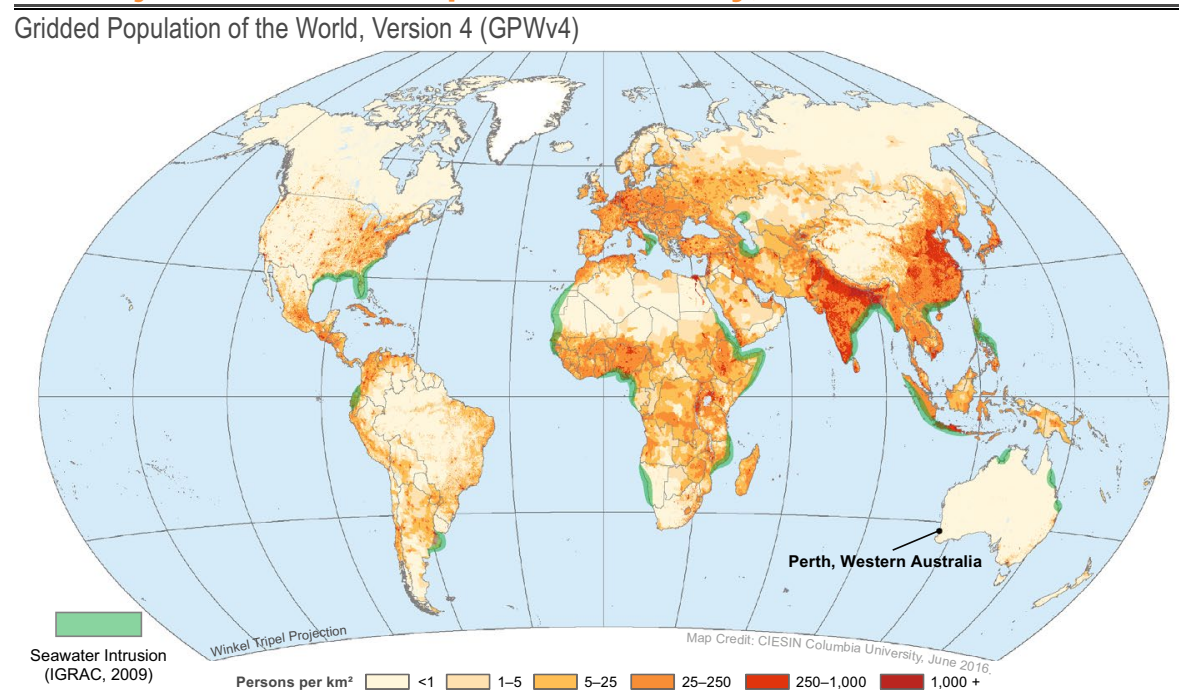

Fig. 1 World population density map derived from gridded population of the world, version 4 (CIESIN 2016). Countries with high population density are also at risk of losing readily accessible fresh water reserves to seawater intrusion if management strategies are not developed. Areas shaded in green around coastal margins are already identified as experiencing seawater intrusion and up-coning (Van Weert et al. 2009) 
the full interface geometry and may be difficult to install in highly urbanized areas. Electrical resistivity imaging (ERI) presents a potentially valuable, low-cost tool for mapping the seawater interface, but only if the resulting formation conductivity distribution can be interpreted with confidence.

Examples of ERI applied for mapping seawater intrusion are presented for transects parallel, or perpendicular to the coastline (Abdul Nassir et al. 2000; de Franco et al. 2009; Koukadaki et al. 2007; Pidlisecky et al. 2016; Wilson et al. 2006). Transects that run parallel to the coastline will not provide any specific geometry of the seawater interface, however may still provide some useful information (e.g., Pidlisecky et al. 2016).

Current literature on ERI and the seawater interface suggests many challenges and knowledge gaps. The consequence is uncertainty regarding: (1) the connection between the inverted and true subsurface conductivity distribution and (2) how the geo-electrical setting connects to coastal hydrogeology and in particular the geometry of the seawater interface. For example, we found no systematic studies of ERI for a high-quality, shallow coastal aquifer underlain by an impermeable substrate. This broad class of coastal aquifer system is common worldwide (e.g., Biscayne aquifer, Florida (Sonenshein 1995), YarkonTaninim aquifer, Israel (Paster et al. 2006; Schwarz et al. 2016)). We also found no systematic comparisons of numerical modeling and field ERI experiments for a diverse set of aquifer systems, which include detailed topography and accurate models of salinity distribution based on seawater intrusion monitoring (SIM) wells.

Of particular interest in our study is the scenario where a high-quality, high-permeability coastal aquifer overlies a shallow clayey substrate. This is common along coastal margins, and we will show that this presents particular challenges for the application of electrical resistivity imaging. This setting consists of four high-contrast geo-electrical boundaries including:

1. the air interface Topographic relief along limestone-dominated coastal margins can vary significantly, from sand dunes, to cliffs, to variably sloped beachfronts. We strongly suspect that accurate elevations must be included in ERI inversion, and note that many ERI studies neglect geometry of this key interface,

2. the water table interface This is a near horizontal surface in high-permeability unconfined aquifers. It exists where the unsaturated zone rapidly changes across the capillary fringe to more electrically conductive, fully saturated aquifer sediments,

3. the seawater interface This is the transition zone between formation saturated with seawater and sediments saturated with fresh, potable, groundwater. This broadly wedgeshaped transitional zone is expected to have an electrical conductivity contrast of at least $1: 100$,

4. the aquifer to confining substrate interface This often sub-horizontal major geo-electrical interface should be divided laterally into parts. The first is the contrast between the aquifer and impermeable substrate on the ocean side of the seawater interface. The second is the transition from fresh potable groundwater to the impermeable substrate on the landward side of the seawater interface.

Superimposed on these four high-contrast geo-electrical boundaries are contrasts linked to variation in lithology. We suspect that lithological changes within the aquifer present a second-order impact on resistivity imaging, compared to the extreme contrasts at each of the four interfaces described above. The caveat to the above is where shallow conductive clays occur close to surface. Such layers may indeed have a strong influence on the outcome of 
resistivity imaging. We will provide many field and numerical experiments to explore the above.

Constraints on ERI inversion can be deployed if drilling, wireline logging, and/or other geophysical data are available. In this case, joint, collaborative and cooperative inversion strategies can be deployed (e.g., Gallardo and Meju 2007, 2011; Le et al. 2016; Marker et al. 2015; Soueid Ahmed et al. 2015; Takam Takougang et al. 2015; Zhou et al. 2014). We will provide field-based examples of how characterization of coastal aquifer systems can be advanced by integration of ERI with complementary data, such as ground penetrating radar (GPR).

Ultimately, resistivity imaging and indeed any near-surface hydrogeophysical method should assist predictive transport modeling processes and contributed to decision making for long-term management of high-quality coastal groundwater resources.

\subsection{Background: The Seawater Interface}

The characteristic wedge shape of the seawater interface is the combined result of many factors. These include (1) the density contrasts between fresh and seawaters, (2) the distribution of hydraulic properties, (3) flow-through of groundwater toward the ocean, (4) rainfall recharge and (5) the distribution of groundwater abstraction and recharge. The shape of the classic theoretical seawater wedge can be obtained from the Ghyben-Herzberg approximation (Verruijt 1968) and is a naturally occurring result of the density difference between saline and fresh water.

Seawater is approximately $2.5 \%$ denser than fresh water due to dissolved solids (i.e., mostly $\mathrm{NaCl}$ ). Denser seawater tends to drive under less dense fresh water in a steady-state mixing environment (Pool and Carrera 2011; Verruijt 1968; Wentworth 1947). Figure 2 provides a schematic for three shallow coastal hydrogeological settings. These include (1) an unconfined aquifer, (2) an unconfined aquifer above a low-permeability substrate, and (3) an aquifer containing a shallow semi-pervious layer above a low-permeability substrate. We will analyze field ERI experiments for all these settings.

Fresh water and saline water are miscible liquids, although the difference exists only in the solute concentration so a zone where saline and fresh water mixing will exist. Models for the mixing zone historically used a simple sharp interface (Verruijt 1968). Modern approximations are based on density-dependent miscible systems which account for variable density mixing zones (Abarca and Clement 2009; National Water Commission 2012; Diersch 2014; Lu 2011; Lu et al. 2013; Werner et al. 2013). The width of the mixing zone can be highly variable, from millimeters in laboratory-based experiments (Abarca and Clement 2009), to kilometers in field-scale examples. Some examples include the Everglades National Park, USA, where a wide mixing zone of approximately 6-28 km is identified by hydrogeological tracers (Price et al. 2003), and at Laizhou Bay, China, where a zone of approximately $1.5-6 \mathrm{~km}$ is identified (Wu et al. 1993).

\subsection{Background: Electrical Resistivity Imaging}

Electrical resistivity imaging (ERI) is a geophysical method used to estimate subsurface electrical properties (Dahlin 2001; Herman 2001; Samouëlian et al. 2005). Fundamentally, an electrical current is injected into the earth between a pair of electrodes and voltage is measured between another pair of electrodes. Multi-channel instruments allow for the rapid acquisition of various electrode configurations. A typical multi-channel array resistivity 


\section{Schematic: Without Substrate}

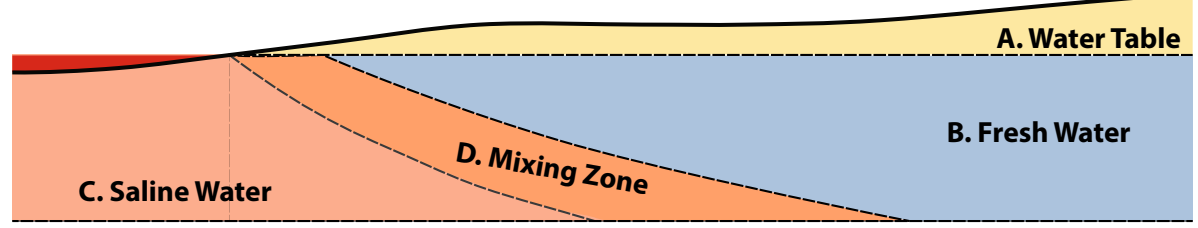

Schematic: With Substrate

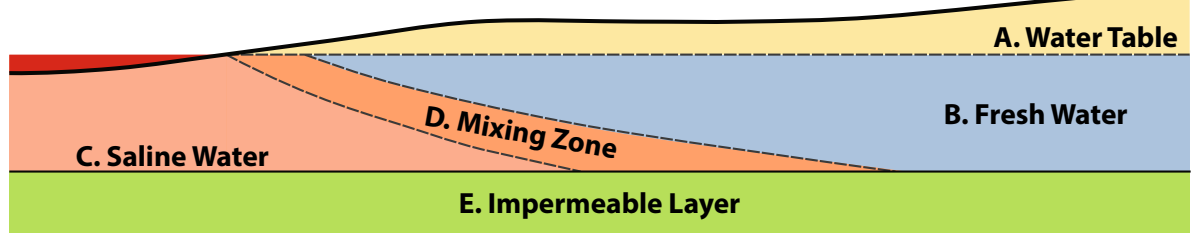

Schematic: With Substrate and Semipervious Layer

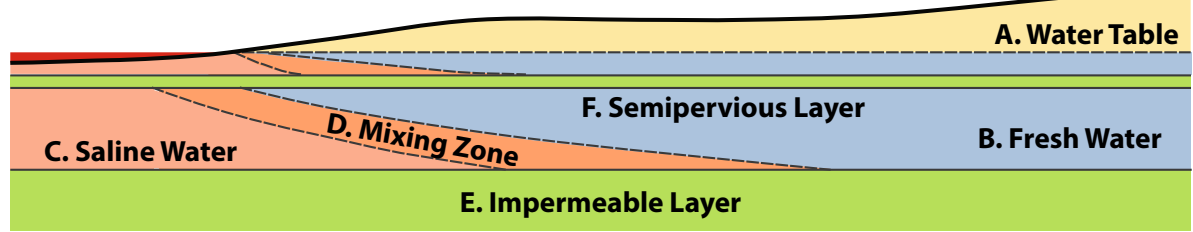

Fig. 2 Schematic representation of three shallow coastal hydrogeological systems, and respective seawater interface geometries, for recovery by ERI methods. Key hydrogeological zones to be resolved by ERI are a: the phreatic water table, b: the saturated potable groundwater, c: the saturated saline groundwater, d: the mixing zone, e: an impermeable substrate, and f: a thin semi-pervious intra-aquifer clayey layer

survey consists of electrodes connected to a transmitter/receiver system via a multi-core cable. The apparent resistivity $(\rho)$ is calculated for every electrode quadrupole by Eq. 1

$$
\rho=k \frac{V}{I}
$$

where $V$ is voltage, $I$ is current, and $k$ is geometric factor.

There are many electrode configurations (Dahlin and Zhou 2004). Some standard configurations are shown in Fig. 3. The multiple-gradient array is relatively modern and suited to multi-channel acquisition. It has high signal-to-noise characteristics, and is similar to the pole-dipole array for some quadrupole arrangements, with other characteristics similar to a Schlumberger array (Dahlin and Zhou 2006; Loke et al. 2013).

Multi-channel ERI acquisition systems are common in modern exploration. Several authors consider methods for efficiently combining ERI arrays to improve subsurface resolution (e.g., Athanasiou et al. 2007; Ishola et al. 2015; Loke et al. 2007). For any given set of electrodes, the total possible number of non-reciprocal electrode combinations is given below (Noel and Xu 1991; Stummer et al. 2002) where $n$ represents the number of electrodes present in the array.

$$
N_{\text {combinations }}=\frac{[n *(n-1) *(n-2) *(n-3)]}{8}
$$




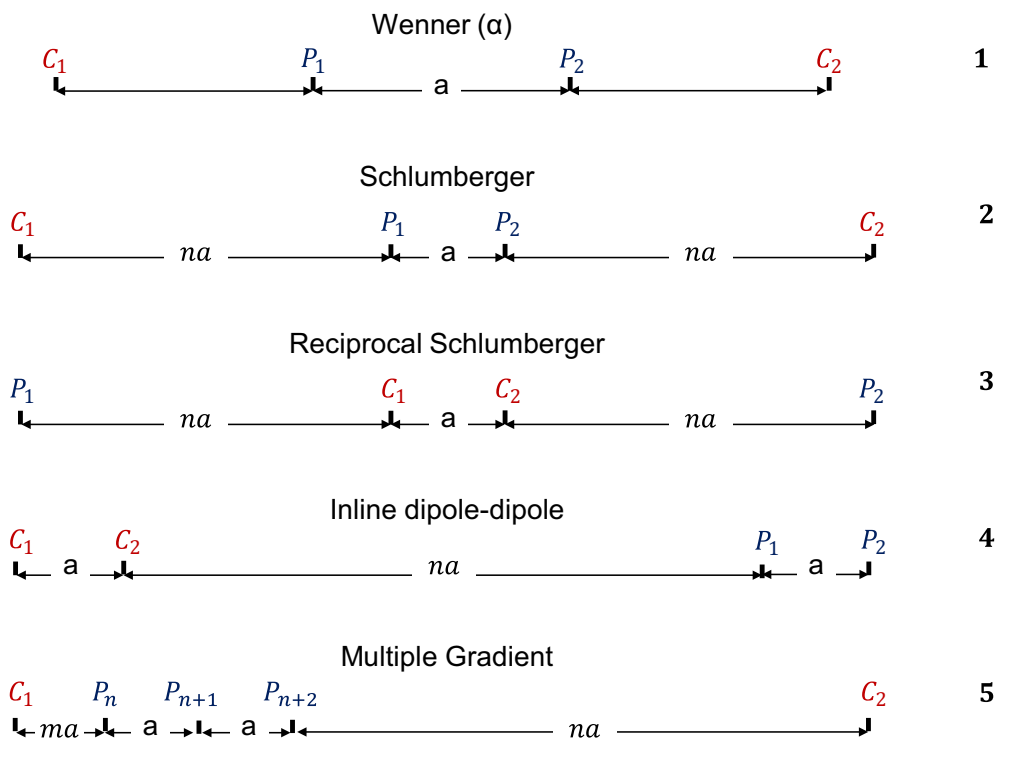

Fig. 3 Schematic showing common electrical resistivity imaging arrays. Arrays 3, 4, and 5 are suitable for multi-channel acquisition and thus efficient field acquisition. Current electrodes are color-coded red, while potential electrodes are in blue. The letter "a" denotes unit spacing, while "na" and "ma" denote multiples of "a" associated with various array parameters

For example, a 24-electrode cable has 31,878 possible 4-electrode arrangements. However, acquiring all of these electrode arrangements is prohibitively time-consuming and does not guarantee a superior outcome.

Optimized arrays, with trade-offs between acquisition efficiency and optimum ERI resolution, is an active field of research for ERI imaging (e.g., Loke et al. 2014a, b, 2015b; Stummer et al. 2002; Szalai et al. 2013; Wilkinson et al. 2012, 2006). Several methods of optimization exist; however, the analysis of resolution matrices has proven popular. This method finds the minimum number of electrodes required to maximize the sum of the resolution matrix elements for a given number of electrode combinations (Loke et al. 2013). Some practical aspects of the optimized arrays, such as electrode polarization effects and noise mitigation, are addressed by Wilkinson et al. (2012).

Depth of investigation for ERI is generally related to electrode separation. Some suggest the depth of penetration of $<30 \%$ of the array length (Roy and Apparao 1971; Szalai et al. 2009). Edwards (1977) suggests that the effective median depth of investigation of a dipole-dipole array is between 14 and $22 \%$ of total line length. The actual depth of investigation must be the result of many variables, such as the array configuration, geo-electrical setting, signal-to-noise ratio during acquisition, and the inversion strategy deployed. Modern approximations for depth of investigation are made with a range of depth-of-investigation algorithms (Christiansen and Auken 2012; Oldenburg and Li 1999).

A comparison of electrode configurations for a range of geo-electrical settings, including analysis over an exceptionally shallow seawater interface $(<5 \mathrm{~m}$ below a horizontal surface) model, is provided by Martorana et al. (2009). They suggest that the dipole-dipole array has advantages for resolving the seawater interface. However, the model study does 
not include topographic relief and the field examples do not span a full seawater interface or provide wells data to verify the inferred results. We note that the substrate used in these models appears to be unrealistic at $0.2 \mathrm{Ohm}-\mathrm{m}$.

The general effects of topography on outcomes from commonly used ERI arrays are examined by Fox et al. (1980) and Tsourlos et al. (1999). They find that incorporation of topography effects is often essential. Tsourlos et al. (1999) conclude that slope angles of $>10^{\circ}$ produce significant and misleading artifacts in ERI-derived conductivity images where topography is not considered. Historic 2D inversion approaches using rectangular blocks with a finite-difference scheme are unable to satisfactorily model steep topographic changes. Modern 2D inversion approaches tend to use finite-element meshes incorporating a variety of shapes, such as triangles, hexagons, and warped rectangles, to accurately reproduce steep and complicated surface geometries, while topographic relief in 3D datasets can be incorporated in unstructured tetrahedral meshes (Rücker et al. 2006). Sloping beachfronts, limestone cliffs, and vegetated sand dunes are all common topographic features along coastal margins. We will include topography in all of our analysis of ERI and coastal hydrogeology.

\subsection{Background: Location, Hydrogeology, and an ERI Control Site}

The coastal margin of Perth, Western Australia, has and will continue to undergo rapid urbanization. It is endowed with a range of high-quality freshwater unconfined aquifer systems. This stretch of coastline is well suited for testing ERI. A broad range of aquifer geometries exist, and seawater intrusion monitoring wells have measured landward movement of the seawater interface. Figure 4 shows seven ERI test sites. Many more transects were collected throughout the course of this research; however, this set provides a notable range of aquifer geometries and imaging outcomes.

Our work is presented in three parts. The first provides analysis of ERI with numerical and field experiments based on a long-term seawater intrusion monitoring site. In the second, well logs and GPR are able to highlight challenges for ERI in a complex geo-electrical and hydrogeological environment. In the third part, we compare ERI outcomes at a diverse range of coastal hydrogeological settings along an approximately $100 \mathrm{~km}$ length of coastline. Here, ERI is deployed at locations with (1) rapid urbanization, (2) historically high rates of abstraction of shallow groundwater, and (3) undisturbed native coastal vegetation.

\section{ERI-A Control Site for Field and Numerical Experiments}

The Quinns Rocks transect is ideally suited as an ERI research and calibration site. It is located approximately $30 \mathrm{~km}$ north of the Perth, Western Australia. This site has a set of established seawater intrusion monitoring (SIM) wells, with groundwater chemistry collected from 1990 to the present. The suburb has undergone extensive and rapid development over this period, accompanied by significant population growth $(\sim 1932-20,070$ people) from 1990 to 2015 (ABS 2018).

Figure 5 shows the relative position of the SIM wells and the field ERI transect. Multiple ERI surveys were acquired along a continuous pathway, broadly perpendicular to the shoreline. No other continuous pathways were available for use, and no access was permitted in the local declared rare flora reserve (Ecoscape Australia Pty Ltd 2004). The pathway is a regularly maintained pedestrian walkway, which provides long-term reliable 


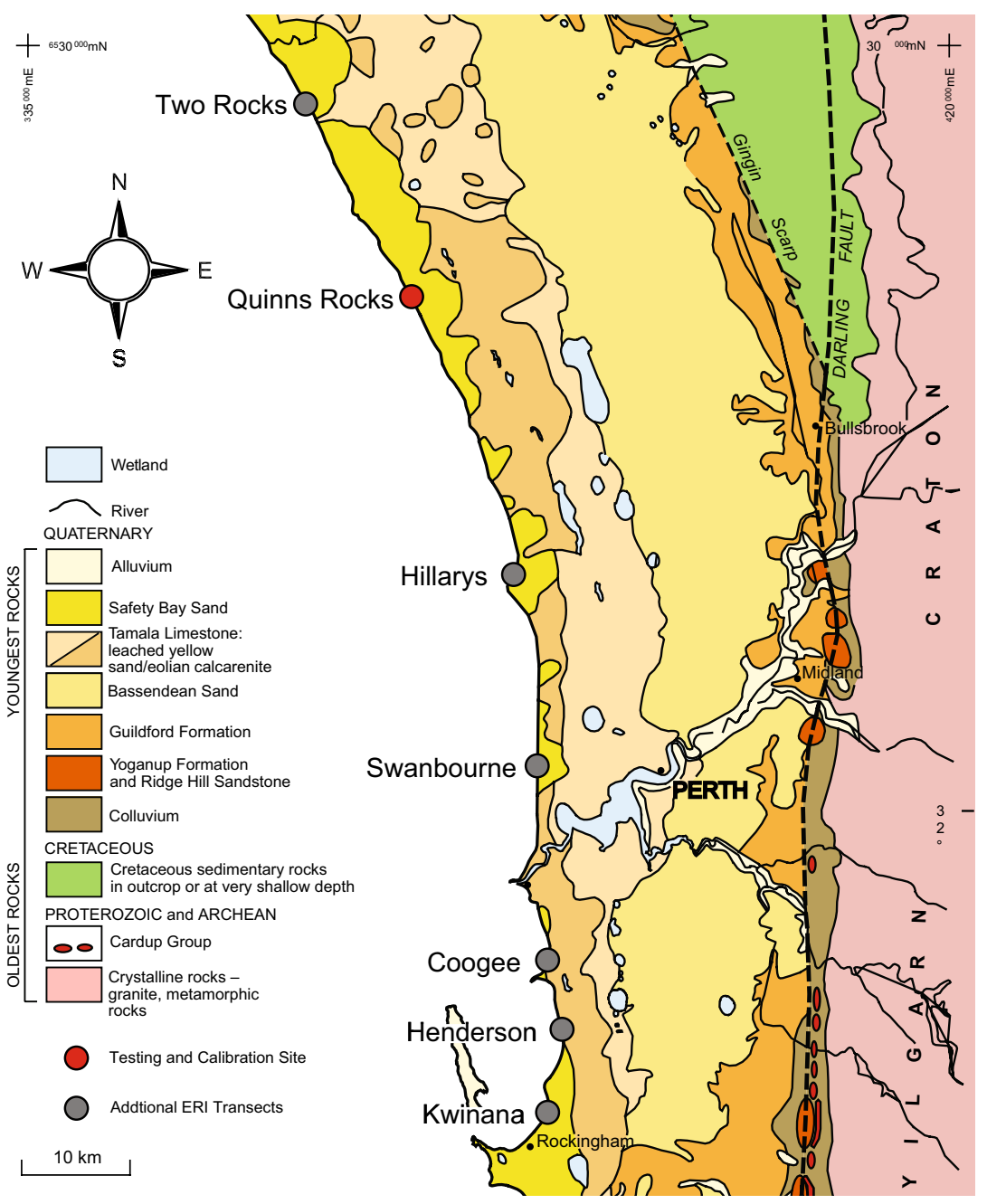

Fig. 4 Map showing the location of ERI transects with respect to shallow geology of the Perth Basin, including the Quinns Rocks ERI research and calibration site (shown in red). Each transect is separated by approximately 15-20 km, covering a total distance of approximately $100 \mathrm{~km}$ along the coastline of Perth, Western Australia. These transects cover a wide range of settings, with Two Rocks being a relatively undeveloped area, while the others are in highly urbanized areas. The hydrogeological settings also range from a thin $(<30 \mathrm{~m})$ high-permeability aquifer over clayey substrate (e.g., Quinns Rocks, Hillarys, Swanbourne) to an aquifer over $150 \mathrm{~m}$ thick (e.g., Two Rocks), and finally a high-permeability unconfined aquifer with shallow clayey layers and shale substrate (e.g., Coogee, Henderson, Kwinana). Base image courtesy of the Geoscience and Resource Strategy Division, Department of Mines, Industry Regulation and Safety, modified from Gozzard (2007) by the authors with permission. @ State of Western Australia 2018

access for repeat geophysical surveys without risk of disturbance to the highly sensitive local bushland.

Records from the SIM well series suggest the seawater interface has moved inland over the last 20 years to be located between SIM 3-90 and SIM 6-90, over $180 \mathrm{~m}$ from the shoreline. The combination of borehole and water chemistry information provides the necessary input for creation of numerical models of subsurface groundwater and 


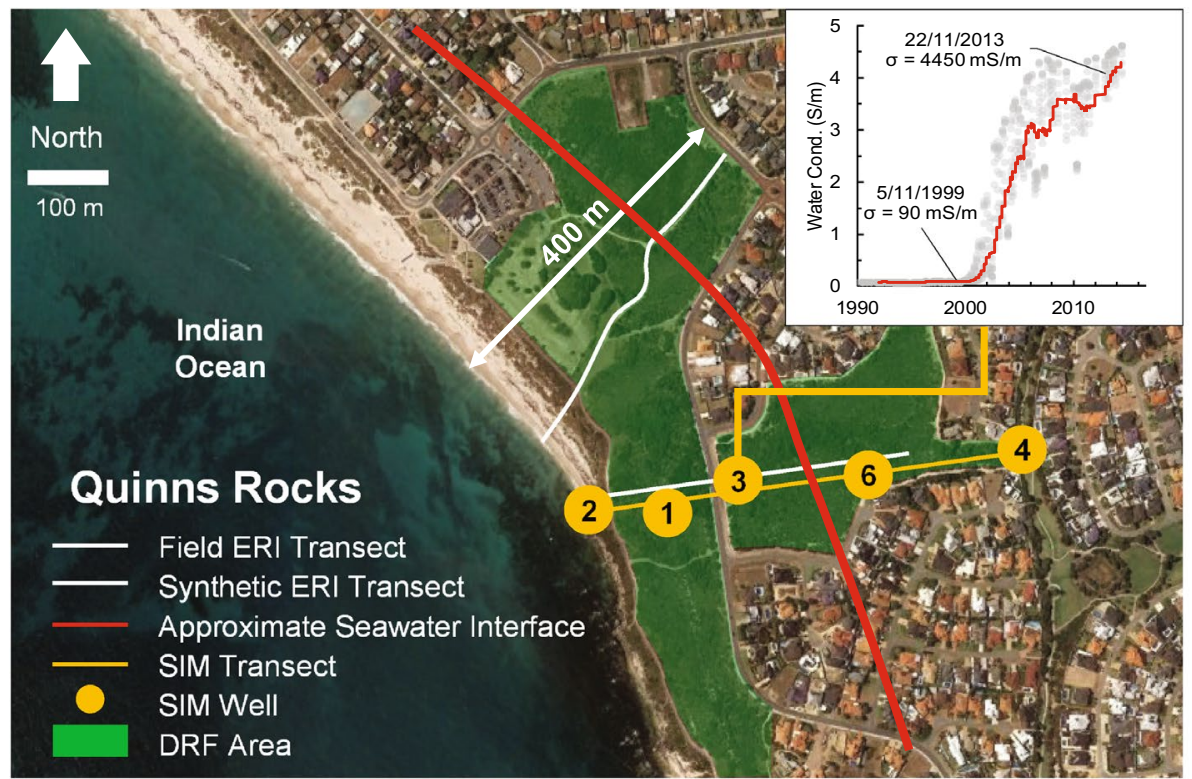

Fig. 5 Photographic image showing the field ERI research transect and SIM wells at Quinns Rocks, Perth, Western Australia. Information from the SIM wells is used to build numerical models of both water and formation electrical conductivity. The field ERI transect runs along a pedestrian walkway, indicated by the solid white line. The graph inserted in the upper right-hand corner of the image provides a measure of seawater intrusion through time in SIM-3. The groundwater in the well was potable until approximately 2001 after which the seawater interface passed SIM-3, and salinity rapidly approached that of seawater. Prior to 1990, there were few dwellings in the Quinns Rocks area (Base satellite imagery (C2017 Google Earth)

formation conductivity. Synthetic ERI datasets were computed over the formation conductivity model for a variety of electrode arrays, and identical parameters were used to acquire field ERI data for a range of electrode arrays.

\subsection{An ERI Calibration Site: Hydrogeology and the Seawater Interface}

The sedimentary facies of the near-shore environment in the Quinns Rocks area is primarily Tamala Limestone and Safety Bay Sand (Davidson 1995). The Tamala Limestone is an expansive reach of Quaternary eolianite limestone found along the majority of coastal Western Australia. Hydraulic conductivity values associated with the Tamala Limestone from regional groundwater models are 75-3000 m/day, with values at Quinns Rocks ranging from 70 to $235 \mathrm{~m} /$ day (Kretschmer and Degens 2012; Smith et al. 2012a). The wide range of values throughout the Tamala Limestone is attributed to well-developed dual-pore systems, e.g., cave systems, and secondary porosity development (e.g., Smith et al. 2012a) in particular areas along the coastal margin of Perth.

A hydrogeological seal comprising glauconitic clay and silty-shale was reported at approximately $30 \mathrm{~m}$ below sea level in several lithological logs from the SIM wells (Water Information Reporting database 2015). This is likely to be the Pinjar Member (Davidson 1995; Ivkovic et al. 2012; Leyland 2012), and we refer to this layer as the clayey substrate. 
The Tamala Limestone can be observed as outcrop, and a sample of the limestone was recovered. Laboratory measurements suggest a formation factor of approximately 14, and porosity of close to 35\%, consistent with suggested values for the Tamala Limestone near Quinns Rocks (Smith et al. 2012a, b). These values are used to convert distribution of groundwater electrical conductivity to formation conductivity.

Figure 6 shows subsurface hydrogeology of a synthetic transect across the SIM wells at Quinns Rocks. It includes interpretation of the seawater interface and formation resistivity based on the formation factor recovered from the sample. The formation conductivity model in Fig. 6 is used for numerical simulation of ERI data, which are then compared with outcomes from a series of field ERI experiments completed at the Quinns Rocks site.

\subsection{ERI Inversion Strategies}

The degree to which resistivity imaging can match the true subsurface resistivity distribution is driven by a combination of acquisition parameters and the inversion strategy. A large number of strategies are possible; however, to progress our analysis across a number of geo-electrical settings, we must select a limited number of strategies. Several appendices are included to explicitly define inversion parameters and provide the imaging outcomes from alternative inversion strategies.
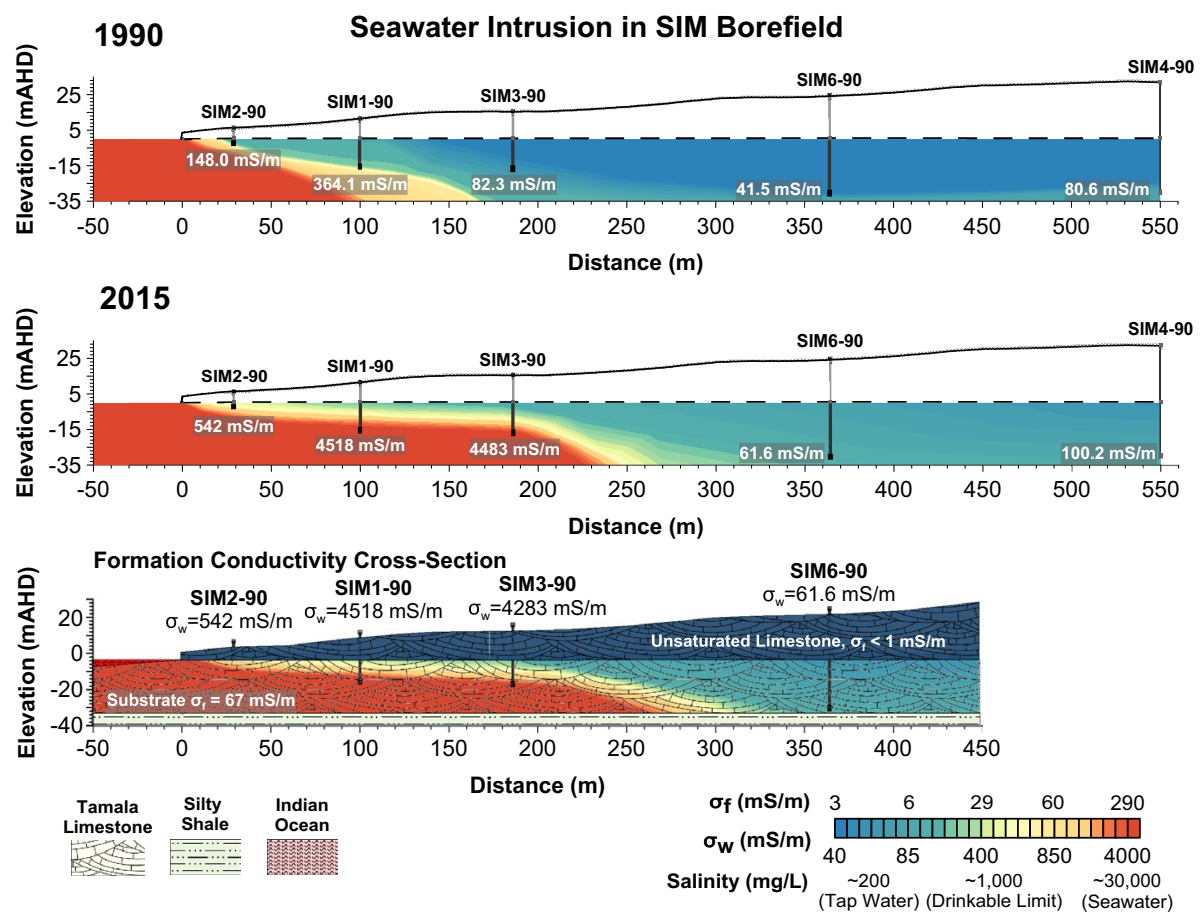

Fig. 6 Images of the Quinns Rocks groundwater solute concentration models for 1990 and 2015 accompanied by a geo-electrical cross section through the series of seawater intrusion monitoring (SIM) wells approximately perpendicular to the coastline at the ERI control site. The model is based on geological logging, wireline logging, and water chemistry information from the SIM wells. A fifth well, SIM 4-90, is located approximately $100 \mathrm{~m}$ farther inland and shows no significant change from SIM 6-90 
Table 1 Summary of our "standard" parameters for inversion of field and synthetic ERI data

\begin{tabular}{ll}
\hline Parameter & Value \\
\hline Initial damping factor & 0.15 \\
Minimum damping factor & 0.02 \\
Number of nodes between electrodes & 8 (4 nodes, Refined mesh) \\
Layer thickness increase with depth & 1.05 \\
First layer thickness (\% of unit step) & 0.25 \\
Damping factor increase with depth & 1.05 \\
Robust data constraint cutoff & 0.05 \\
Model block width & $1 / 2$ electrode step \\
RMS convergence threshold & $5 \%$ \\
Line search RMS change limit & 0.5 \\
Reference resistivity for half-space & Average value of 1st iteration \\
Optimization method & Incomplete Gauss-Newton \\
\hline
\end{tabular}

Inversion is completed with the software RES2DINV (Loke 2016b). The complete list of inversion parameters is in Appendix 3

The industry standard RES2DMOD (Loke 2016c) is used for forward modeling and RES2DINV (Loke 2016b) for inversion. RES2DINV is based on a modified Occam-style 2D ERI Inversion code (Loke 2003). Table 1 contains a summary of parameters used to invert field and synthetic data, while Appendix 3 provides the full list of our standard inversion parameters.

We test a range of ERI inversion parameters, particularly the cutoff factor, used within RES2DINV (Loke 2016b), and produce extensive sets of numerical resistivity imaging outcomes. These allow comparison of outcomes from inversion with different cutoff factors for the geo-electrical model shown in Fig. 6. These sets of images are provided in Appendix 1 and reveal the impact of systematically changing robust data and model constraints. They also assist in selecting our "standard" inversion parameters as provided in Appendix 3.

We also identify an alternative inversion pathway with sufficient merit to reproduce all inversion outcomes and present these in Appendix 4. For the alternate strategy, we used an "expanded model" and a "diagonal roughness filter". Our standard inversion parameters represent an approach commonly deployed in the literature (e.g., Binley et al. 2015; Carriere et al. 2013; Krishnaraj et al. 2014; Loke et al. 2013), which use a trapezoidal model (i.e., not expanded). This limits models cells to pseudo-depth points, so creating the familiar tapered edges on resistivity images. However, limiting the model in such a manner may introduce edge artifacts (Loke 2016a). The "standard" approach with the trapezoidal model does reduce the number of model cells; however, modern computers are capable of handling the demands of an expanded 2D section.

As explained by Farquharson (2007), the normal roughness filter only has components in the $x$ and $y$ directions. This tends to cause vertically or horizontally aligned structures (Loke 2016a). The diagonal roughness filter introduces two additional smoothing constraints in the diagonally up and down directions (Farquharson 2007). This approach can effectively generate dipping and angled interfaces while using the L1 model norm. Note that Appendix 4 provides resistivity imaging from the alternative 
inversion strategy, along with images expressing ERI resolution distribution and graphical representations of inversion misfits.

We note that all data files, including field data, model data, and inversion results, are available for the reader and we encourage comparison with our results.

\subsection{ERI Control Site: Numerical Experiments}

The geoelectrical model shown in Fig. 6 provides the basis for our analysis of ERI along coastal margins. For this setting, we have computed synthetic ERI data for Wenner, Schlumberger, and dipole-dipole electrode configurations with the parameters set out in Table 2. ERI inversion outcomes are assessed for individual arrays and combinations of arrays. We later compare these numerical outcomes with those from field measurements at the calibration site.

Of particular interest is a comparison of artifacts that may arise from unconstrained inversion for the three common electrode configurations, as well as any improvement or deterioration in ERI imaging that may occur by inverting combinations of electrode configurations. Note that the Schlumberger array referred to below is the hybrid Wenner-Schlumberger configuration as described in Pazdirek and Blaha (1996).

Figure 7 shows the outcome of ERI inversion for the geo-electrical model based on distribution of formation conductivity shown in Fig. 6. The first example excludes topography as we note several instances where ERI has been presented but appears to neglect the influence of topography along coastal margins (e.g., Heen and Muhsen 2017; Igroufa et al. 2010; Krishnaraj et al. 2014). We take the opportunity to highlight the significance of both topographic relief and electrode configurations on ERI inversion with the numerical example.

From Fig. 7, the inadequacies of the classic Wenner array are immediately clear as it fails to recover the substrate below the seawater wedge. Both dipole-dipole and Schlumberger arrays overshoot the substrate boundary below the wedge. Notice that the position of the substrate below the high-resistivity fresher groundwater appears well resolved in all cases. However, the existence and depth of the lower substrate would likely be misinterpreted from resistivity images derived from the Wenner synthetic data. The shape and resistivity of the seawater wedge are most accurately recovered from the dipole-dipole data.

There are many ways to represent how effectively an inversion process has fit the numerical data to measurements. Global RMS error is necessary, but is rarely sufficient. We will

Table 2 Numerical modeling array parameters from RES2DMOD

\begin{tabular}{lllllcl}
\hline Test & Array & No. sensors & $n$ & $a$ & No. points & Max. K. \\
\hline Model (w/o Topo.) & Wenner & 44 & - & 14 & 301 & 10,000 \\
& Schlumberger & 44 & 17 & 14 & 1037 & $10,000^{\mathrm{a}}$ \\
& Inline dipole-dipole & 44 & 5 & 14 & 773 & $10,000^{\mathrm{a}}$ \\
Model (w/ Topo.) & Wenner & 55 & - & 18 & 477 & 10,000 \\
& Schlumberger & 55 & 17 & 18 & 1716 & $10,000^{\mathrm{a}}$ \\
& Inline dipole-dipole & 55 & 5 & 18 & 1168 & $10,000^{\mathrm{a}}$ \\
\hline
\end{tabular}

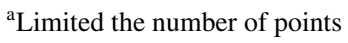




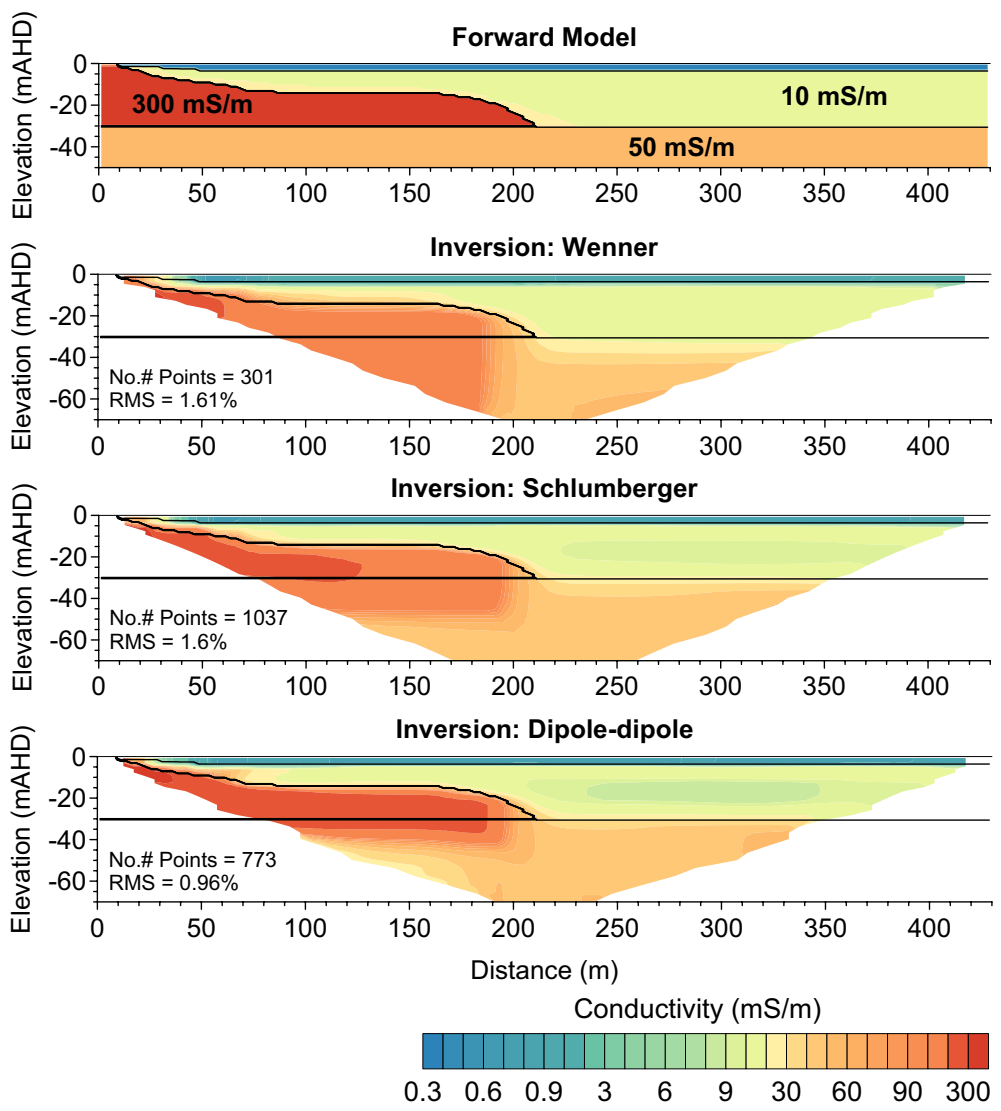

Fig. 7 Images showing the forward geo-electrical model of formation conductivity distribution plus three inverted conductivity sections. The inverted sections are computed from synthetic ERI data of the forward model for different electrode configurations. The forward geo-electrical model is based on water chemistry and lithology from the Quinns Rocks seawater monitoring wells (i.e., Fig. 6). The three survey configurations compared are (1) Wenner (top), (2) Schlumberger (middle), and (3) dipole-dipole (lower). Inversions for these models are unconstrained. The general location of the seawater interface is recovered by inversion for each example given; however, the dipole-dipole survey produced the truest representation of the full geometry of the seawater interface and lower substrate

highlight some additional representations. Firstly, an appreciation of the spatial distribution of misfit can be obtained if model and field apparent resistivity pseudo-plots are compared and accompanied by an image of mismatch percent against pseudo-depth. The distribution of relative mismatch between observed and calculated values (i.e. measured data and inversion output) is a valuable tool for quality control and assessment of model fit. They may reveal an unexpected distribution of percentage mismatch, or the existence of outlier points. We provide examples of mismatch distribution for the forward-modeled Wenner, Schlumberger, and dipole-dipole experiments represented in Fig. 7 and later provide an example of the same mismatch representations for the Quinns Rocks field ERI data (the Wenner array). 

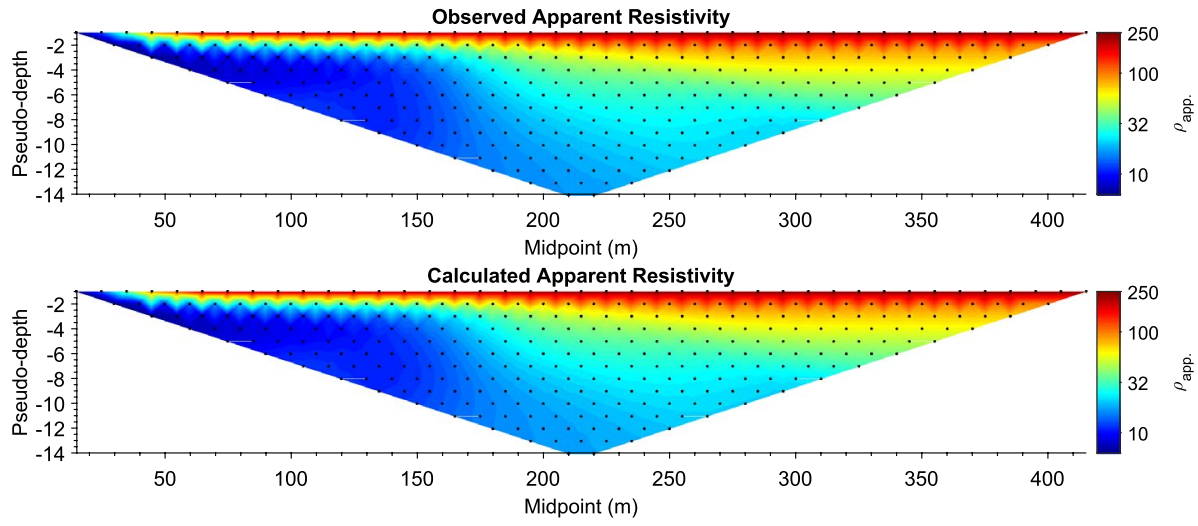

Pseudo-depth Datapoint Mismatch

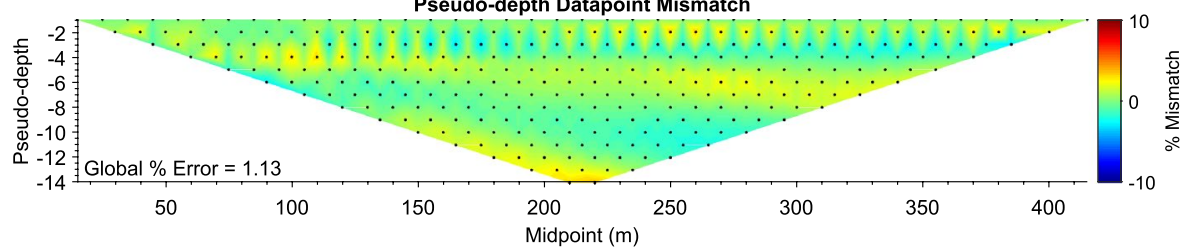

Fig. 8 Pseudo-sections for the observed (top), and calculated (middle) apparent resistivity, and percentage mismatch (bottom) for modeled Wenner configuration. These data are calculated for a model with a shallow resistive layer, a conductive seawater wedge, and conductive lower substrate, as shown in Fig. 7. Areas of largest misfit exist near the seawater wedge and shallow resistive interfaces
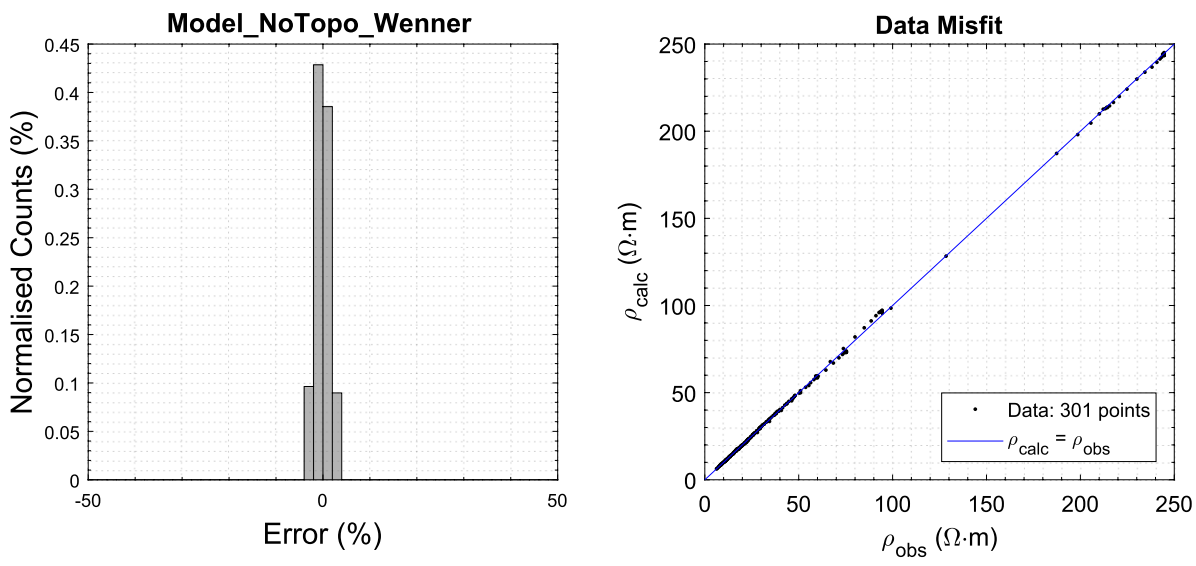

Fig. 9 Plots showing the distribution of error and misfit between observed and calculated data. These plots describe the inversion of ERI data computed over the synthetic forward model without topography, using a Wenner configuration. The distribution of errors is Gaussian, and observations are consistent with calculated measurements

Figures 8, 9, 10, 11, 12, and 13 show pseudo-plots for the observed, and calculated data, as well as the percentage misfit for each data point. As expected for forward model examples, the residual errors are small, appear to have a Gaussian distribution, 

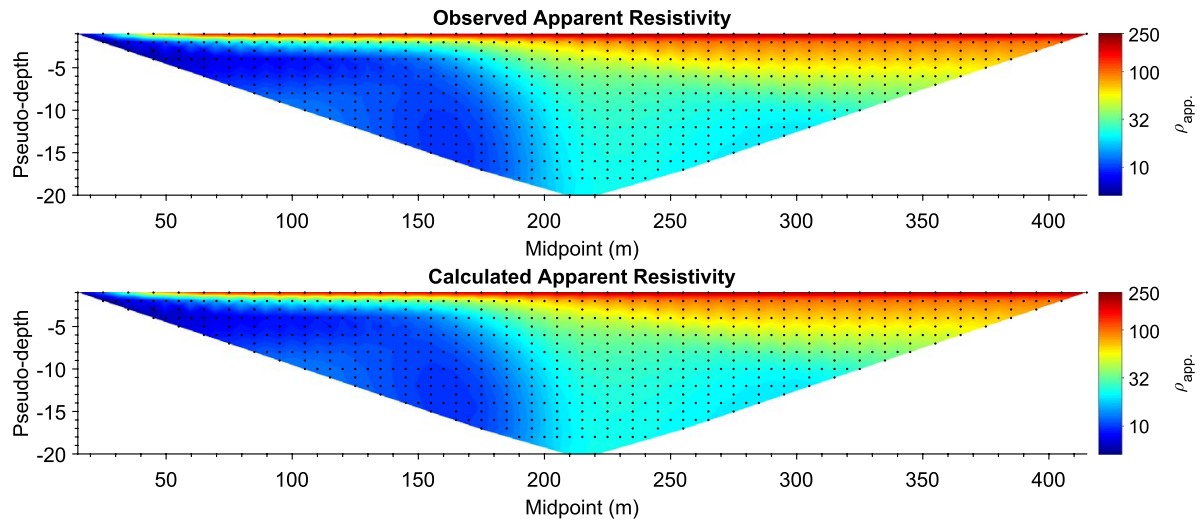

Pseudo-depth Datapoint Mismatch

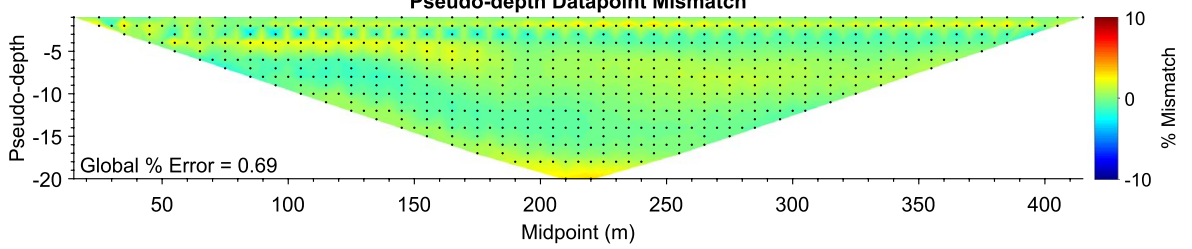

Fig. 10 Pseudo-sections for the observed (top) and calculated apparent resistivity (middle) and percentage mismatch (bottom) between observed and calculated values for the Schlumberger configuration
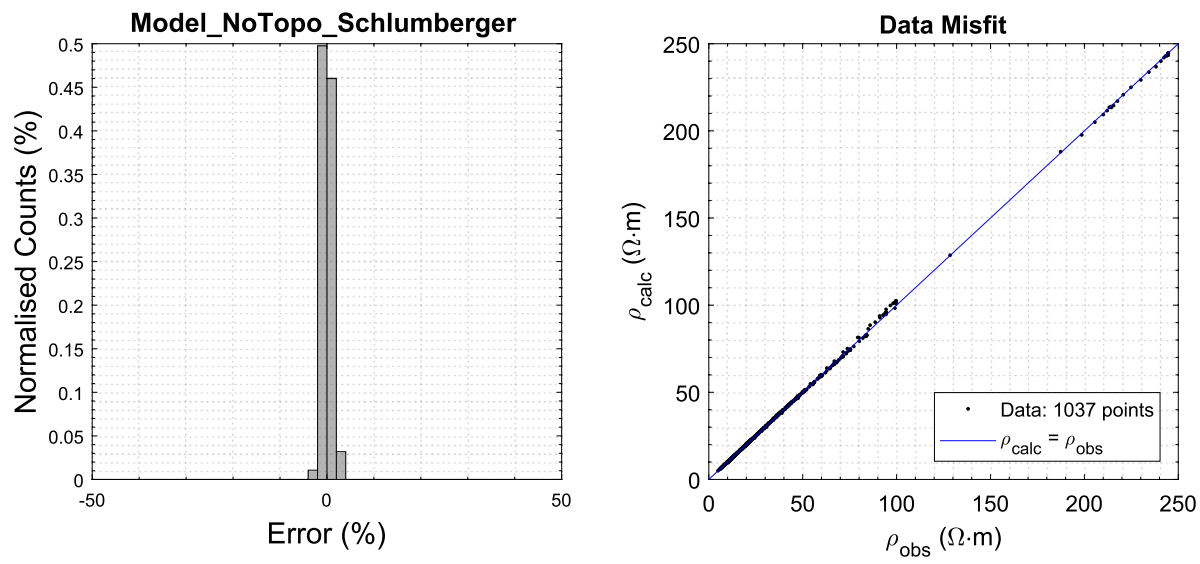

Fig. 11 Plots showing the distribution of error and misfit between observed and calculated data. These plots describe the inversion of ERI data computed over the synthetic forward model without topography using a Schlumberger configuration. Elevated levels of misfit are observed in the high resistivity shallow subsurface, where the high contrast boundary exists (e.g., water table)

and possess an excellent match between model apparent resistivity and measured (i.e., simulated field measurements) in the cross-plot. For these synthetic examples, we can observe that the inversion strategy has performed exceedingly well. Higher levels of misfit occurs in the shallow subsurface, consistent with the high-contrast shallow boundary present in the forward model. The limited data density in the near-surface with the Wenner and Wenner-Schlumberger array are the likely source of this misfit. 

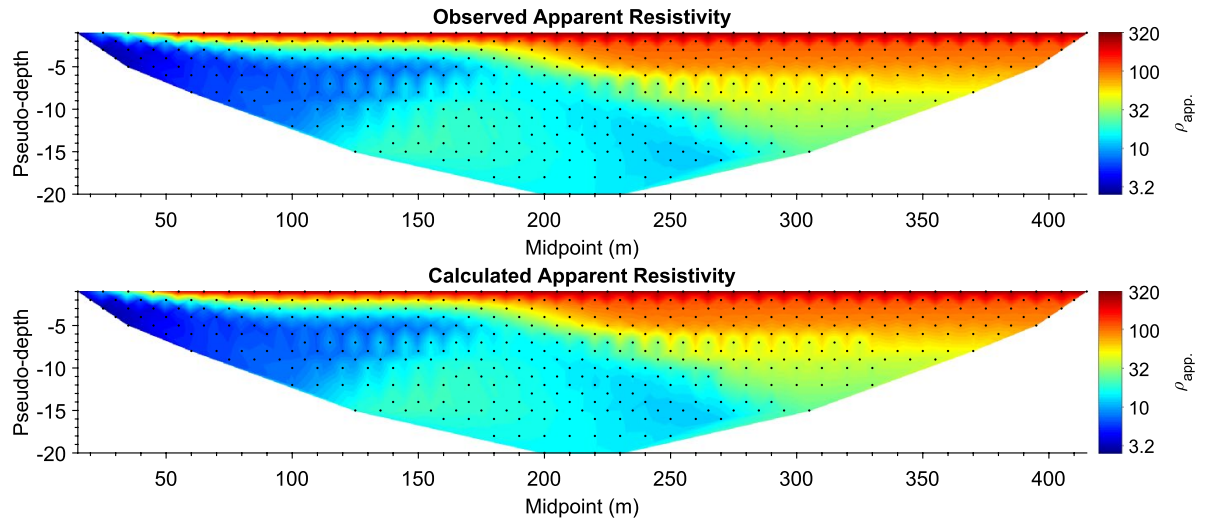

Pseudo-depth Datapoint Mismatch

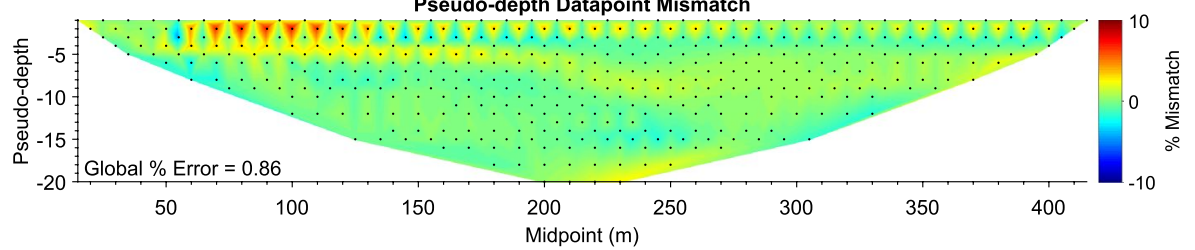

Fig. 12 Pseudo-sections for the observed (top) and calculated apparent resistivity (middle) and percentage mismatch (bottom) between observed and calculated values for the dipole-dipole configuration. This model includes a shallow resistive layer, a conductive seawater wedge, and conductive lower substrate, and is without topography. Areas of largest misfit exist near the seawater wedge and shallow resistive interfaces
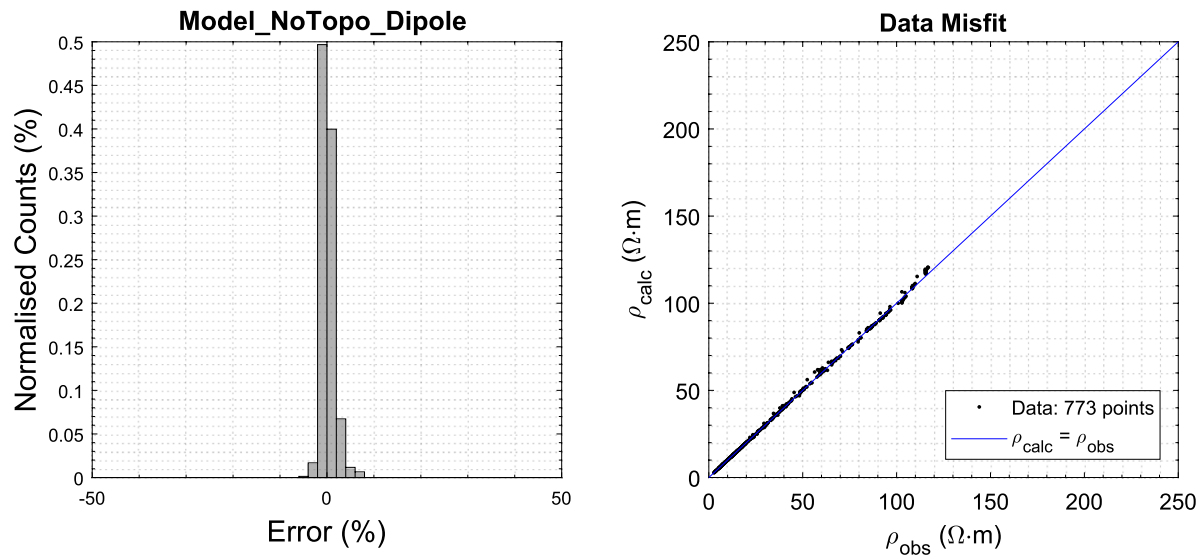

Fig. 13 Plots showing the distribution of error and misfit between observed and calculated data. These plots describe the inversion of ERI data computed over the synthetic forward model without topography using a dipole-dipole configuration

We note that the Delaunay triangulation used to present the misfit plots provides a generally accurate representation of the distribution, particularly where points are regularly distributed (e.g., Fig. 9). Some electrode configurations present irregular pseudo-depth plotting points. Triangulation across these points tends to produced minor visual artifacts, such as unexpected patterns or smeared error distributions (e.g., Figs. 10, 11). 


\section{Forward Model}

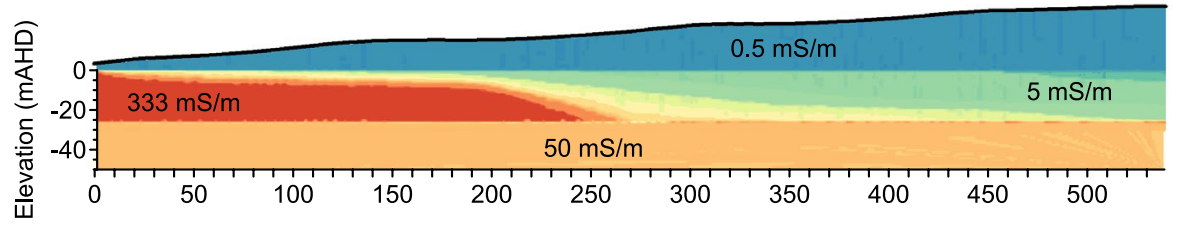

Inversion: Wenner

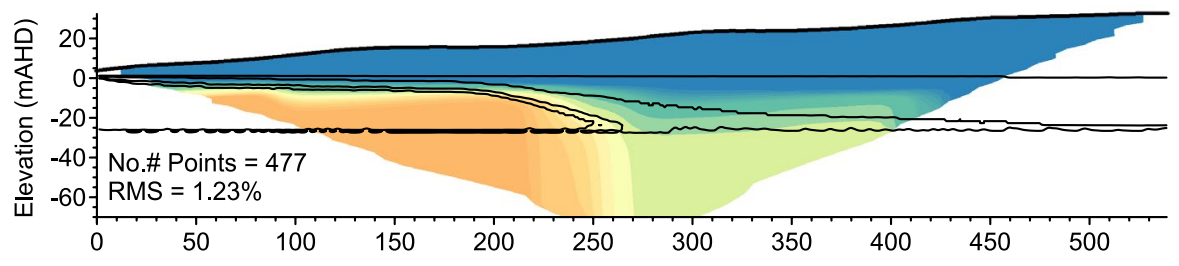

Inversion: Schlumberger

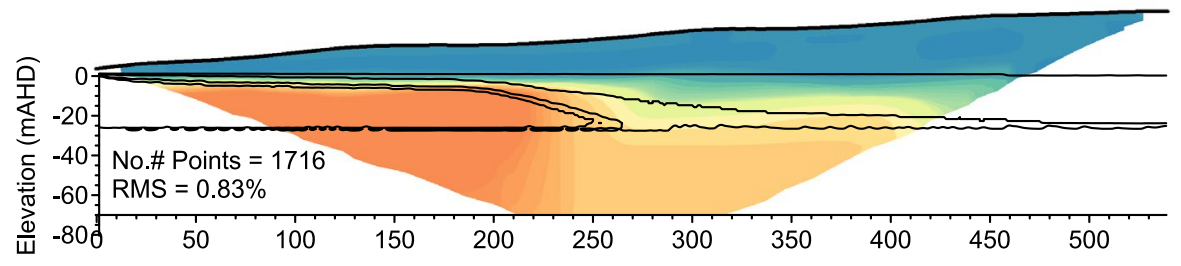

Inversion: Dipole-dipole

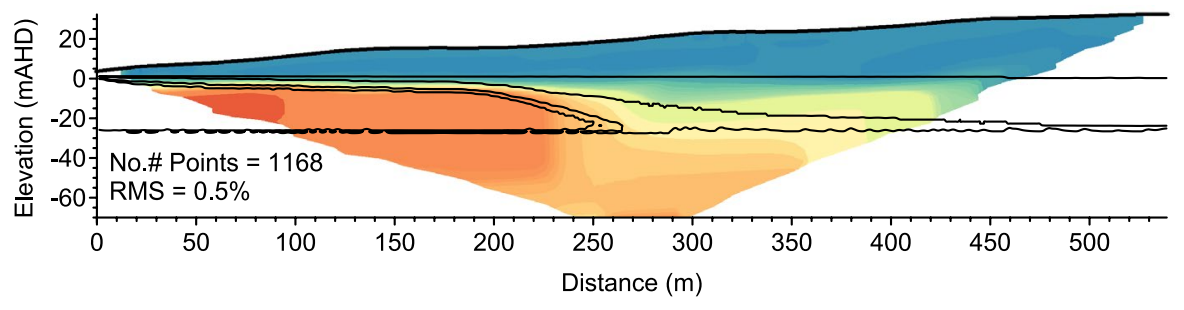

Conductivity $(\mathrm{mS} / \mathrm{m})$

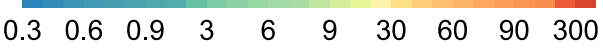

Fig. 14 Images showing the geo-electrical model incorporating topography, plus ERI-derived formation conductivity distribution for standard electrode arrays. The forward geo-electrical model is converted from the Quinns Rocks hydrogeological model shown in Fig. 6. These images can be compared with those from Fig. 7 where the geo-electrical model excludes topography. The inclusion of topographic relief significantly affects resolution and accuracy of key interfaces in the inverted ERI conductivity distribution for conventional electrode arrays

Figure 14 shows the second example for the geo-electrical model defined by Quinns Rocks SIM wells as shown in Fig. 6. This model includes accurate topographic relief along the transect [i.e., recovered from 5 m LIDAR data (Geoscience Australia 2017)]. Here, we 
are able to highlight the consequence of the variably thick upper, highly resistive unsaturated zone between air and the water table on the outcome of resistivity imaging.

A comparison of dipole-dipole ERI-derived conductivity distribution in Figs. 7 and 14 shows that topography has a significant impact on resistivity imaging. Notice the reduction

\section{Forward Model}

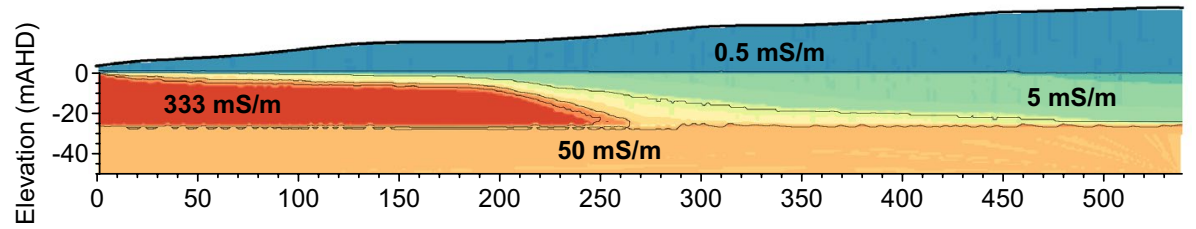

\section{Combined Inversion: Wenner \& Schlumberger}

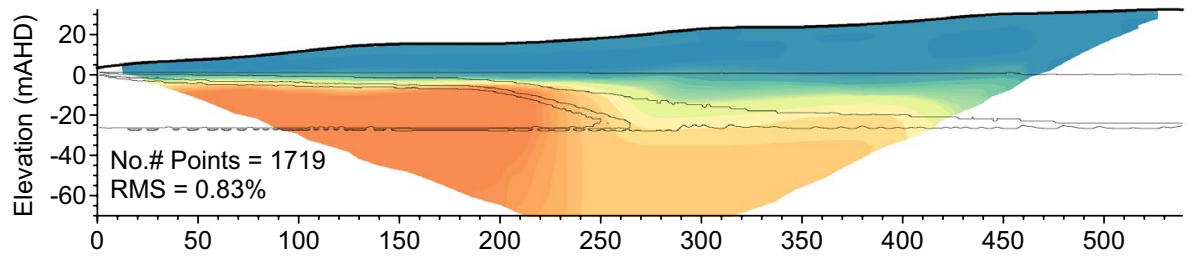

Combined Inversion: Dipole-dipole \& Wenner

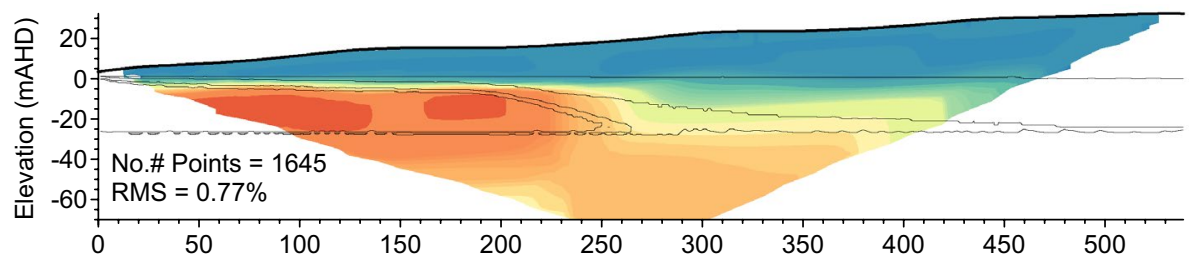

Combined Inversion: Dipole-dipole \& Schlumberger

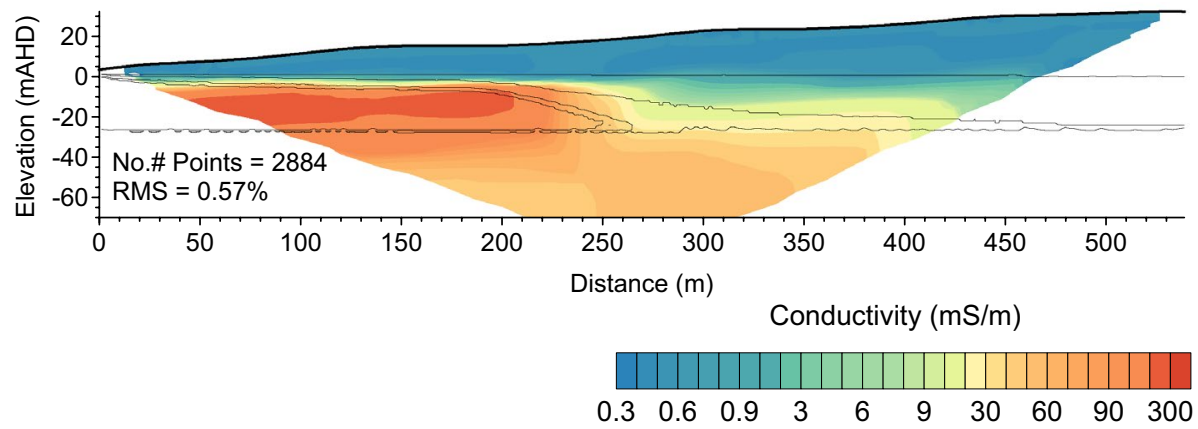

Fig. 15 Geo-electrical model incorporating topography plus ERI-derived formation conductivity distribution for combined electrode arrays. The forward geo-electrical model is converted directly from the Quinns Rocks hydrogeological model shown in Fig. 6. These images can be compared with those from Figs. 7 and 14. Only the inversion of synthetic ERI data for two dipole-dipole hybrid data is able to credibly locate the high conductivity of the wedge and the depth of substrate interface below the seawater wedge 
in accuracy with which resistivity imaging recovers details of the seawater wedge and substrate in Fig. 14. The recovered geo-electrical model should have uniform conductivity of $330 \mathrm{mS} / \mathrm{m}$ in the wedge, and $50 \mathrm{mS} / \mathrm{m}$ in the substrate. Similar observations are present in outcomes of field ERI data, presented later in this text.

Inversion outcomes shown in Fig. 14 generally underestimate the conductivity of the wedge and fail to resolve the substrate below. While the location of the substrate beneath the higher resistivity fresh groundwater is generally resolved in each case, the substrate below the conductive seawater wedge is always poorly resolved. In the worst cases, the outcome of inversion of data from the Wenner array gives no indication of the existence of the uniform horizontal substrate.

Figure 15 extends the above analysis to include combination arrays. The number of data points (i.e., quadrupoles) in the combined arrays is shown in each resistivity image. Inversion parameters are identical to those used to generate resistivity images in Figs. 7 and 14.

Inversion of the synthetic ERI data from the combined dipole-dipole/Wenner array and dipole-dipole/Schlumberger arrays provides significant improvement in definition of the saline groundwater wedge and lower substrate (see Fig. 15) when compared to outcomes from individual arrays. Only the combined dipole-dipole/Schlumberger array provides clarity on the location of the substrate interface below the saline groundwater wedge. In practice, hybrid dipole-dipole surveys are relatively efficient to acquire and are readily incorporated into multichannel acquisition.

\subsection{ERI Control Site: Field ERI Experiments}

Field experiments were completed with the SYSCAL Pro 72 ERI system (Iris Instruments). Coordinates were measured with a RTK GPS system (Navcomm SF3040). The total length of the Quinns Rocks ERI transect is approximately $440 \mathrm{~m}$, with electrodes spaced every $10 \mathrm{~m}$. The electrodes were $200 \mathrm{~mm}$ long, $10 \mathrm{~mm}$ diameter, stainless steel pegs. Each electrode position is saturated with brackish water and use resistance checks across each electrode pair as a quality control measure. Each electrode configuration uses an injection voltage of $400 \mathrm{~V}, 4-8$ stacks per quadrupole with requested quality factor set to zero (i.e., no changes in successive measurements) and $250 \mathrm{~ms}$ current injection time with a $100 \%$ duty cycle waveform.

Inversion of field data uses identical parameters to those used for synthetic data, i.e., Table 1. Figure 16 shows resistivity imaging for ERI field data from the control site. With the exception of the schlumberger array, outcomes from the inversion of field data are highly consistent with the conductivity distribution obtained from inversion of synthetic data computed for the seawater interface model at this site (see Fig. 14).

In Fig. 16, the resistivity imaging clearly shows the substrate on the landward side of the wedge where there is higher resistivity fresher groundwater. However, below the saline wedge, the substrate is only interpretable in the dipole-dipole resistivity image. The black dotted line on the resistivity images in Fig. 16 is the interpreted shape of the seawater interface. Without knowledge of shape of this interface or the existence of the substrate from drilling, there would be little prospect of accurately interpreting these key elements of coastal hydrogeology from the Wenner or Schlumberger resistivity images. These observations are consistent with those from resistivity imaging of synthetic data over the seawater interface model in Sect. 2.3.

Inversion of field dipole-dipole ERI data shows higher error than inversion of the data from Wenner or Schlumberger style arrays. In RES2DINV, the measure of error for the robust inversion is the mean absolute error, shown in Eq. 2.

$$
E_{\mathrm{abs}}=\frac{1}{N} \sum_{i=1}^{N}\left|\log \left(\rho_{\mathrm{cal}}\right)-\log \left(\rho_{\mathrm{obs}}\right)\right|
$$




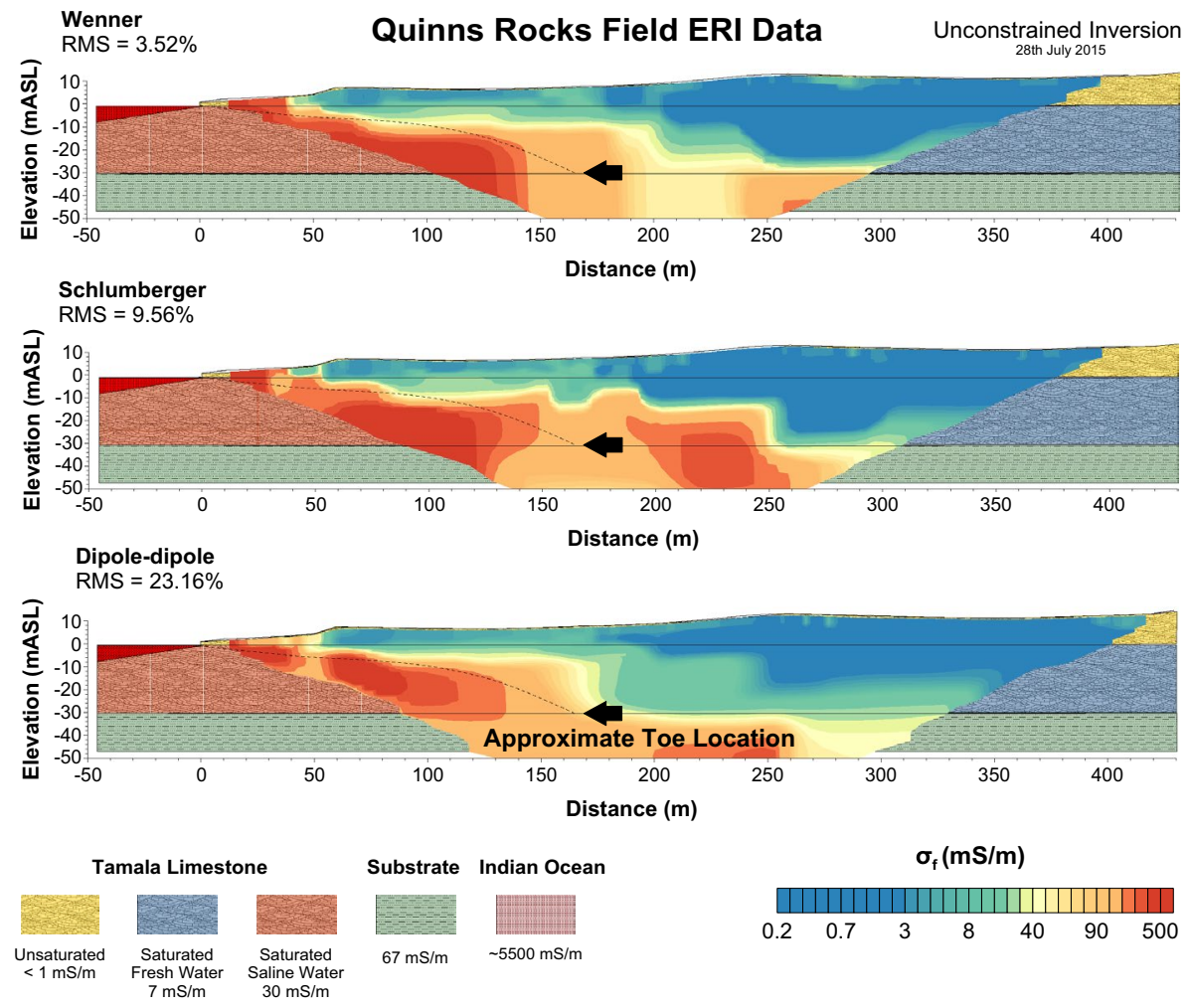

Fig. 16 Resistivity imaging from unconstrained inversion of field ERI data for different electrode configurations. The configurations shown are Wenner (top), Schlumberger (middle), and dipole-dipole (bottom). Data were collected on 28 July 2015. The water table and the clayey substrate are located at 0 and - $30 \mathrm{mASL}$, respectively, as shown in geo-electrical model in Fig. 6. The existence and, to some extent, the geometry of the seawater interface are revealed by all array configurations. However, the substrate is poorly resolved in both Wenner and Schlumberger examples, which is consistent with the outcome from our numerical experiments (see Fig. 14)

where $E_{\text {abs }}$ is the measure of error, $N$ is the number of data points, $\rho_{\text {cal }}$ are calculated resistivity values, and $\rho_{\text {obs }}$ are observed resistivity values.

This measure of error follows the standard definition of mean absolute error (Weisstein 2017) and is generally preferred over root mean square error (RMSE) (Chai and Draxler 2014; Willmott and Matsuura 2005; Willmott et al. 2009). However, and more generally, all forms of global error can be misleading. For example, the Wenner electrode configuration fails to recover any change in conductivity associated with the lower clayey substrate in both synthetic and field examples, yet the final inversion has significantly lower error than inversion of the dipole-dipole or Schlumberger data.

Measures of global error are strongly affected by quality and number of data points inverted. Wenner data have a relatively small number of low geometric factor (i.e., high quality) quadrupoles compared to dipole-dipole data, which, for the same number of electrodes, have more data points with generally higher geometric factor (i.e., lower quality). As usual, reducing the number of data points available for inversion tends to reduce global 

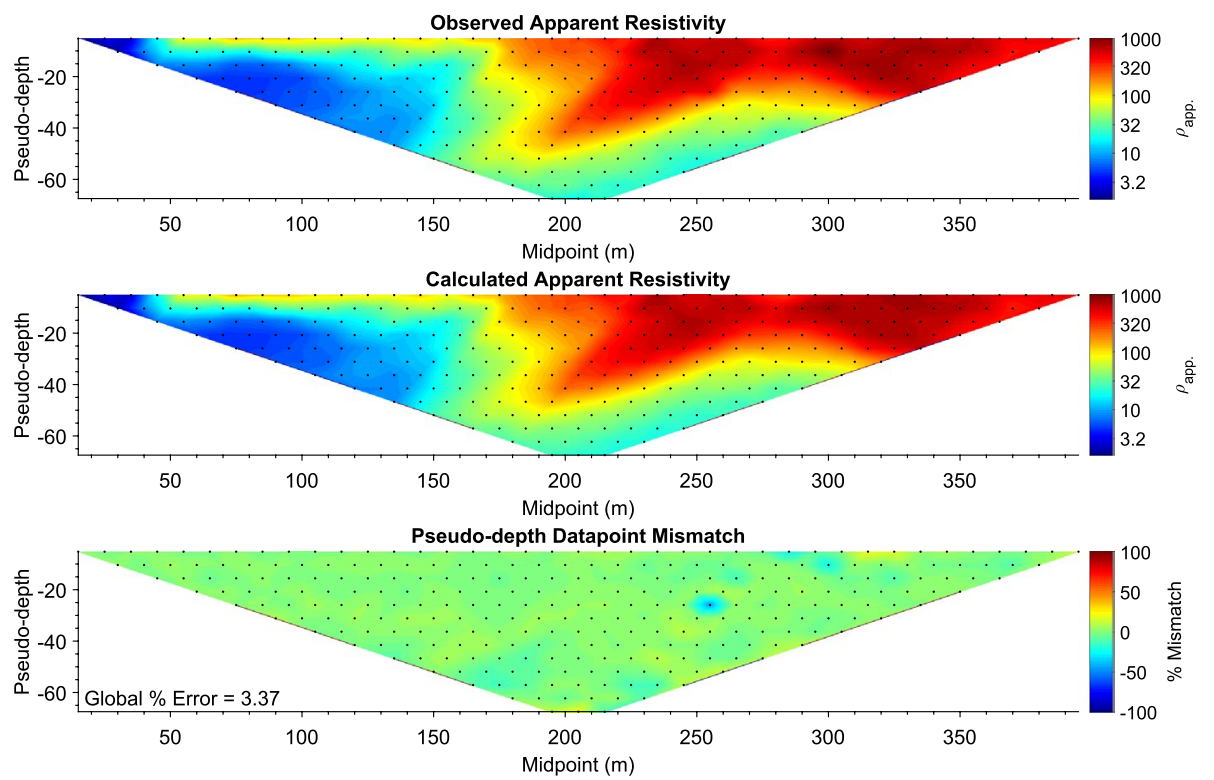

Fig. 17 Images depicting the observed apparent resistivity distribution (top), calculated (i.e., inverted) apparent resistivity distribution (middle), and apparent resistivity misfit (bottom). This set of images is for the Wenner configuration field data collected at Quinns Rocks
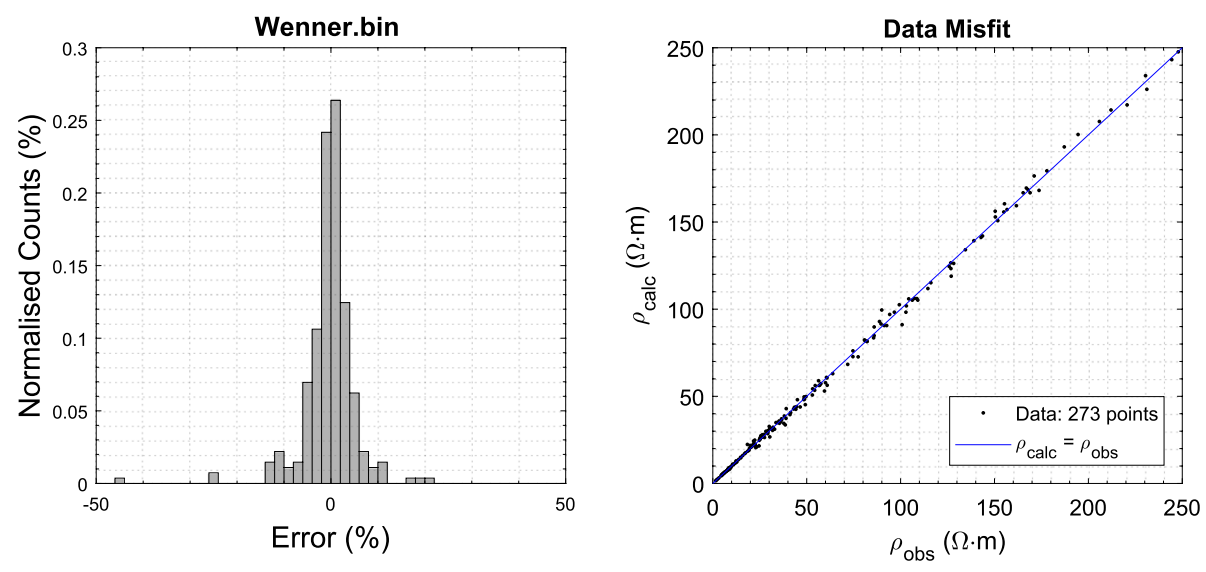

Fig. 18 Histogram and cross-plot of misfit and error distribution in the inverted apparent resistivity image compared to the observed apparent resistivity. The error and misfit appear normally distributed throughout

misfit. However, this strategy will diminish the illumination of any subsurface target and ultimately degrade imaging outcomes. General inadequacies in global error estimates leading to unrealistic models are well documented, such as global misfit in electrical methods (Le et al. 2016), and hydrologic and hydro-climatic models (Legates and McCabe 1999).

Spatial assessment of apparent resistivity misfit distribution after inversion can be an important method for quality control of both the field data and the inversion outcome. This is illustrated in Figs. 17 and 18. Here, we compare apparent resistivity pseudo-sections 
from field (i.e., observed or measured) data and inverted (i.e., calculated) data for the Quinns Rocks Wenner electrode configuration survey. These images are accompanied by (1) a map of apparent resistivity misfit distribution, (2) a histogram of misfit, and (3) a cross-plot of measured apparent resistivity versus apparent resistivity from final inversion outcome (i.e., see comparable analysis for the synthetic example in Fig. 8). The misfit image shows a relatively uniform error distribution. The histogram points toward the expected normal distribution of error, and the cross-plot shows relatively few outliers (i.e., points offset from the $\rho_{\text {obs }}=\rho_{\text {calc }}$ trend line). The analysis shows the quality of the match between measured and calculated ERI apparent resistivity is generally excellent. That is, the vast majority of points have exceedingly small, relatively random mismatch.

Our analysis indicates that, in the near-shore setting, the outcome of unconstrained inversion has a first-order dependence on electrode configuration, which is linked to illumination for the specific geo-electrical setting. While each of the arrays suggests the seawater interface is located at approximately $170 \mathrm{~m}$ inland, only the dipole-dipole-based resistivity imaging provides confidence as to the existence of the substrate, which is a highly significant element of coastal hydrogeology.

\section{ERI in Complex Geo-Electrical/Hydrogeological Architectures}

The idea of a conventional saline groundwater wedge may be far from the reality for some dynamic coastal margins. The Cockburn area, south of Perth, Western Australia (Fig. 4), combines multiple layers of extremely high transmissivity sands, seaward-dipping stratigraphy, and an expansive high-conductivity sheet-like clay/shale substrate (Pollock et al. 2006; Smith and Hick 2001). For this site, multiple drill-holes, wireline logging, and GPR data are needed to resolve key elements of the coastal hydrogeology.

As with many ERI sites, access at the Coogee site was restricted to pre-existing pathways. Figure 19 shows the location of the ERI transects, GPR transects, and monitoring wells $\mathrm{C} 1 \mathrm{a}$ and $\mathrm{C} 1 \mathrm{~b}$. The ERI cross-lines were collected to assess geo-electrical symmetry parallel to the coast. The $250 \mathrm{MHz}$ shielded antenna GPR data were collected to: (1) provide detailed shallow stratigraphy (e.g., dips) and (2) recover a shallow expression of the seawater interface near to the shoreline where ERI illumination is limited.

Figure 20 shows resistivity imaging outcomes from dipole-dipole, multiple-gradient, and combined electrode configurations. The combined array includes all quadrupoles from the multiple-gradient and dipole-dipole ERI surveys. Inversion parameters are the same as those given in Table 1. Wireline electrical logs from well C1a suggest a shallow layer with slightly elevated conductivity close to the water table. The dipole-dipole and combined array appear to resolve this semi-continuous layer, whereas outcomes from the multiple-gradient array are unable to resolve this layer beyond C1a. The conductivity distribution from wireline logs in Fig. 21 compares exceedingly well with outcomes from resistivity imaging from the dipole-dipole array.

Another key observation from Fig. 20 is that the saline groundwater interface near the swash zone is not evident in the ERI imaging outcomes. Evidence from GPR data, in Fig. 23, shows the seawater interface to be descending steeply in the region where ERI coverage with the standard inversion strategy is low. The alternate inversion strategy presented in Appendix 4 shows the resolution of model cells in the swash zone close to the start of the transect to be relatively high. This strategy produces an outcome perhaps better aligned with the anticipated subsurface conductivity distribution than in the standard inversion strategy presented below. 


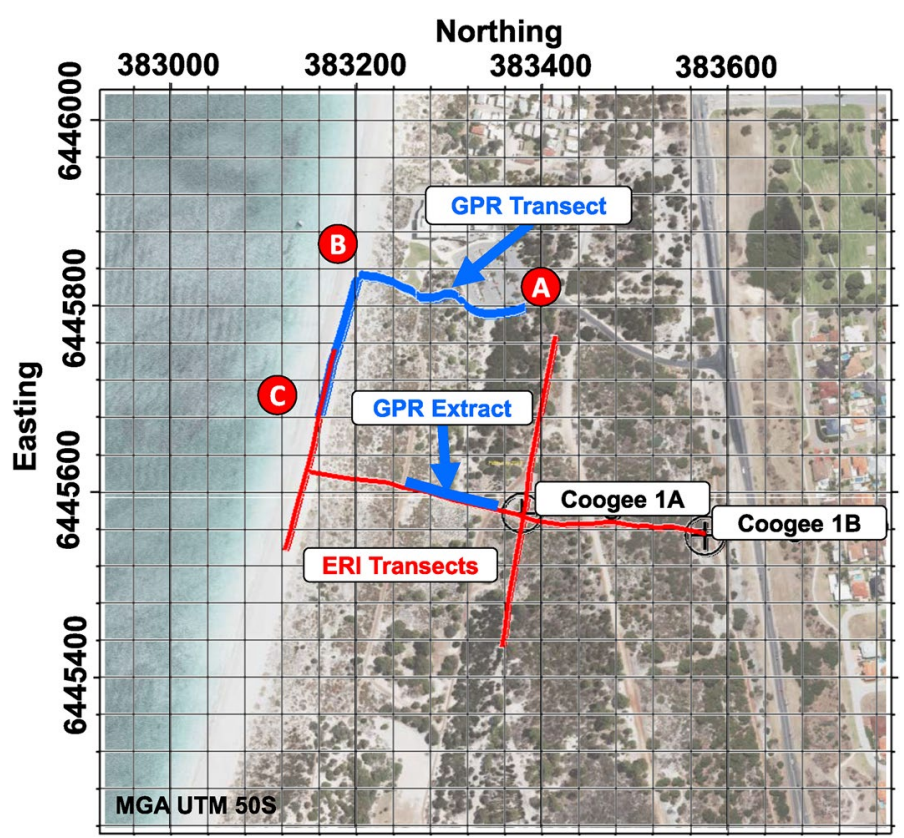

Fig. 19 Map of the Coogee test site, showing well locations (C1a, C1b), ERI transects, and GPR transects. Figure 22 provides a 3D perspective of the resistivity imaging. Figure 23 shows the annotated GPR section, where points A, B, and C, are at the start, end, and corner of the beach GPR transect, respectively [Aerial Photograph reproduced by permission of the Western Australian Land Information Authority (Landgate) 2018]

Figure 21 shows the wireline logging and lithology recovered at monitoring wells $\mathrm{C} 1 \mathrm{a}$ and $\mathrm{C} 1 \mathrm{~b}$. It includes resistivity images from ERI transects that pass parallel and perpendicular to the coastline. Gamma wireline logs and samples from sonic logging provide accurate depths to the shale substrate (i.e., the Kardinya Shale). The induction logs provide the depth to the saline groundwater interface within coarse sands immediately above the shale. The electrical conductivity of groundwater extracted from 2-m-long well screens, set immediately above the shales, was close to $5500 \mathrm{mS} / \mathrm{m}$. Here, ERI is unable to differentiate the conductive Kardinya Shale from coarse sands saturated with $5500 \mathrm{mS} / \mathrm{m}$ groundwater. At monitoring well C1a, the saline water exists as a relatively flat layer with a sharp transition (between - 16 and - 18 m AHD) to fresh groundwater above and Kardinya shale below as indicated in Fig. 21.

Figure 22 shows the three ERI transects collected at the Coogee test site. The correlation of ERI resistivity and induction logging resistivity at the transition from fresh to saline groundwater for the transect parallel to the coast and passing C1a is exceptional. Transects parallel to the coast can validate the $2 \mathrm{D}$ assumption made for imaging of the transect perpendicular to the coast, however are of little value if collected in isolation.

A second parallel transect was acquired along the beach within $20 \mathrm{~m}$ of the ocean. It shows uniform apparently layered conductivity distribution. However, 2D ERI imaging this close to the ocean is unlikely to represent the true subsurface resistivity distribution. This is due to the highly conductive ocean (approximately $5500 \mathrm{mS} / \mathrm{m}$ ) which must present strong 3D asymmetry in subsurface electrical conductivity distribution. 

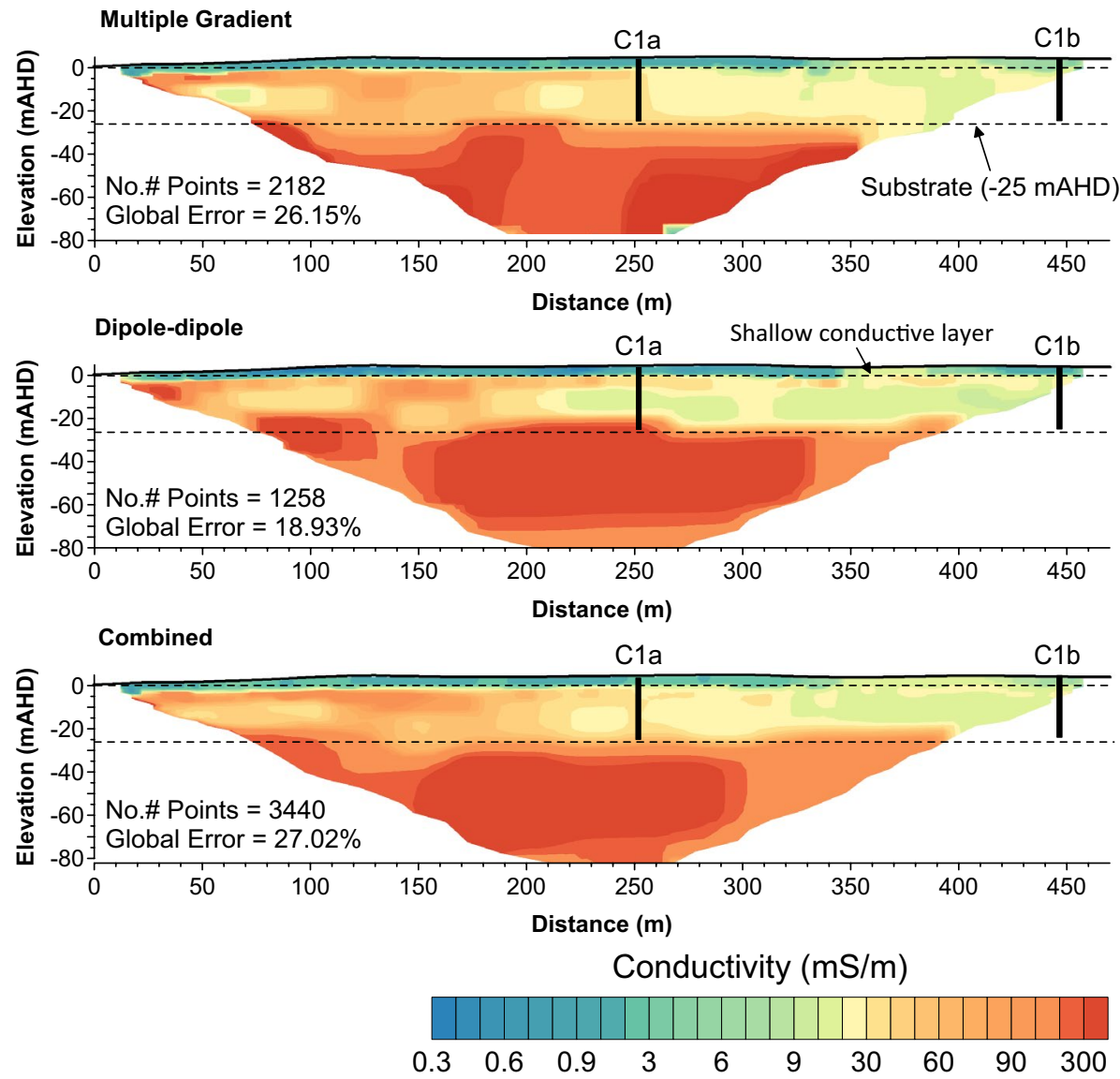

Fig. 20 Inverted conductivity distribution from the multiple-gradient array (top), the dipole-dipole array (middle), and a combined array (bottom) at the Coogee ERI test site. A black, dashed line indicates the substrate recovered from sonic core logging at $\mathrm{C} 1 \mathrm{a}$ and $\mathrm{C} 1 \mathrm{~b}$. Each array is unable to locate the substrate interface from the borehole logging. It is difficult to differentiate the saline water at the base of the aquifer from the clayey substrate because both have similar high conductivity

This may be manifested in the generation of the resistive, $100 \mathrm{mS} / \mathrm{m}$ layer between two highly conductive layers (900 and $400 \mathrm{mS} / \mathrm{m}$ ) above and below. Although submarine freshwater discharge is possible (i.e., the $100 \mathrm{mS} / \mathrm{m}$ layer), it is unlikely that the image shows the correct subsurface resistivity.

Figure 22 also shows an extract from GPR collected at the site. The GPR image reveals persistent shallow dipping stratigraphy with dips approximately $15^{\circ}$ in a northwest direction. Depth of penetration for GPR is often insufficient to image below the water table, so GPR is not frequently deployed for seawater intrusion detection. However, relatively flat and low-lying topography at this site allowed for the deployment of this high-resolution imaging technique. This detail cannot be recovered from resistivity imaging, however may be a key element of coastal hydrogeology with a potential significance as input to flow and solute transport modeling. 


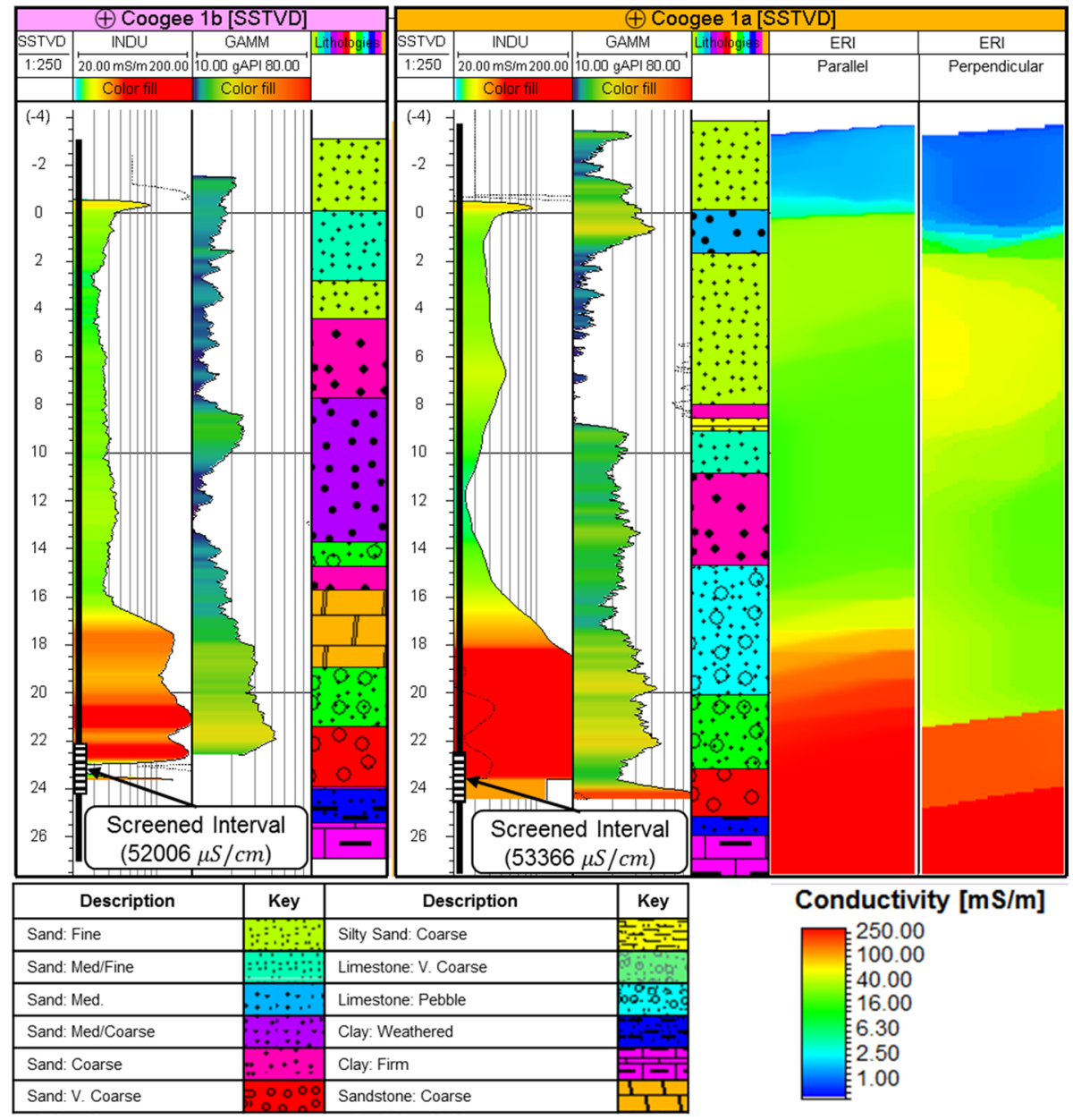

Fig. 21 Strip logs for the Coogee test site, including water chemistry, lithological logs, geophysical log data, and ERI-derived resistivity at monitoring wells $\mathrm{C} 1 \mathrm{a}$ and $\mathrm{C} 1 \mathrm{~b}$. Note the gamma log and lithological log profile clearly show the basal Kardinya Shale at 25 meters below height datum (mBHD), while the induction log shows a high response (i.e., conductive seawater) from $18 \mathrm{mBHD}$. High conductivity in the sands immediately above the Kardinya shale (i.e., between approximately 18 and $25 \mathrm{~m}$ ) is associated with high salinity groundwater. Also note the shallow, silty-sand layer is present at $\sim 9 \mathrm{mBHD}$ in the induction log for monitoring well $\mathrm{C} 1 \mathrm{a}$. This corresponds to the base of the shallow moderately conductive unit also recovered in the ERI transects

Figure 23 shows a second representation of the GPR data both along and perpendicular to the beachfront. Highly conductive seawater rapidly attenuates the GPR signal and permits differentiation of fresh groundwater from conductive saline groundwater. The GPR signal is completely attenuated along the beachfront. However, within 30-40 m of the beach, strong GPR reflectors below the water table indicate the presence of shallow fresh groundwater. The second image provides a 3D representation of the RMS amplitude attribute applied to the GPR data. This image highlights the high-angle seawater 


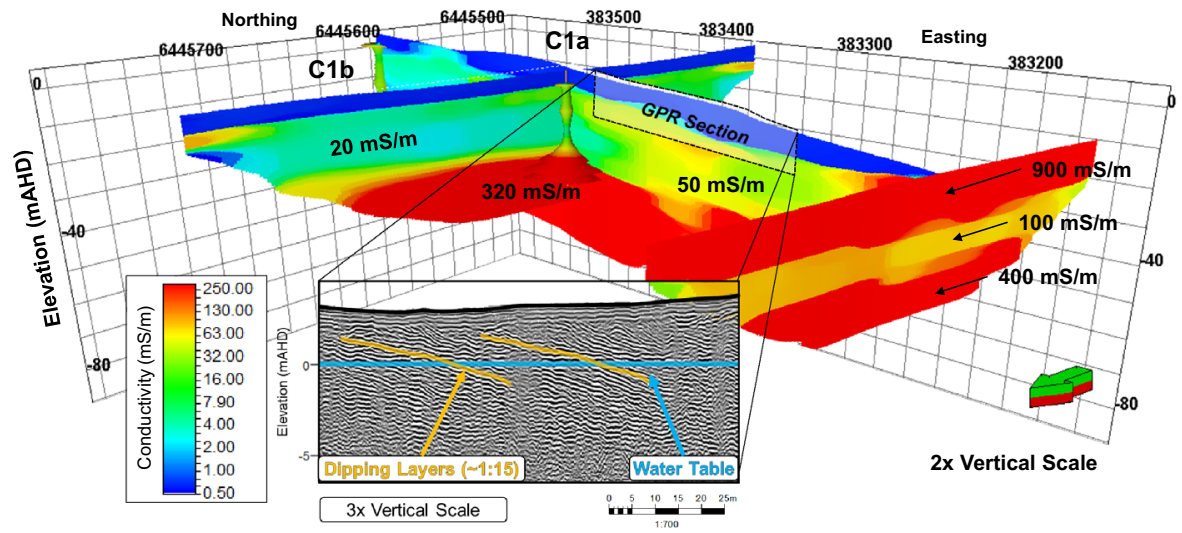

Fig. 22 3D visualization of the electrical conductivity distribution at Coogee, including the induction logging at $\mathrm{C} 1 \mathrm{a}$ and $\mathrm{C} 1 \mathrm{~b}$. A strong correlation exists between the shallow conductive layer in the induction logging and perpendicular resistivity image, as well as the depth to the conductive substrate from parallel resistivity image
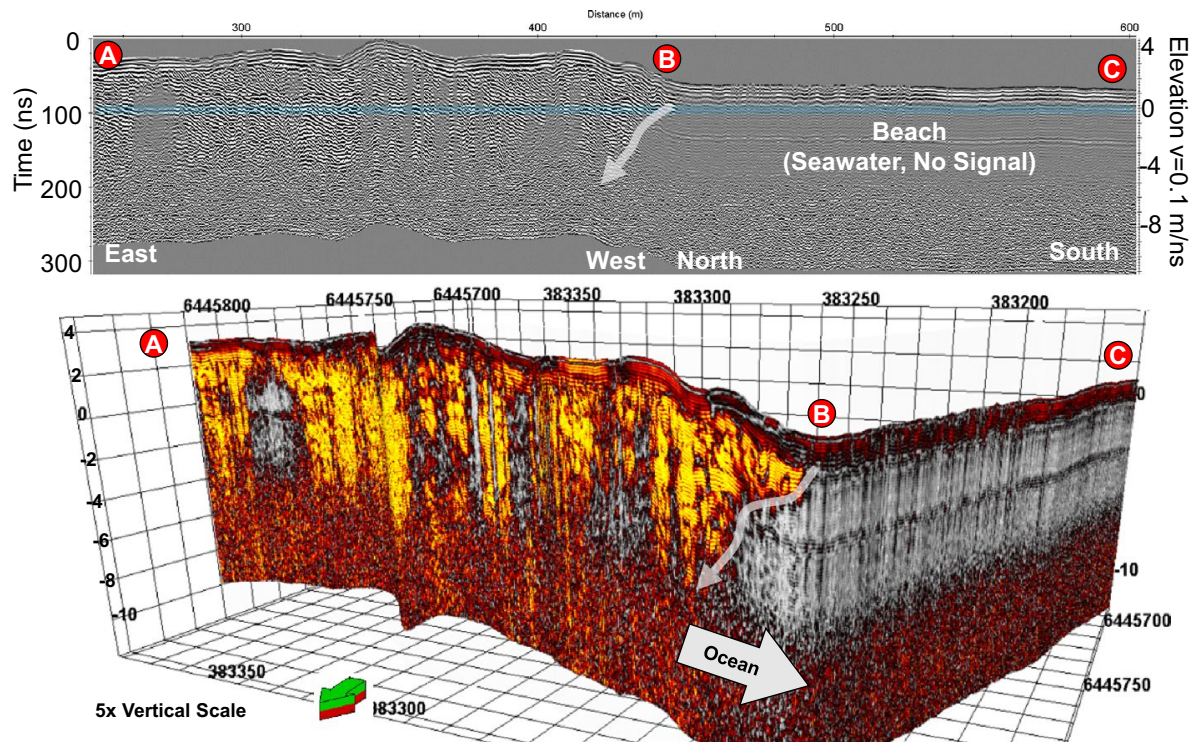

Fig. 23 Image and visualisation of GPR transects from the Coogee site, showing the degradation of signal nearby to the ocean. The $2 \mathrm{D}$ profile (top) shows the reflectors visible at the east/west part of the profile, while the north/south section along the beach is attenuated. RMS amplitudes are overlain on the 3D image (bottom) highlighting the signal quality change from the resistive fresher water to the conductive seawater and beachfront sediments. Areas of landward low RMS are related to concrete path and road crossings, rather than subsurface structures

interface close to the shore. It closely resembles location of the shallow saline groundwater interface, observable in the dipole-dipole resistivity image.

In summary, we found that while the ERI provided valuable information, three specific challenges are recognized, that is: (1) ERI could not separate saline water from the 
clay substrate, (2) ERI could not identify the persistent shallow dips across the site, and

(3) ERI could not effectively image as saline water close to the ocean.

\section{ERI and Aquifer Geometry: Transects Along $100 \mathrm{~km}$ of Coastal Margin}

The elongated Perth Basin includes several distinct geo-electrical architectures and multitiered aquifers systems, extending for over $500 \mathrm{~km}$ of Western Australia's southwestern coastline. Shallow unconfined aquifers exist within several hundred kilometers of Perth, and mostly overlie the Leederville and Yarragadee confined aquifer systems. Within these confined systems, high-quality potable groundwater persists for a considerable distance beyond the coastline, to ultimately exit the groundwater system as submarine discharge at the continental shelf (Post et al. 2013).

The seawater interface in the unconfined aquifer (e.g., the Tamala Limestone) is typically separated from a deeper, freshwater, confined aquifer by a clayey layer, or aquiclude. In places along the coastal margin of Perth, the aquiclude is known to be thin (e.g., tens of meters). As such, if seawater intrusion is occurring in the unconfined aquifer, then the seawater wedge has likely progressed inland over a clayey substrate historically enclosed by fresh groundwater above and below.

If the clayey substrate is dominantly a low-cation-exchange-capacity (CEC) clay, then we might expect the clayey substrate to be electrically resistive compared to that part of the seawater wedge which has moved inland, within the unconfined aquifer above. Such is the case where the Pinjar formation forms the shallow substrate. This scenario is common to the north of Perth city. For a substrate dominated by high CEC clays, such as the Kardinya Shale, the electrical conductivity is likely to be high, and potentially comparable to that of the saline groundwater wedge. Where the resistivity of the seawater wedge and a high CEC clayey substrate are similar, interpretation of the interface between them will be problematic.

Further, if the seawater wedge is moving, or geo-electrical architecture is complex, then the shape of the seawater wedge in resistivity imaging outcomes may not be consistent with the classic, steady-state groundwater wedges shown in Fig. 2.

\subsection{Field Experiments}

Field sites along Perth's coastal margin are selected to demonstrate the extent to which coastal hydrogeology, including the seawater interface, can be resolved by ERI methods. We compare transects from sites where (1) high-permeability shallow sediments overlie moderate to low-permeability sand and silt, (2) a thin, high-quality aquifer overlies a shallow moderately conductive impermeable substrate, and (3) a thin, exceedingly high-permeability aquifer overlies an expansive high-conductivity shale substrate (see Fig. 2). Further, we examine distance of the seawater interface from the shore line in a set of ERI transects located progressively closer to the densely populated, historically high groundwater usage coastal margin next to Perth.

Figures 24 and 26 show resistivity imaging from sites along a 100-km stretch of Perth's increasingly urbanized coastal margin. Figure 24 provides ERI images for distinctly different aquifer systems, and Fig. 25 provides a set of images with the seawater wedge located progressively further inland. All these key locations (see Fig. 4) present the opportunity for long-term time-lapse ERI. 

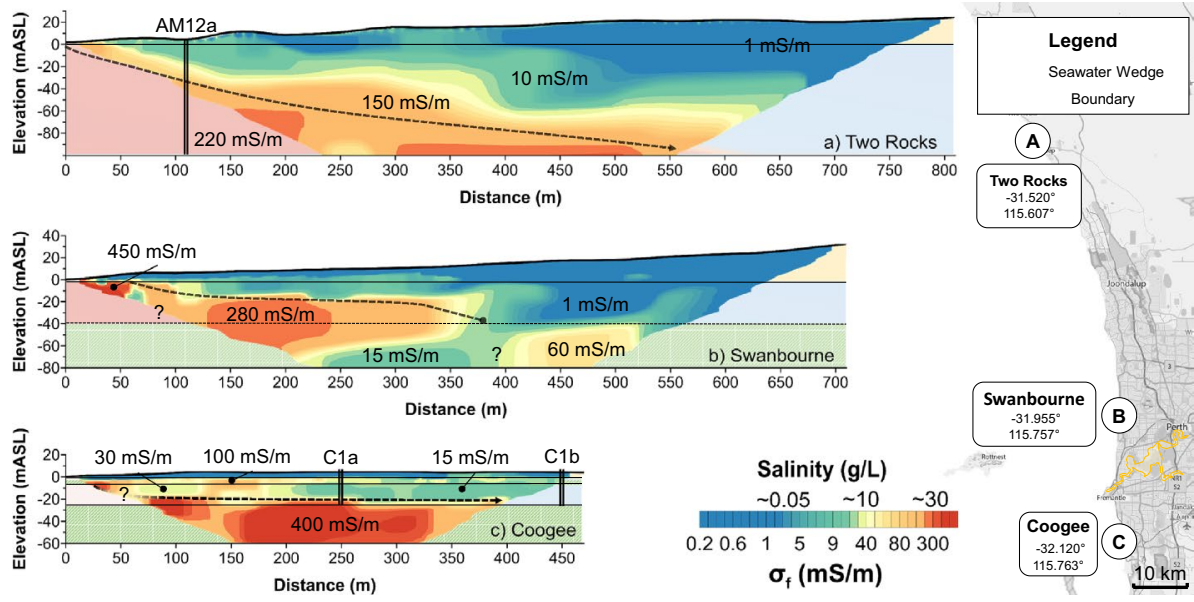

Fig. 24 Interpretation of three classes of significant hydrogeological boundaries from the inverted conductivity distribution of ERI data, featuring; (a) deep aquifer, (b) shallow aquifer with moderately conductive substrate, and (c) shallow aquifer with high-conductivity substrate. Question marks indicate areas of some uncertainty (map data annotated from (C) OpenStreetMap contributors). Note that the salinity estimates are based on saturated local aeolian limestone and will be significantly different for clays or clayey lithology

First-order challenges at each ERI site were (1) to resolve the saline groundwater wedge relative to fresh groundwater within the aquifer layer and (2) to identify the presence, nature, and depth of any low-permeability substrate. We focus on these geometries because they are critical inputs to understanding, numerically modeling, and managing coastal hydrogeology.

All ERI lines commence as close to the ocean as possible and extend as far as possible inland. Transect length was typically limited by roads or other infrastructure. The Two Rocks and Swanbourne transects provide greatest depth of investigation, extending $720 \mathrm{~m}$ inland from the shore line, while the Coogee Transect extends $480 \mathrm{~m}$ inland with the limitation in all cases being major roads and infrastructure. All transects had sufficient penetration to resolve the substrate materials below the shallow high-quality, high-permeability aquifer, which is generally $<50 \mathrm{~m}$ below sea level at the shore line.

Resistivity imaging at the Two Rocks site reveals a saline groundwater wedge that is observed for the full length of the transect. The geometry is reasonable with reference to geological and wireline logs from a deep artesian monitoring bore, AM12a located about $100 \mathrm{~m}$ from the shoreline along the transect (see Fig. 24). Well AM12a provides evidence for three stratigraphic units. These are (1) the high-permeability superficial aquifer (5-1000 m/day), (2) the Kings Park Formation starting at above $50 \mathrm{~m}$ from surface and mostly consisting of moderate to low-permeability fine sand and silt $(0.1-15 \mathrm{~m} /$ day), and (3) the deep Osborne Formation, containing the impermeable Kardinya shale $\left(10^{-4}-10^{-6} \mathrm{~m} /\right.$ day $)$. The estimates for the hydraulic conductivity of each layer are provided in Davidson and $\mathrm{Yu}(2008)$.

Wireline induction logging in AM12a (Fig. 25) provides evidence for high electrical conductivity in the Superficial and Kings Park Formations within the saline groundwater wedge. The ERI indicates that the wedge extends a considerable distance inland, extending through shallow high-permeability sediments to the low-to-moderate permeability sediments of the Kings Park Formation. The wedge terminates at, or above, the Kardinya shale. These depths are beyond the penetration of ERI; however, it is interesting to note 


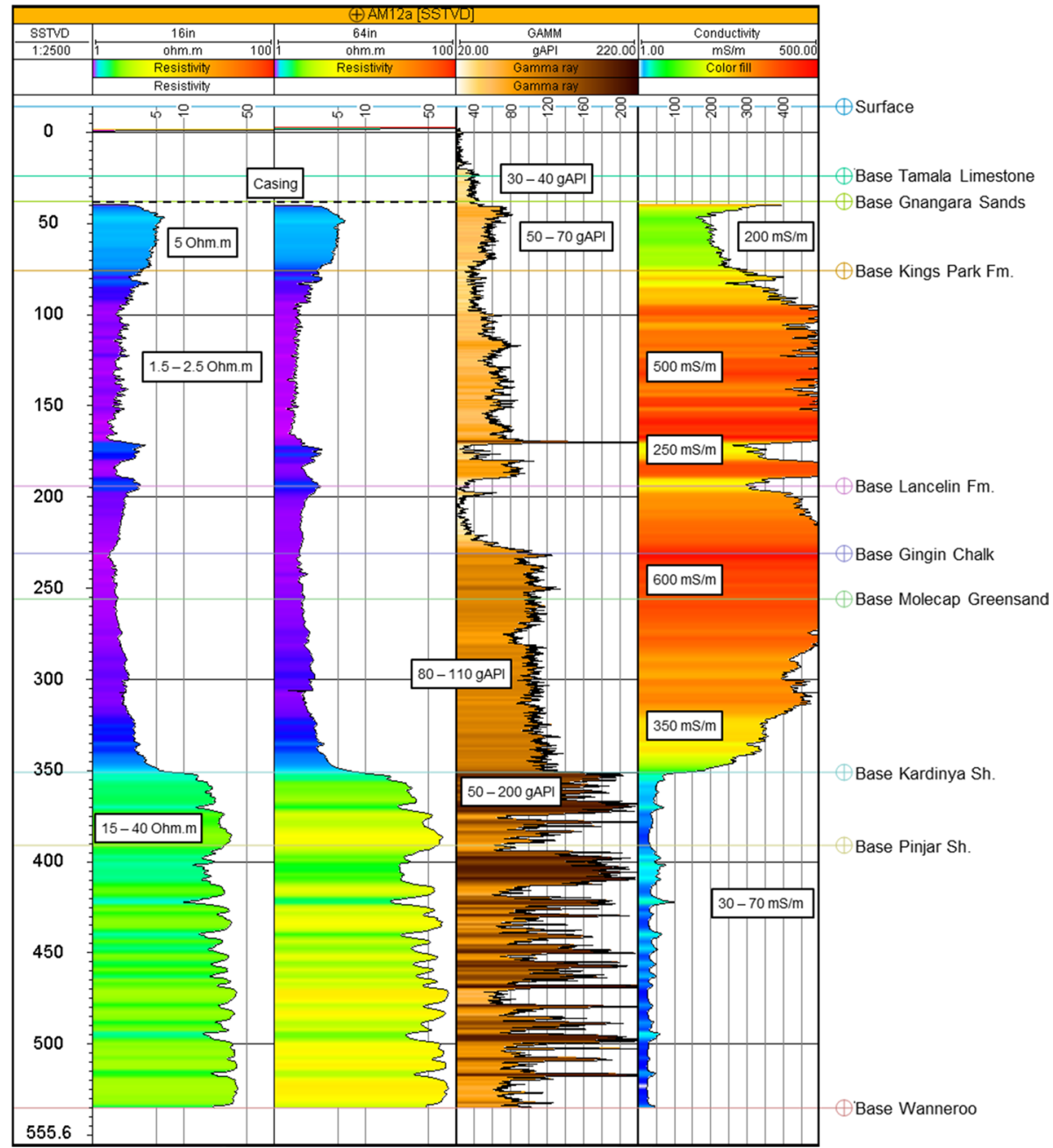

Fig. 25 Strip logs showing the wireline logging from the artesian monitoring well AM12a, located approximately $100 \mathrm{~m}$ from the shoreline at the Two Rocks transect (see Fig. 24). The resistivity logs suggest that conductive saline groundwater could exist to considerable depths. These logs are comparable to the resistivity imaging outcome and indicate that the Kings Parks Formation at this site has little effect on the saline groundwater wedge distribution

that groundwater below the Kardinya Shale (i.e., within the confined Leederville aquifer) is likely to be fresh or brackish (Leyland 2011). More generally, the Leederville aquifer provides a major potable groundwater supply for Perth (Department of Water WA 2015).

In contrast to the Two Rocks resistivity image, the Swanbourne ERI image reveals a distinct high-conductivity saline wedge set above a much lower resistivity horizontal substrate. Here, we are presented with characteristic resistivity imaging artifacts within the substrate layer. Geological models in the area (Davidson 1995; Leyland 2012) suggest the substrate layer has a relatively uniform conductivity; however, the imaging suggests a sharp lateral change in conductivity from 15 to $60 \mathrm{mS} / \mathrm{m}$ directly under the apparent toe of the wedge. For our standard inversion strategy, this type of artifact commonly occurs below the transition from fresh 

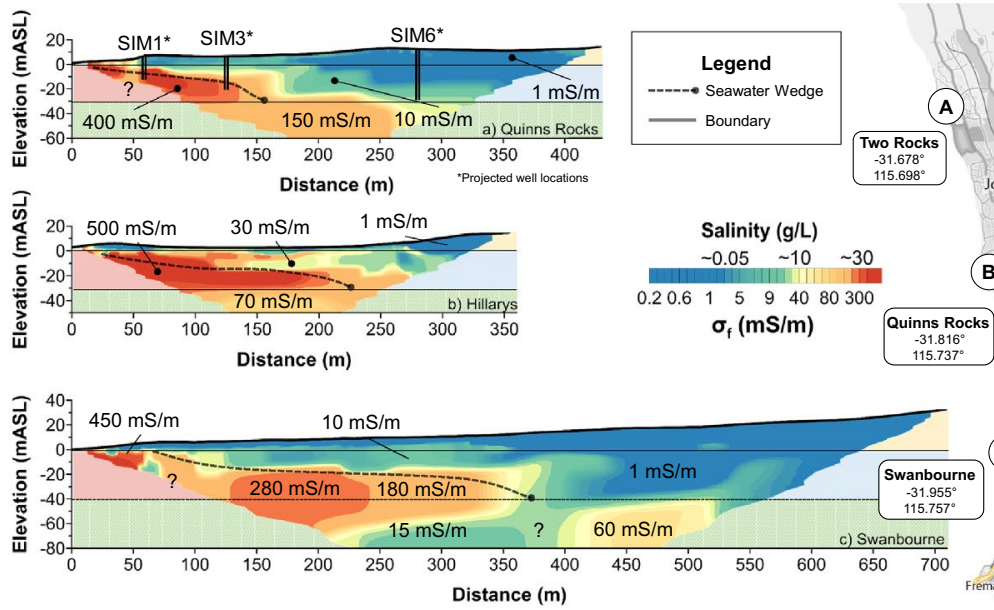

(B)

\section{0} $\sigma_{\mathrm{f}}(\mathrm{mS} / \mathrm{m})$

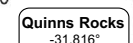
$-31.816^{\circ}$
$115.737^{\circ}$
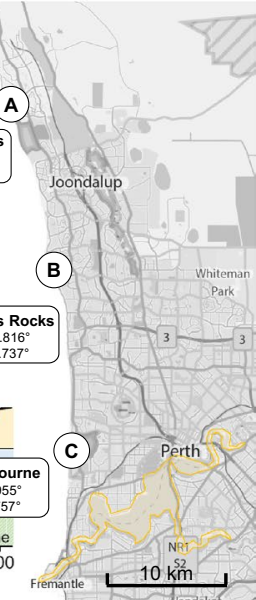

Fig. 26 Interpreted location of the seawater interface toe progressing further inland with proximity to increasingly urbanized Perth metropolitan suburbs and the saline Swan River estuary. Questions marks indicate areas of some uncertainty (map data annotated from (C) OpenStreetMap contributors). Note that the salinity estimates are based on saturated local aeolian limestone and will be significantly different for clays or clayey lithology

to saline groundwater within the substrate. It is consistent with observations for resistivity imaging of numerically simulated ERI data for similar geo-electrical settings (e.g., Fig. 24). The Swanbourne ERI transect is a salient example of where our alternate ERI inversion strategy as presented in Appendix 4 may present significant advantages for representing the saline water interface and substrate. For the Swanbourne Image in Appendix 4, the possible resistivity "overshoot" and "undershoot" in the substrate on each side of the conductive saline groundwater wedge toe is gone.

From a hydrogeological point of view, it is reasonable that the saline groundwater wedge is located above a lower conductivity substrate, especially if the saline water wedge has moved inland, as is already demonstrated in the set of Quinn Rocks SIM wells further to the north. Accurate imaging of the electrical conductivity distribution, representing the full coastal hydrogeology at sites like Swanbourne, remains as a research challenge for resistivity imaging.

In our third example (i.e., the Coogee Transect), a thin and relatively flat high-permeability saline groundwater layer is indistinguishable from the high electrical conductivity Kardinya shale substrate (see Figs. 20, 24). Drilling indicated that the conductivity in two wireline logs and ERI imaging are well matched. However, two aspects of coastal hydrogeology remain unresolved. These are: (1) resolving saline and fresh water close to the swash zone where illumination from a land based ERI system is limited and (2) differentiating a shale substrate from a thin horizontal layer of saline water with in the aquifer above.

Figure 25 contrasts ERI experiments at three different saline water interface geometries. In Fig. 26, we will examine similar setting where a wedge over a shallow substrate is located a successively greater distances inland.

The three resistivity images in Fig. 26 present a seawater interface at ERI sites located progressively closer to the increasingly urbanized older suburbs of Perth, where local groundwater abstraction has been highest. These suburbs are located nearby Perth, next to the saline Swan River estuary (O'Callaghan et al. 2007). The position of the wedge at 
the northern site, Quinns Rock is constrained by five SIM wells perpendicular to the coast. These wells provide some constraints for the interpretation of the wedge geometry.

Two new sites are introduced in Fig. 26. These are the Hillarys site, located $25 \mathrm{~km}$ south of the Quinns Rocks, and Swanbourne ERI site, $55 \mathrm{~km}$ south of the Quinns Rocks. These sites span suburbs which are newly developed (e.g., Quinns Rocks) to older, wellestablished suburbs (e.g., Swanbourne). Based on resistivity imaging outcomes, the saline groundwater wedge at the Swanbourne site has possibly moved over $300 \mathrm{~m}$ inland; however, this interpretation requires validation through new monitoring wells.

Local drivers for the shape and position of the saline water interface include the shape of the coastline, localized freshwater recharge (e.g., rainfall, storm water, and irrigation), aquifer transmissivity, permeability of the substrate, and local household/municipal bore field abstraction from the shallow aquifer. Despite possible local variability in wedge geometry, the resistivity imaging in Fig. 26 provides a basis to interpret a wedge that is located at progressively greater distance inland.

Confidence in the ERI interpretation could have only come from a combination of (1) analysis of outcomes from numerical modeling over comparable geo-electrical settings and (2) calibration of outcomes from execution of a range resistivity imaging strategies, confirmed with data gathered from drill holes as we have presented.

\section{Summary of Major Outcomes}

We have completed a comprehensive study of ERI applications for resolving coastal hydrogeology. During this process, we identify benefits, limitations, and new research challenges. These points are summarised in Table 3, below.

Table 3 Summarized outcomes of experiments undertaken during this research

\begin{tabular}{|c|c|c|c|}
\hline & Key points & Comment & $\begin{array}{l}\text { Evidence in } \\
\text { document }\end{array}$ \\
\hline 1 & $\begin{array}{l}\text { Imaging deficiencies and } \\
\text { artifacts are identified in } \\
\text { electrode arrays }\end{array}$ & $\begin{array}{l}\text { Imaging artifacts cannot be avoided in a complex high-contrast } \\
\text { geo-electrical settings, as exists at coastal margins. We find } \\
\text { that some commonly deployed arrays, such as the Wenner } \\
\text { array, cannot resolve key features of coastal hydrogeology. } \\
\text { We identify areas of potential misinterpretation for different } \\
\text { electrode configurations through numerical modeling and } \\
\text { systematic comparison of field ERI data with drill-hole data }\end{array}$ & Fig. 7 \\
\hline 2 & $\begin{array}{l}\text { Topography impacts on } \\
\text { imaging outcomes }\end{array}$ & $\begin{array}{l}\text { Steep topographic relief is common at many coastal margins. } \\
\text { It should always be included at the acquisition and imaging } \\
\text { (i.e., inversion) stages. We show the imaging outcomes may } \\
\text { misrepresent true subsurface resistivity distribution if topog- } \\
\text { raphy is neglected }\end{array}$ & Fig. 14 \\
\hline 3 & $\begin{array}{l}\text { Commonly deployed arrays } \\
\text { can be combined }\end{array}$ & $\begin{array}{l}\text { Quadrupoles from different arrays are readily combined post- } \\
\text { acquisition to improve data density and subsurface illumina- } \\
\text { tion. We found that, in practice, it was useful to consider } \\
\text { inversion outcomes from both independent and combined } \\
\text { arrays. One reason is that some configurations were sensitive } \\
\text { to noise (e.g., shallow pipes or fences) and tended to degrade } \\
\text { overall imaging outcome. This only became apparent from } \\
\text { field data imaging outcomes }\end{array}$ & Fig. 20 \\
\hline
\end{tabular}


Table 3 (continued)

Key points

Comment

Evidence in

document

4 Outcomes from transects perpendicular to the coastline are better suited to resolving the seawater interface

5 The ERI inversion strategy will significantly impact on the resistivity imaging outcomes

6 Constrained inversion can potentially improve imaging outcomes

7 The seawater wedge and conductive substrate may have similar electrical resistivity

8 Geometry of the seawater interface

9 Value of integrating multiple geophysical methods and drill-hole data

Coastal hydrogeology is often $2 \mathrm{D}$ along the coastline. Certainly, the saline groundwater interface is expected to be dominantly 2D for linear coastal margins. For this reason, the first priority should be to collect ERI perpendicular to the coastal margin. Imaging parallel to the coastal margin can add value by demonstrating the uniform geo-electrical properties exist parallel to the coast. However, 2D inversion may not be appropriate for transects parallel to the shoreline, especially along the beachfront, where any assumption of two dimensionality for this orientation is breached by the close proximity of the seawater (i.e., $\sim 0.3 \mathrm{Ohm} \mathrm{m}$ )

In a setting containing large and abrupt geo-electrical contrasts (e.g., across the saline water interface, water table, or substrate), the application of an L1-style norm within the inversion strategy is likely to generate a more realistic representation of conductivity distribution at the coastal margins. The L2 smoothness-constrained norm generally does not permit sufficient rate of change of conductivity to accommodate the step-like changes in conductivity contrasts which are common at coastal margins

Although constrained inversion can potentially improve imaging of key elements of coastal hydrogeology, such constraints do require detailed prior knowledge of the exact geo-electrical contrast location. It is rare that sufficiently accurate and reliable information is available, and incorrect presumption about the location of high-contrast boundaries tends to significantly degrade imaging outcomes

Differentiating between sub-horizontal saline groundwater interface and a high-cation-exchange-capacity shale may be exceedingly difficult using electrical methods. Examples from the Coogee site (Sect. 3) highlight this challenge

Electrical resistivity with suitable acquisition and inversion parameters can image significant coastal hydrogeological architectures, including;

1. Classic seawater wedge in deep unconfined aquifer

2. Seawater wedge in shallow unconfined aquifer with impermeable substrate

3. Steep interface with basal layer of seawater above highly conductive impermeable substrate

Electrical resistivity imaging is well-suited investigations intended to map distribution of shallow saline groundwater. However, we have identified several weaknesses such as lack of resolution near the swash zone, the inability of electrical methods to differentiate a layer of saline water in sand from a high CEC clayey substrate and inability to recover key stratigraphic characteristics like dip. In many situations, other geophysical technologies or drilling are required to provide the full hydrogeological architecture. For example, GPR was able to image the very shallow wedge descending below the beach zone. Seismic methods (e.g., reflection, refraction tomography, surface wave analysis) may have value, but are expensive. Wells and wireline logs offer valuable and reliable, but highly localized information, critical for understanding and managing coastal hydrogeology. We have provided examples of integrating ERI, drilling and wireline $\log$ data
Fig. 22

Appendix 1

Appendix 1 Appendix 2

Fig. 22

Fig. 24

Fig. 23 


\section{Conclusions and Future Work}

Coastal margins around the world are often densely populated and vulnerable to seawater intrusion. Predicting the consequences of groundwater management strategies in these systems requires high-quality information on solute concentration and distribution. ERI has the potential to supply this information. We have provided a comprehensive study of electrical resistivity imaging along coastal margins, including substantial evidence from seawater monitoring wells. The geo-electrical architecture in these settings typically consists of several high-contrast geo-electrical boundaries, such as the water table, seawater wedge, and a clayey substrate. These boundaries are often below beaches, undulating dunes, or steep cliffs.

Our numerical and field experiments showed that several ERI field configurations provide baseline information from which key elements of the saline water interface can be interpreted. However, each configuration exhibited limitations and characteristic artifacts. For example, inversion of data collected with the Wenner electrode configuration failed to identify a shallow clayey substrate in both numerical modeling and field data. In contrast, inversion of data containing dipole-dipole quadrupoles did resolve the substrate, highlighting illumination as a key driver for resolving architecture of coastal hydrogeology with ERI.

To assess ERI for a range of saline water interface geometries, we completed surveys at select locations along $100 \mathrm{~km}$ of shoreline. Of particular note is our comparison between inverted resistivity imaging for (1) a classic wedge-shaped seawater interface in a deep unconfined aquifer, and (2) several sites where the high-quality aquifer with a seawater wedge terminates against a shallow clayey substrate. Our systematic field ERI experiments along an extended coastline show clear relationships between landward extent of saline water and proximity to the urbanized inner suburbs of Perth, Western Australia.

We summarize current and future challenges for ERI along coastal margin in Table 4. Advances in these areas will facilitate accurate reconstruction of coastal hydrogeology and in particular the seawater interface in time and space for electrical resistivity imaging.

Table 4 Current and future research areas

\begin{tabular}{|c|c|c|}
\hline Research Area & Comment & Examples \\
\hline $\begin{array}{l}\text { Joint, cooperative, } \\
\text { and collabora- } \\
\text { tive inversion }\end{array}$ & $\begin{array}{l}\text { Additional information, such as airborne EM, GPR, } \\
\text { wireline logging, seismic or lithological logs, should } \\
\text { be able to improve reconstruction of coastal hydro- } \\
\text { geology. However, there are few practical examples } \\
\text { demonstrating the value of joint/cooperative inversion } \\
\text { and the additional cost of acquiring the necessary } \\
\text { data may be prohibitive }\end{array}$ & $\begin{array}{l}\text { Hamdan and Vafidis (2013), } \\
\text { Hermans et al. (2012) and } \\
\text { Steklova and Haber (2017) }\end{array}$ \\
\hline $\begin{array}{l}\text { Optimized elec- } \\
\text { trode arrays }\end{array}$ & $\begin{array}{l}\text { Optimizing electrode arrangements intended to achieve } \\
\text { optimal ERI resolution at coastal margins may prove } \\
\text { valuable. Optimized arrays have potential to reduce } \\
\text { time-of-acquisition with improved resolution }\end{array}$ & $\begin{array}{l}\text { Ishola et al. (2015) and Loke } \\
\text { et al. }(2014 a, b 2015 a, b)\end{array}$ \\
\hline $\begin{array}{l}\text { Joint/collaborative } \\
\text { groundwater } \\
\text { and ERI inver- } \\
\text { sion }\end{array}$ & $\begin{array}{l}\text { Joint/collaborative groundwater flow and transport } \\
\text { modeling, coupled with geo-electrical inversion of } \\
\text { ERI data, has potential to improve spatial and tempo- } \\
\text { ral resolution of the seawater wedge, mixing zone and } \\
\text { fresh groundwater. Also inversion outcomes based on } \\
\text { continuous monitoring of wells and ERI transects can } \\
\text { then be used to better predict future movements of the } \\
\text { seawater interface under various abstraction scenarios }\end{array}$ & $\begin{array}{l}\text { Beaujean et al. (2014), } \\
\text { Johnson et al. (2010) and } \\
\text { Nguyen et al. (2009) }\end{array}$ \\
\hline
\end{tabular}


Table 4 continued

\begin{tabular}{|c|c|c|}
\hline Research Area & Comment & Examples \\
\hline $\begin{array}{l}\text { Joint land/marine } \\
\text { surveying }\end{array}$ & $\begin{array}{l}\text { Current instrumentation limits usage of ERI to land- } \\
\text { bound cables. Future technology opportunities for } \\
\text { submarine electrodes and weighted, waterproof } \\
\text { cabling can potentially improve coastal resistiv- } \\
\text { ity imaging results by expanding surveys offshore, } \\
\text { increasing resolution in key areas of interest (e.g., } \\
\text { marine discharge of freshwater) }\end{array}$ & $\begin{array}{l}\text { Crook et al. (2008), Hender- } \\
\text { son et al. (2010) and Loke } \\
\text { and Lane (2004) }\end{array}$ \\
\hline $\begin{array}{l}\text { Time-lapse ERI } \\
\text { monitoring }\end{array}$ & $\begin{array}{l}\text { Time-lapse ERI monitoring has proven effective in a } \\
\text { range of scenarios. However, there is little published } \\
\text { evidence of time-lapse ERI applied to seawater intru- } \\
\text { sion monitoring in urban settings. The movement } \\
\text { of the saline wedge can occur rapidly depending on } \\
\text { shallow abstraction rates, or it may occur slowly over } \\
\text { decades as a result of climate change (e.g., declining } \\
\text { rainfall recharge). Time-lapse ERI monitoring will } \\
\text { likely need to be specifically designed to capture } \\
\text { very short-period changes (e.g., from tidal forcing) } \\
\text { and long period effects (e.g., resulting from climate } \\
\text { change) }\end{array}$ & $\begin{array}{l}\text { de Franco et al. (2009), } \\
\text { Ogilvy et al. (2009), } \\
\text { Ronczka et al. (2015) and } \\
\text { Uhlemann et al. (2016) }\end{array}$ \\
\hline
\end{tabular}

Acknowledgements This research was funded by the Curtin University Postgraduate Scholarship, from Curtin University, Perth, Western Australia, and Department of Water, Western Australia. It is part of a research collaboration between Department of Water and Environmental Regulation (DWER) of Western Australia and Curtin University. We extend our thanks to the Associate Professor Dr. Farquharson for valuable review and commentary. We additionally extend thanks to Schlumberger for providing the Petrel E\&P software platform used in this research and Dr. M.H. Loke for further discussion and advice. Supporting resistivity data, including raw data, processed files, and inversion parameter files are available on-request from the corresponding author. Water table, water conductivity, and lithological information are freely available from Water Information Reporting, (http://wir.water.wa.gov.au/). Synthetic data were created with RES2DMOD. Field data were processed with Iris Instrument ProSys2. All data were inverted with RES2DINV v4.05-v4.07. Imagery was created using Adobe Illustrator CC 2015, MATLAB 2017a, Microsoft PowerPoint, and Surfer 14.

Open Access This article is distributed under the terms of the Creative Commons Attribution 4.0 International License (http://creativecommons.org/licenses/by/4.0/), which permits unrestricted use, distribution, and reproduction in any medium, provided you give appropriate credit to the original author(s) and the source, provide a link to the Creative Commons license, and indicate if changes were made.

\section{Appendices}

\section{Appendix 1: Testing of Inversion Parameters on Synthetic Data}

For geophysical inversion, common points of discussion are: (1) the appropriateness of $L_{1}$ and $L_{2}$ norms (Claerbout and Muir 1973; Constable et al. 1987) and (2) the benefits and drawbacks of introducing constraints, which may themselves introduce new uncertainties. While every inversion strategy has subtle differences, the $L_{1}$ - or $L_{2}$-like norms are well known in applied research and are reasonable reference points for comparison. 


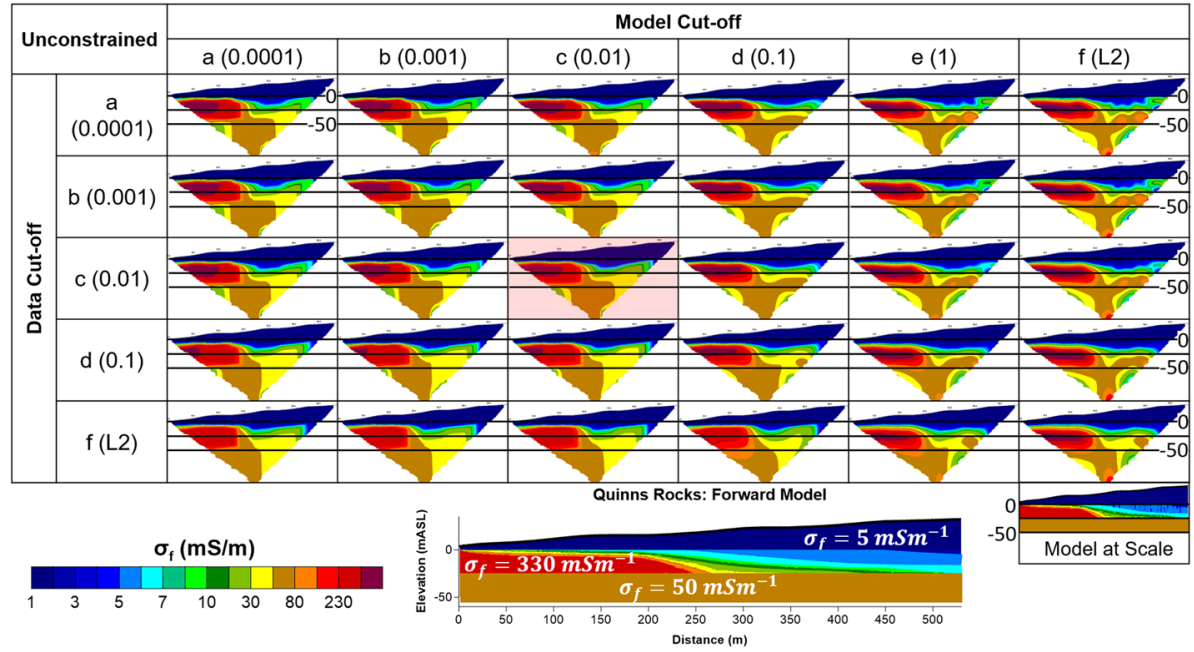

Fig. 27 Grid of resistivity images highlighting the impact of systematically changing RES2DINV (Loke $2016 b$ ) robust data and model cutoff values for unconstrained inversion. Inversions are completed over a synthetic model of a saline water wedge including topography. When compared to the synthetic model, the inverted resistivity images show artifacts, such as overshoot and undershoot, at high contrast boundaries (e.g., proximal to the seawater wedge). The resistivity image within the central highlighted box (red shaded background) indicates cutoff values nearest to those used for our standard inversion workflow (see parameters in Appendix 3). The inversion workflows selected are not exhaustive, and data can be made available if others wish to test further alternatives

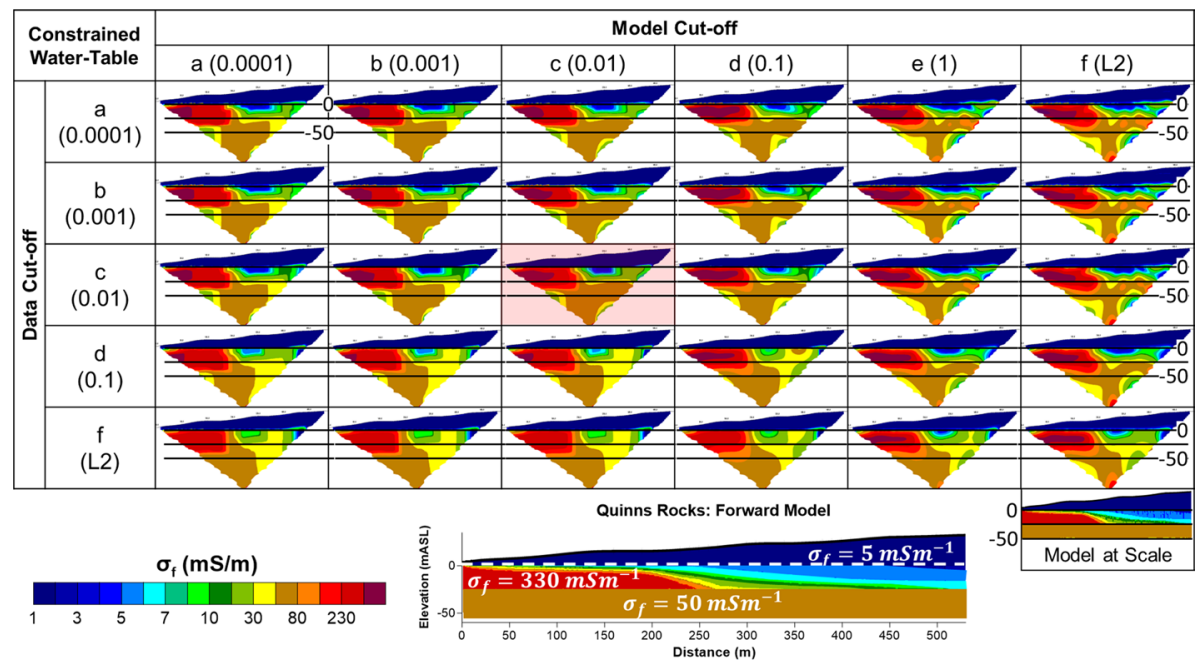

Fig. 28 Grid of resistivity images highlighting the impact of systematically changing RES2DINV (Loke 2016 b) robust data and model cut off values for inversion with a sharp boundary constraint at the water table. Imaging of the seawater interface below the water table does not appear to be significantly improved with addition of the water table constraint. Artifacts are present from undershoot and overshoot in the substrate. The inversion workflows selected are not exhaustive, and data can be made available if others wish to test further alternatives 


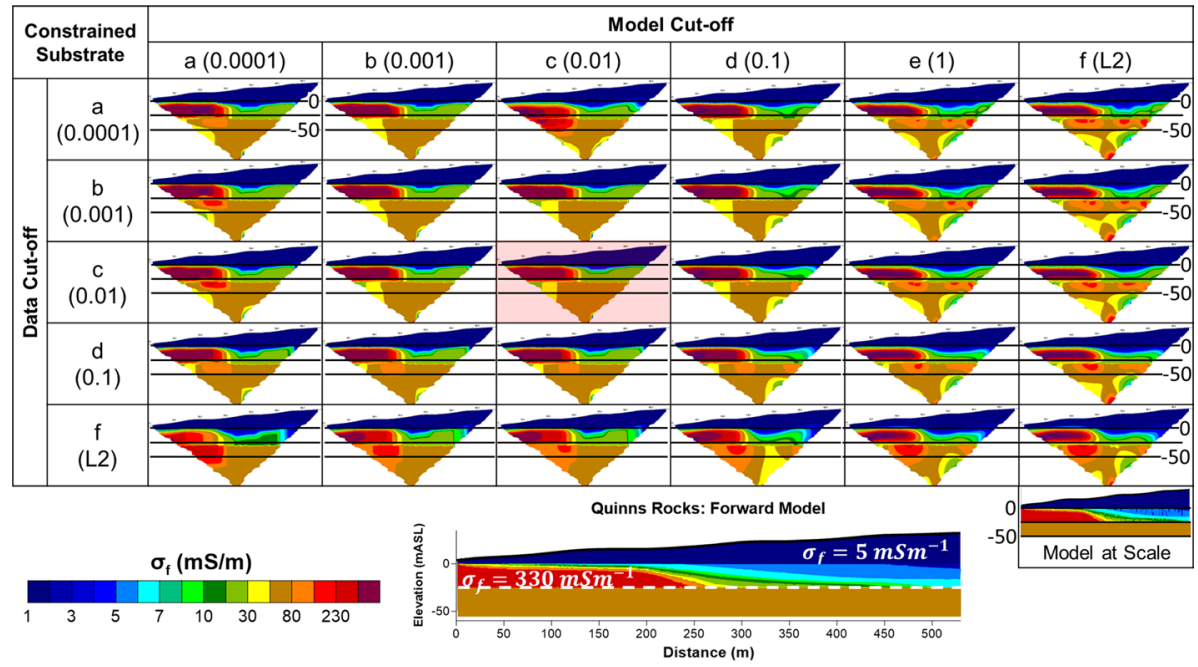

Fig. 29 Grid of resistivity images highlighting the impact of systematically changing RES2DINV (Loke 2016b) robust data and model cut off values for inversion with a sharp boundary constraint at the substrate. The introduction of a constraint at the substrate appears to improve definition of the seawater interface mixing zone for some combinations of robust model and robust data values (see images bc, bd). However, artifacts are introduced in the substrate for many of the images (see images af, ac, fd as examples). The inversion workflows selected are not exhaustive, and data can be made available if others wish to test further alternatives

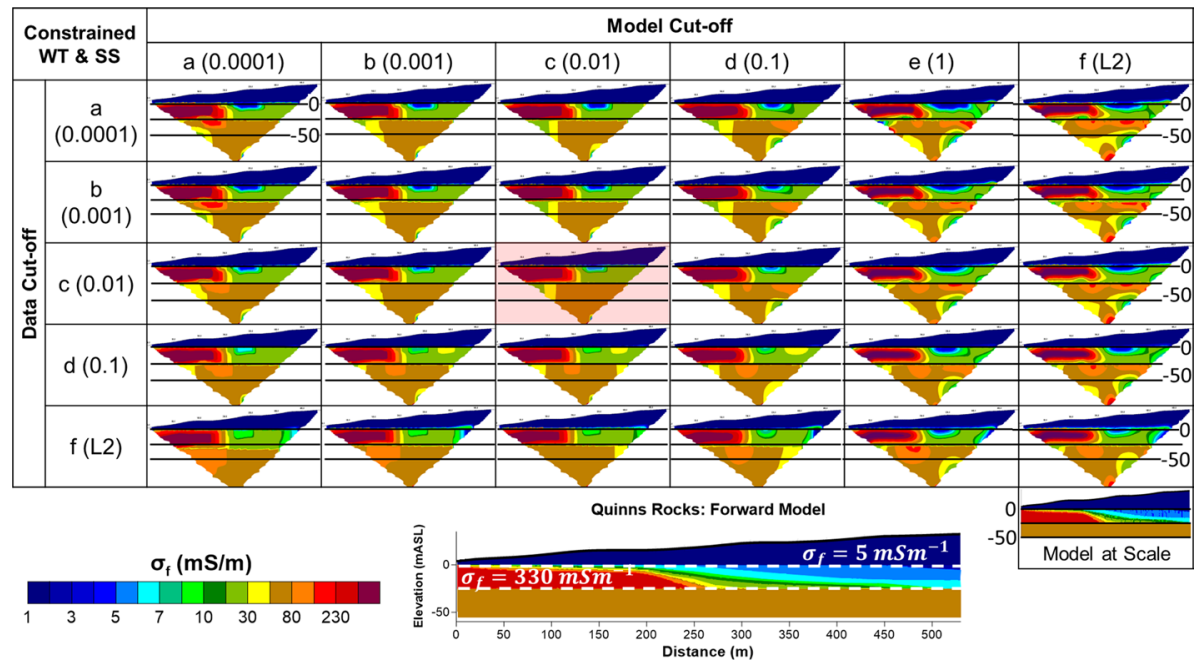

Fig. 30 Grid of resistivity images highlighting the impact of systematically changing RES2DINV (Loke 2016b) robust data and model cut off values for inversion with a sharp boundary constraint at the water table and substrate. With the parameters selected, artifacts appear to have been generated in the substrate. The inversion workflows selected are not exhaustive, and data can be made available if others wish to test further alternatives 
RES2DINV provides the ability to systematically test inversion strategies that range between end-member $L_{1^{-}}$and $L_{2}$-like norm approaches. This implementation is functionally similar to the Ekblom norm, (Ekblom 1974) and uses an iteratively reweighted leastsquares (IRLS) algorithm to allow sharp interfaces in subsurface structure (Farquharson 2007).

In this implementation, if the percentage difference between observed and calculated data is greater than a "cutoff" value, then inversion tends to accommodate high electrical contrast in a manner consistent with application of the robust or $L_{1}$ norm (Farquharson and Oldenburg 1998; Loke 2016b). Below this threshold (i.e., the cutoff value), the inversion outcome tends toward the typical smoothness-constrained Occam-style, $L_{2}$ norm (Farquharson and Oldenburg 1998; Loke 2016b). For example, selecting a high cutoff value of 1 pushes the inversion to a smoothness-constrained $L_{2}$ norm outcome, while selecting a low cutoff factor of 0.001 drives the inversion closer to an outcome expected from a robust or, $L_{1}$ norm.

To highlight the effects of varying the inversion parameters in RES2DINV, we have computed images spanning the full range of available data and model cutoff values. For unconstrained inversion, these are presented in a grid of 30 conductivity-depth sections and are presented in Fig. 27. Three comparable sets of images are provided for constrained inversion, where the constraints are placed at (1) the water table interface (Fig. 28), (2) aquifer/substrate interface (Fig. 29) and (3) both water table and substrate interfaces (Fig. 30). In each case, the inversion is permitted to have a sharp change at each designated interface.

For geo-electrical geometries at the seawater interface, some ERI inversion outcomes can appear blocky and there may be the temptation to attribute this to mesh discretization. The discretization of finite-element grids used is exceedingly fine, as indicated in Table 1. Attempts to create a finer mesh would simply increase calculation time with negligible benefit (e.g., Günther 2004). The slightly blocky appearance is more likely a result of the robust regularization used in the ERI inversion. If a robust regularization is not used, the location of the lower substrate tends to be poorly represented in imaging outcomes. The alternative inversion approach dictated in Appendix 4 appears to reduce the blocky appearance by implementing the diagonal roughness filter and extended models.

\section{Appendix 2: Constrained Inversion of Field Data}

Constrained inversion incorporates additional information such as seismic data, groundwater chemistry, wireline logs, geological descriptions, and/or hydrogeological models into the inversion process. It is intended to direct the inversion process toward the best possible representation of subsurface conductivity distribution (Binley et al. 2015; Zhou 2015; Zhou et al. 2014).

If significant geo-electrical boundaries were known, both seed model and distribution of smoothness constraints could be manipulated to significantly improve the outcome of inversion (e.g., Karaoulis et al. 2014; Le et al. 2016; Soueid Ahmed et al. 2015; Zhou et al. 2014). However, ERI is usually the first technique deployed, often for the purpose of targeting drill holes and constraints are rarely available. Small errors in placement of high-contrast boundary constraints, like the lower clay substrate can translate to significant artifacts especially at greater depths. 

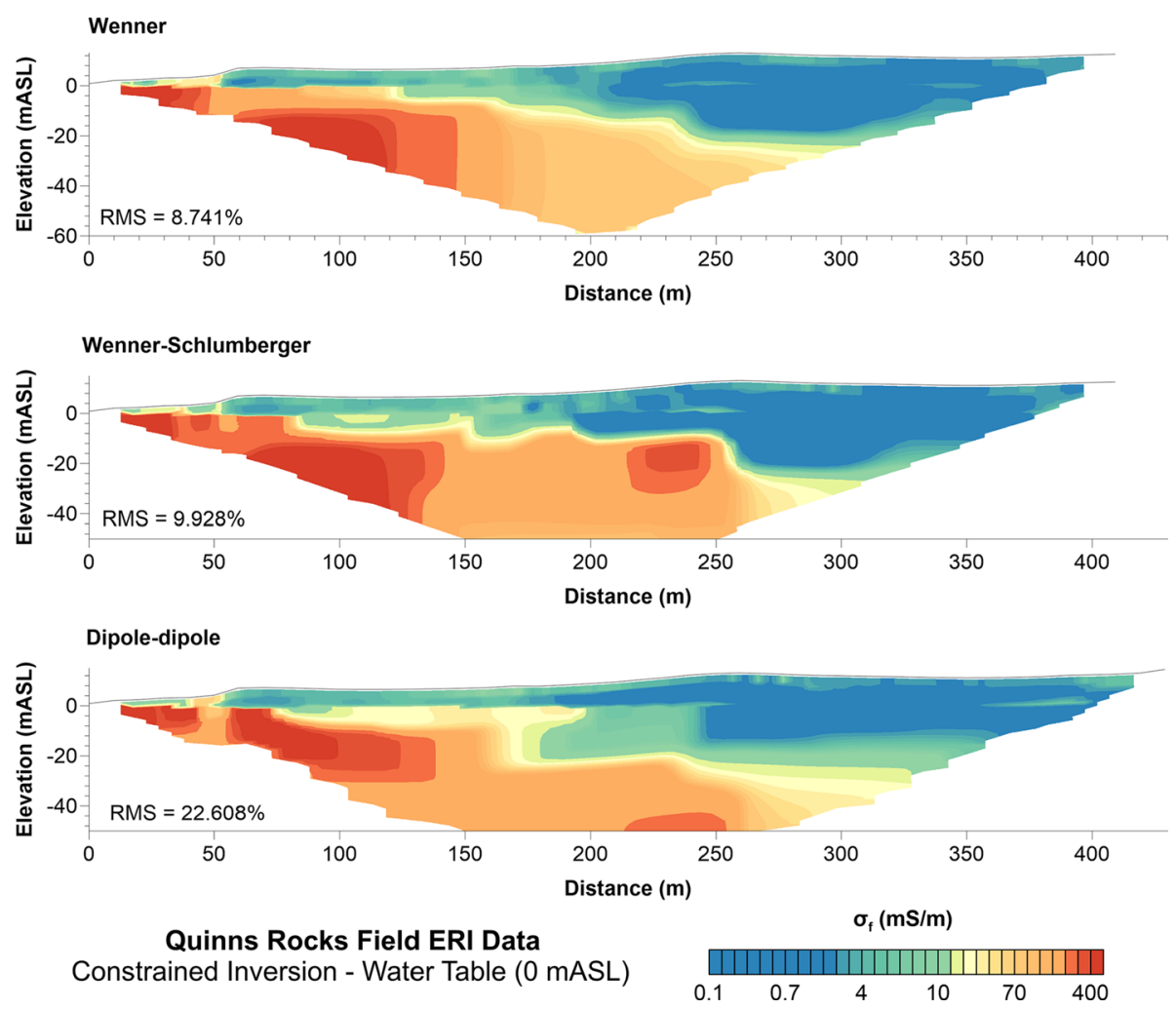

Fig. 31 Formation conductivities resulting from the guided or constrained inversion of ERI field data from each of the three electrode conurations. The sharp boundary constraint is placed on water table, which at this high-permeability coastal aquifer can be reasonably assumed flat. No additional constraints are added, as there is some uncertainty regarding the substrates precise location, and incorrectly forcing boundaries is unlikely to accurately represent the true subsurface geo-electrical structure

Figure 31 shows the outcome of constrained ERI inversion using the water table as the constraint. Setting a "sharp boundary constraint" allows the inversion to generate a large contrast in electrical conductivity from one side of the boundary (i.e., the water table) to the other. Figure 31 shows the inversion outcomes using a constraint placed at the water table, where a high contrast and relatively flat interface exists. This figure can be compared to Fig. 16, which shows the unconstrained inversion outcomes. Forcing the boundary results in higher resistivity at the beach and swash zones, however there is no significant difference in the interpretation of the saline water interface or the lower substrate. The boundary constraint also introduces potentially unrealistic changes into the resistive vadose zone, further inland. 


\section{Appendix 3: Inversion Parameters}

See Table 5.

Table 5 Full inversion parameter listing

Inversion settings

Initial damping factor (0.01-1.00)

Minimum damping factor $(0.001-0.75)$

Local optimization option $(0=$ no, $1=$ yes $)$

Convergence limit for relative change in RMS error in percent (0.1-20) 5

Minimum change in RMS error for line search in percent (0.5-100) 0.5

$\begin{array}{ll}\text { Number of iterations (1-30) } & 10\end{array}$

$\begin{array}{ll}\text { Vertical to horizontal flatness filter ratio }(0.25-4.0) & 1\end{array}$

Model for increase in thickness of layers $(0=$ default $10 \%, 1=$ default $25 \%, 2=$ user defined $) \quad 2$

Number of nodes between adjacent electrodes (1,2 or 4$) \quad 4$

Flatness filter type, Include smoothing of model resistivity $(0=$ model changes only, $1=$ directly on 0 model)

Reduce number of topographic data points? $(0=$ no, $1=$ yes. Recommend leave at 0$) \quad 0$

Carry out topography modeling? $(0=$ no, $1=$ yes $)$

Type of topography trend removal $(0=$ average, $1=$ least-squares, $2=$ end to end $)$

Type of Jacobian matrix calculation $(0=$ quasi-Newton, $1=$ Gauss-Newton, $2=$ mixed $) \quad 2$

$\begin{array}{lr}\text { Increase in damping factor with depth (1.0-2.0) } & 1.05\end{array}$

Type of topographic modeling $\quad 4$

Robust data constrain? $(0=$ no, $1=$ yes $) \quad 1$

$\begin{array}{lr}\text { Cutoff factor for data constrain }(0.0001-0.1)) & 0.05\end{array}$

Robust model constrain? $(0=$ no, $1=$ yes $) \quad 1$

$\begin{array}{ll}\text { Cutoff factor for model constrain (0.0001-1.0) } & 0.005\end{array}$

Allow number of model parameters to exceed data points? $(0=$ no, $1=$ yes $) \quad 1$

Use extended model? $(0=$ no, $1=$ yes $) \quad 0$

Reduce effect of side blocks? $(0=$ no, $1=$ slight, $2=$ severe, $3=$ very severe $) \quad 1$

Type of mesh $(0=$ normal, $1=$ fine, $2=$ finest $) \quad 2$

$\begin{array}{ll}\text { Optimize damping factor? }(0=\text { no, } 1=\text { yes }) & 1\end{array}$

Time-lapse inversion constrain $(0=$ none, 1 and $2=$ smooth, $3=$ robust $) \quad 3$

Type of time-lapse inversion method $(0=$ simultaneous, $1=$ sequential $) \quad 0$

$\begin{array}{lr}\text { Thickness of first layer (0.25-1.0) } & 0.25\end{array}$

$\begin{array}{ll}\text { Factor to increase thickness layer with depth (1.0-1.25) } & 1.05\end{array}$

Use finite-element method (yes $=1$, no $=0$ ) 1

Width of blocks $(1=$ normal width, $2=$ double, $3=$ triple, $4=$ quadruple, $5=$ quintuple $) \quad 1$

Make sure blocks have the same width (yes $=1$, no $=0$ ) 1

$\begin{array}{ll}\text { RMS convergence limit (in percent) } & 0.1\end{array}$

Use logarithm of apparent resistivity ( 0 log app. resistivity, $1=$ resistance values, $2=$ app. resistiv- 0 ity)

Proceed automatically for sequential method $(1=$ yes, $0=$ no) $\quad 0$

$\begin{array}{ll}\text { Limit resistivity values }(0=\text { no, } 1=\text { yes }) & 1\end{array}$

$\begin{array}{ll}\text { Upper limit factor }(10-50) & 50\end{array}$

$\begin{array}{lr}\text { Lower limit factor }(0.02-0.1) & 0.02\end{array}$

Type of reference resistivity $(0=$ average, $1=$ first iteration $) \quad 1$ 
Table 5 (continued)

Inversion settings

Model refinement $(1.0=$ normal, $0.5=$ half-width cells $)$

Combined Marquardt and Occam inversion $(0=$ not used, $1=$ used $)$

Type of optimization method ( $0=$ Gauss-Newton, $2=$ incomplete GN)

Convergence limit for incomplete Gauss-Newton method (0.005-0.05)

Use data compression with incomplete Gauss-Newton $(0=$ no, $1=$ yes $)$

Use reference model in inversion $(0=$ no, $1=$ yes $)$

Damping factor for reference model (0.0-0.3)

Use fast method to calculate Jacobian matrix $(0=$ no, $1=$ yes $)$

Use higher damping for first layer? $(0=$ no, $1=$ yes $)$

Extra damping factor for first layer (1.0-100.0)

Type of finite-element method $(0=$ triangular, $1=$ trapezoidal elements $)$

Factor to increase model depth range (1.0-5.0)

Use sparse inversion method for very long survey lines $(0=$ no, $1=$ yes $)$

Optimize Jacobian matrix calculation $(0=$ no, $1=$ yes $)$

Automatically switch electrodes for negative geometric factor $(0=$ no, $1=$ yes $)$

Force resistance value to be consistent with the geometric factor $(0=$ no, $1=$ yes $)$

Shift the electrodes to round up positions of electrodes $(0=$ no, $1=$ yes $)$

Use active constraint balancing $(0=$ no, $1=$ yes $)$

Type of active constraints $(0=$ normal, $1=$ reverse $)$

Lower damping factor limit for active constraints

Upper damping factor limit for active constraints

Use automatic calculation for change of damping factor with depth $(0=$ no, $1=$ yes $)$

Use diagonal filter $(0=$ no, $1=$ yes $)$

Diagonal filter weight (0.2-5.0)

Limit range of data weights from error estimates? $(0=$ no, $1=$ yes $)$

Lower limit of data weights $(0.2-0.5)$

Upper limit of data weights (2.0-5.0)

Use same data weights from error estimates for different time series? $(0=$ no, $1=$ yes $)$

Calculate model resolution? $(0=$ no, $1=$ yes $)$

Use $\mathrm{L}$ curve method? $(0=$ no, $1=$ yes $)$

Use same norms in L curve method? $(0=$ no, $1=$ yes $)$

Allow damping factor in increase in L curve method? $(0=$ no, $1=$ yes $)$

Use fast Jacobian calculation for dense data sets? $(0=$ no, $1=$ yes $)$

Use higher damping factors at sides of model? $(0=$ no, $1=$ yes $)$

Adjust damping factors for distances between the blocks in the model? $(0=$ no, $1=$ yes $)$

Number of electrodes in segment for sparse inversion method for very long survey lines

Parameters related to IP, borehole, time-lapse, and water layers have been removed for brevity 


\section{Appendix 4: Alternative Processing and Model Resolutions}

The following set of images show the associated outcomes from including the settings listed in Table 6, e.g. the diagonal roughness filter and extended model settings. Farquharson (2007) demonstrates how the diagonal roughness filter allows resolution of dipping interfaces in the L1-style iteratively reweighted least-square inversion approach. The interfaces tend to become vertical or horizontal during inversion otherwise. Loke (2016a) suggests that the "extended model" approach (which is required for the diagonal filter) expands model cells to the border of the model—as opposed to using a single elongate cell.

This approach has two benefits: (1) it limits edge-based artifacts, resulting from the relatively higher side-cell sensitivity, and (2) provides a more realistic interpretation than the traditional pseudo-depth/midpoint plotting convention, which does not imply depth of investigation or subsurface current flow (Loke 2016a).

Table 6 Modified inversion parameter settings for Appendix 4

\begin{tabular}{ll}
\hline Inversion parameter & Value \\
\hline Use extended model? & 1 \\
Use diagonal filter? & 1 \\
Diagonal filter weight $(0.2-5.0)$ & 1.44
\end{tabular}

Table 7 List of figures in Appendix 4

\begin{tabular}{|c|c|c|c|c|}
\hline Figure subset & & Array & Appendix figure & Comparable figure \\
\hline \multirow[t]{3}{*}{ Fwd. modeling (w/ Topo.) } & & $\mathrm{W}$ & Fig. 32 & Fig. 7 \\
\hline & & $\mathrm{SC}$ & Fig. 33 & Fig. 7 \\
\hline & & DP & Fig. 34 & Fig. 7 \\
\hline \multirow{3}{*}{\multicolumn{2}{|c|}{ Fwd. modeling (W/ Topo.) }} & $\mathrm{W}$ & Fig. 35 & Fig. 14 \\
\hline & & $\mathrm{SC}$ & Fig. 36 & Fig. 14 \\
\hline & & $\mathrm{DP}$ & Fig. 37 & Fig. 14 \\
\hline \multirow{3}{*}{\multicolumn{2}{|c|}{ Fwd. modeling (Combined Arrays) }} & $\mathrm{W}$ and $\mathrm{SC}$ & Fig. 38 & Fig. 15 \\
\hline & & W and DP & Fig. 39 & Fig. 15 \\
\hline & & SC and DP & Fig. 40 & Fig. 15 \\
\hline \multirow{3}{*}{\multicolumn{2}{|c|}{$\begin{array}{l}\text { Field data (Quinns Rocks calibration } \\
\text { site) }\end{array}$}} & $\mathrm{W}$ & Fig. 41 & Fig. 16 \\
\hline & & $\mathrm{SC}$ & Fig. 42 & Fig. 16 \\
\hline & & DP & Fig. 43 & Fig. 16 \\
\hline \multirow{3}{*}{\multicolumn{2}{|c|}{ Field data (Coogee site) }} & DP & Fig. 44 & Fig. 20 \\
\hline & & MG & Fig. 45 & Fig. 20 \\
\hline & & MG and DP & Fig. 46 & Fig. 20 \\
\hline \multirow[t]{3}{*}{ Field Data } & Hillarys & DP & Fig. 47 & Fig. 24 \\
\hline & Swanbourne & DP & Fig. 48 & Fig. 26 \\
\hline & Two Rocks & DP & Fig. 49 & Fig. 24 \\
\hline
\end{tabular}

A brief description of each figure is contained in the captions. Images are available digitally for higher resolution

$W$ Wenner, SC Schlumberger, $D P$ dipole-dipole, $M G$ multiple gradient, Cond. conductivity, $F w d$. forward, Topo. topography 

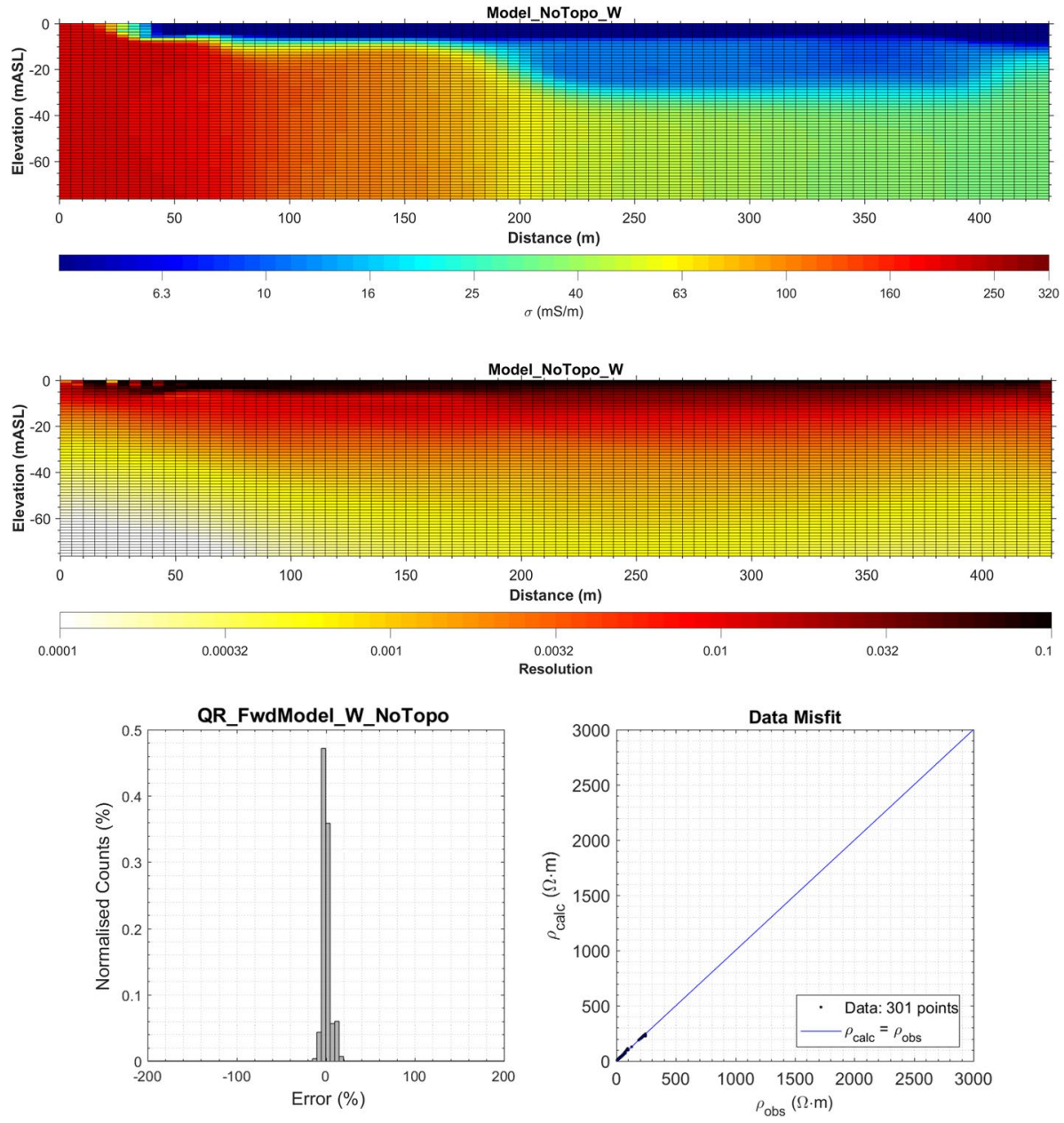

Fig. 32 Inverted conductivity distribution (top), distribution of resolution (middle), and error distribution and statistics (bottom) for the synthetic model of a seawater interface without topographic relief. This example uses the Wenner configuration

Outcomes using the alternate inversion approach are presented with model resolution sections. The concept of model resolution characterizes whether the data can be independently predicted or resolved (Menke 2012). It relates the relationship between the calculated and observed models by the resolution matrix $R$ (Loke 2016a). If $R=I$ (i.e., the resolution matrix is an identity matrix), then every model parameter is uniquely determined. Otherwise, estimated model parameters represent weighted averages of the true model parameters (Menke 2012). Resolution sections can be used to estimate depth of investigation [i.e., (Oldenburg and Li 1999)] and to aid interpretation of inversion outcomes (Table 7). 

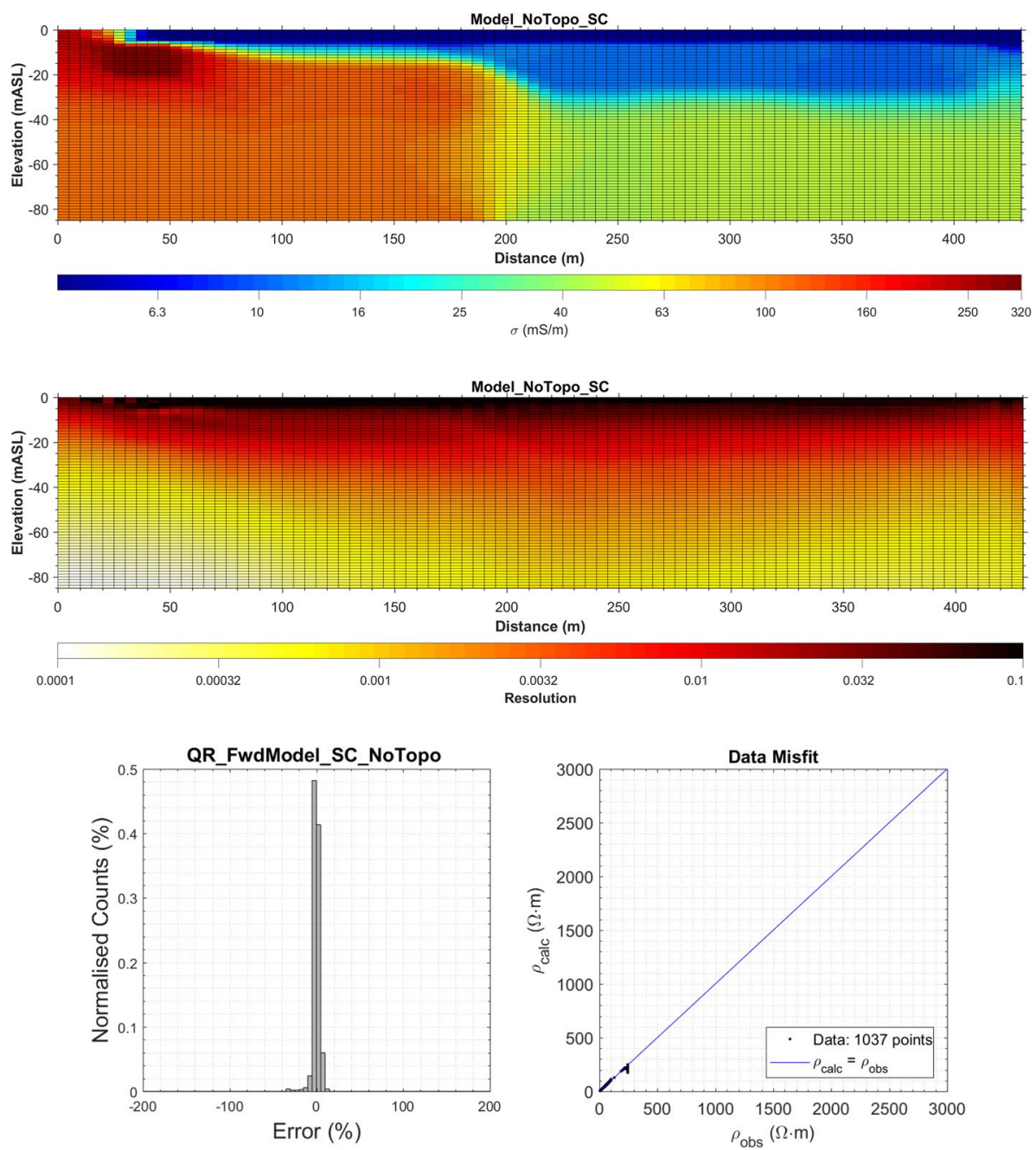

Fig. 33 Inverted conductivity distribution (top), distribution of resolution (middle), and error distribution and statistics (bottom) for the synthetic model of a seawater interface without topographic relief. This example uses the Schlumberger configuration 

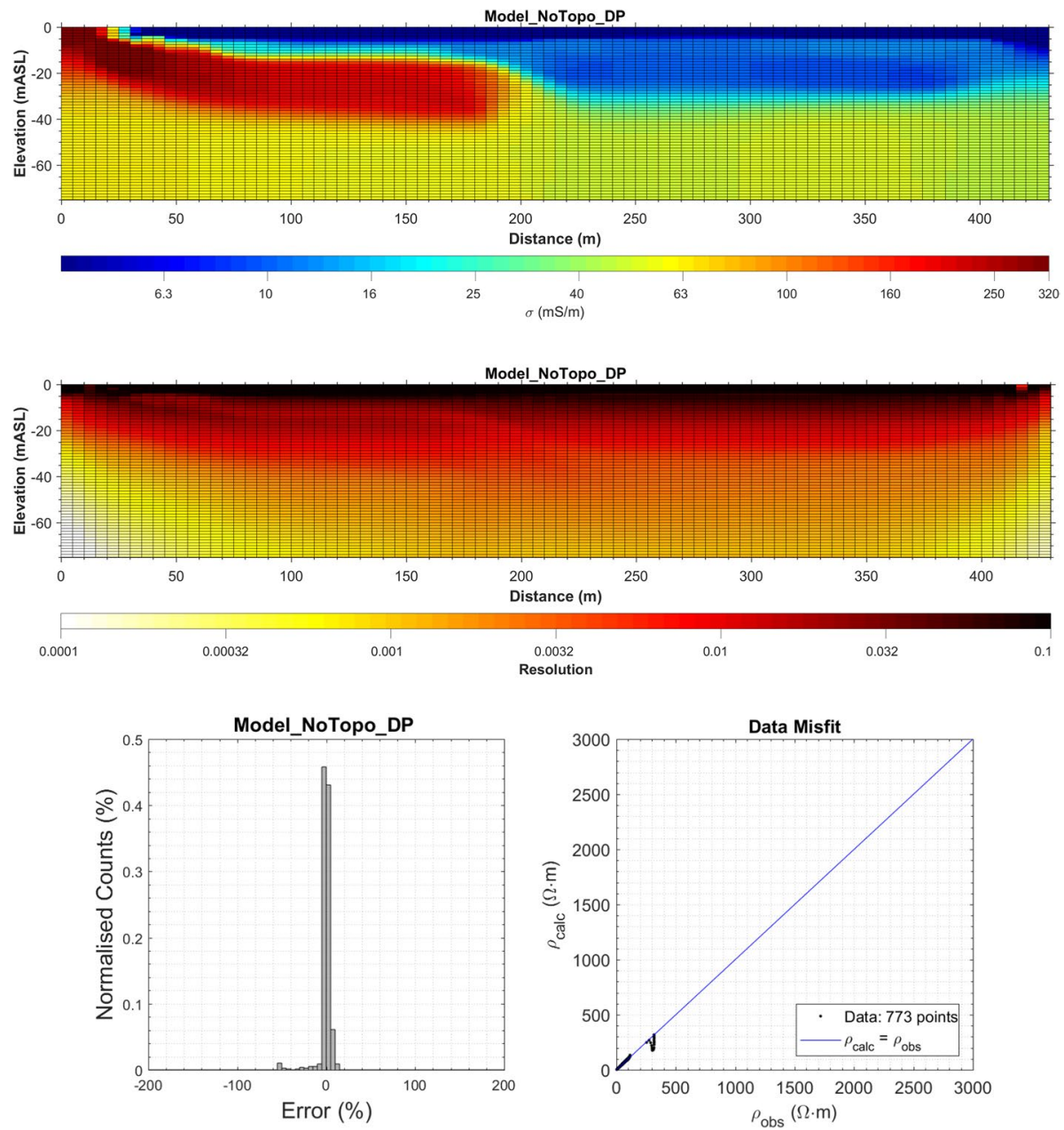

Fig. 34 Inverted conductivity distribution (top), distribution of resolution (middle), and error distribution and statistics (bottom) for the synthetic model of a seawater interface without topographic relief. This example uses the dipole-dipole configuration 

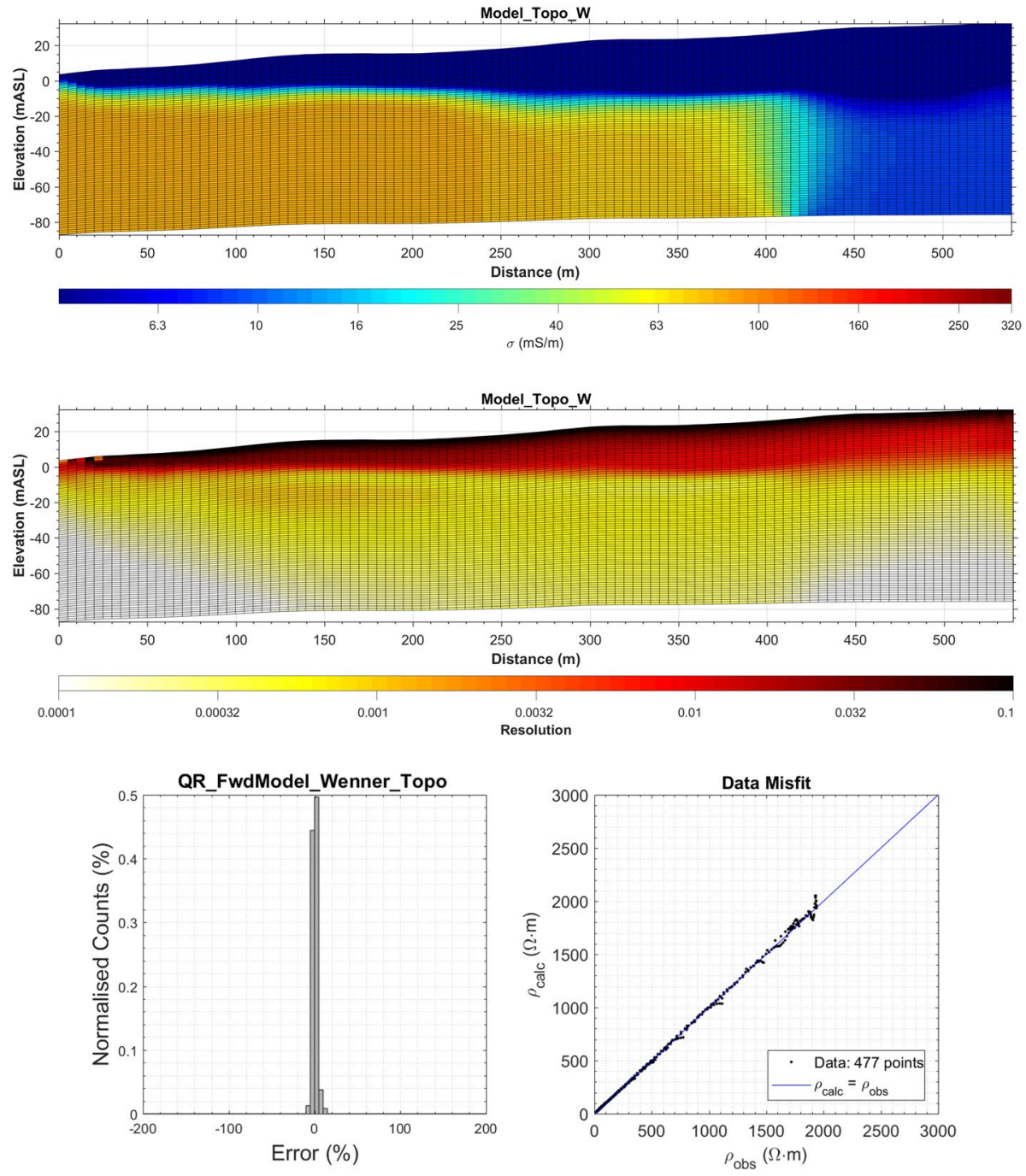

Fig. 35 Inverted conductivity distribution (top), distribution of resolution (middle), and error distribution and statistics (bottom) for the synthetic model of a seawater interface including topographic relief. This example uses the Wenner configuration 

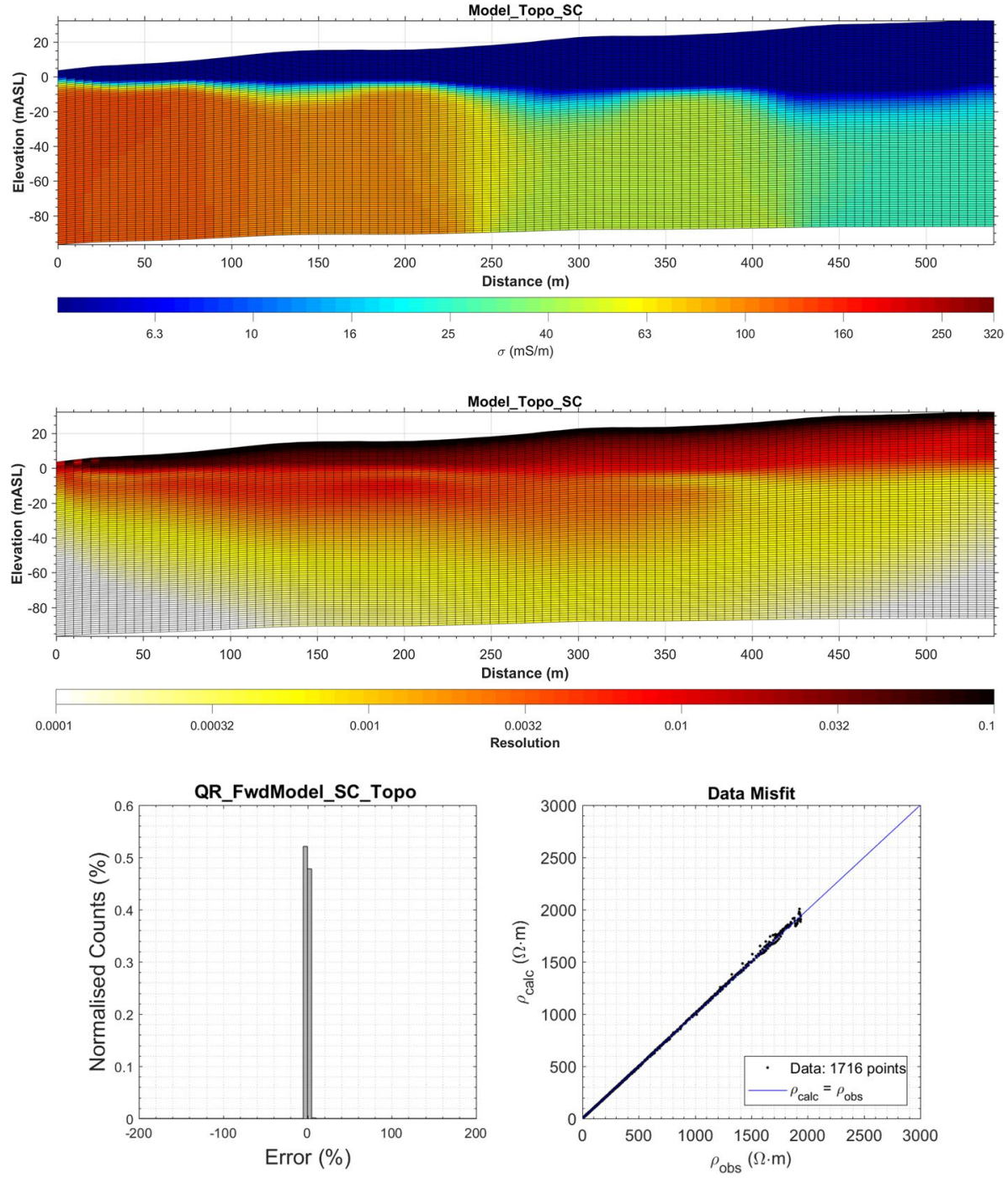

Fig. 36 Inverted conductivity distribution (top), distribution of resolution (middle), and error distribution and statistics (bottom) for the synthetic model of a seawater interface including topographic relief. This example uses the Schlumberger configuration 

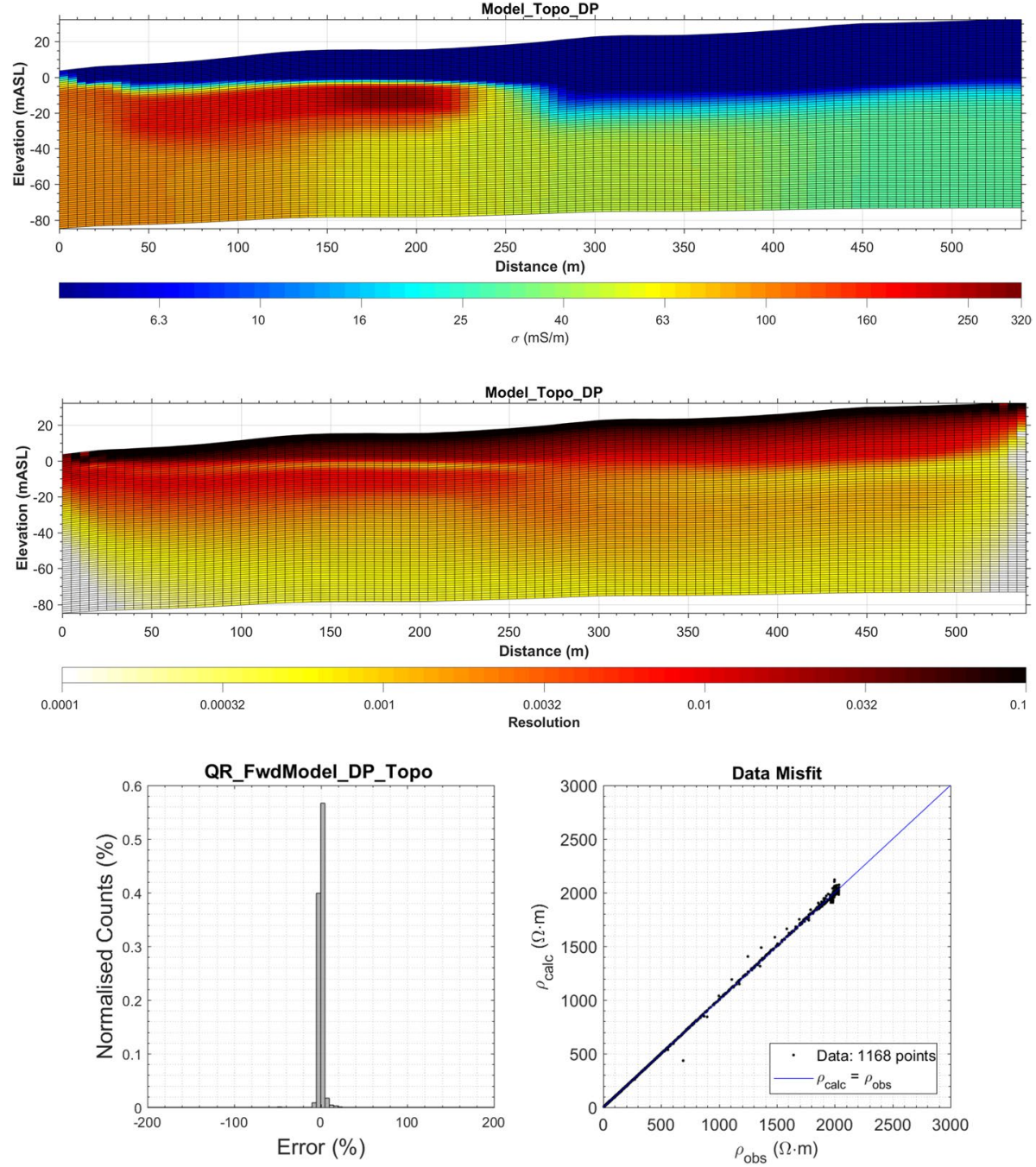

Fig. 37 Inverted conductivity distribution (top), distribution of resolution (middle), and error distribution and statistics (bottom) for the synthetic model of a seawater interface including topographic relief. This example uses the dipole-dipole configuration 

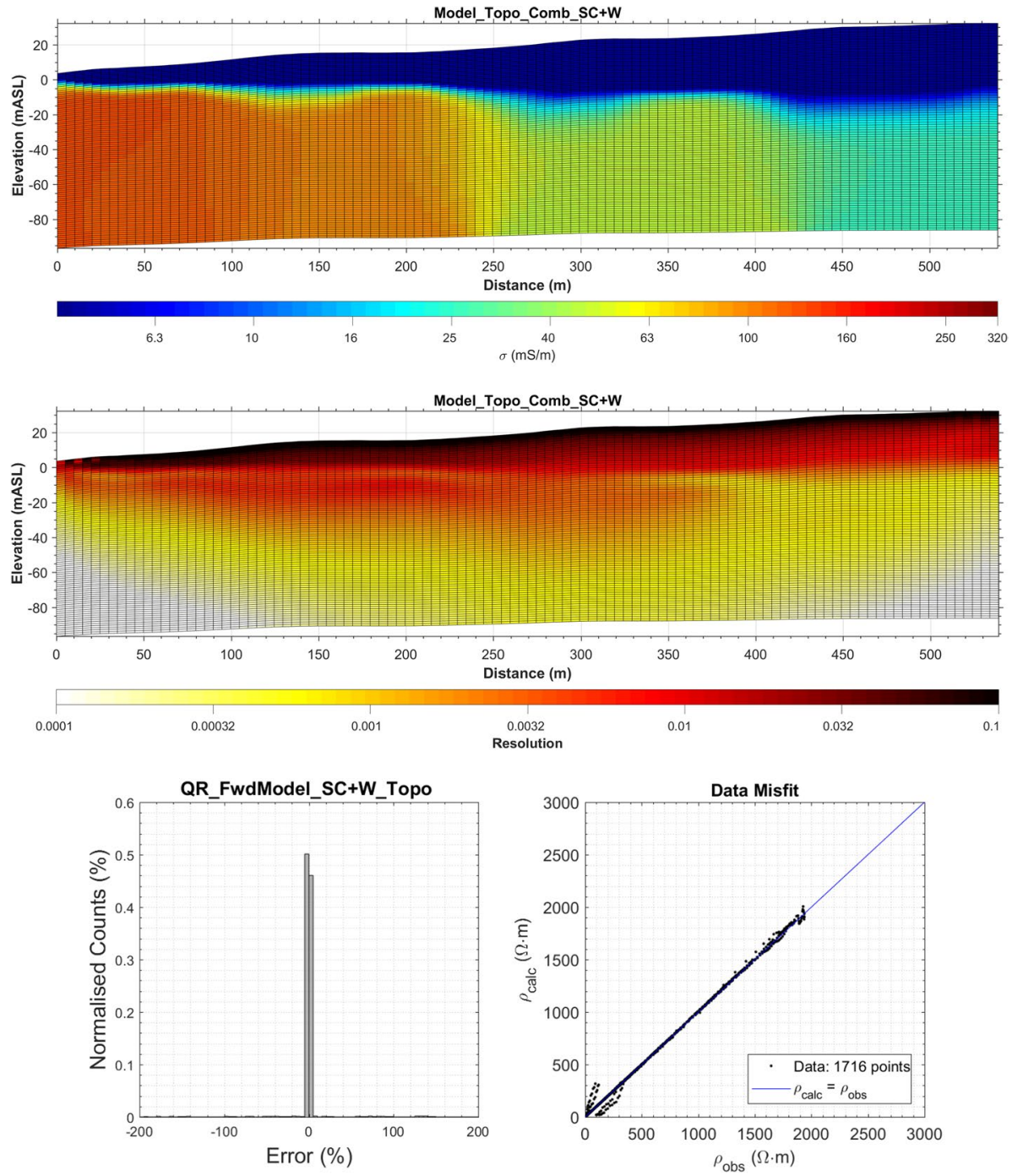

Fig. 38 Inverted conductivity distribution (top), distribution of resolution (middle), and error distribution and statistics (bottom) for the synthetic model of a seawater interface including topographic relief. This example uses the combined Wenner and Schlumberger configuration 

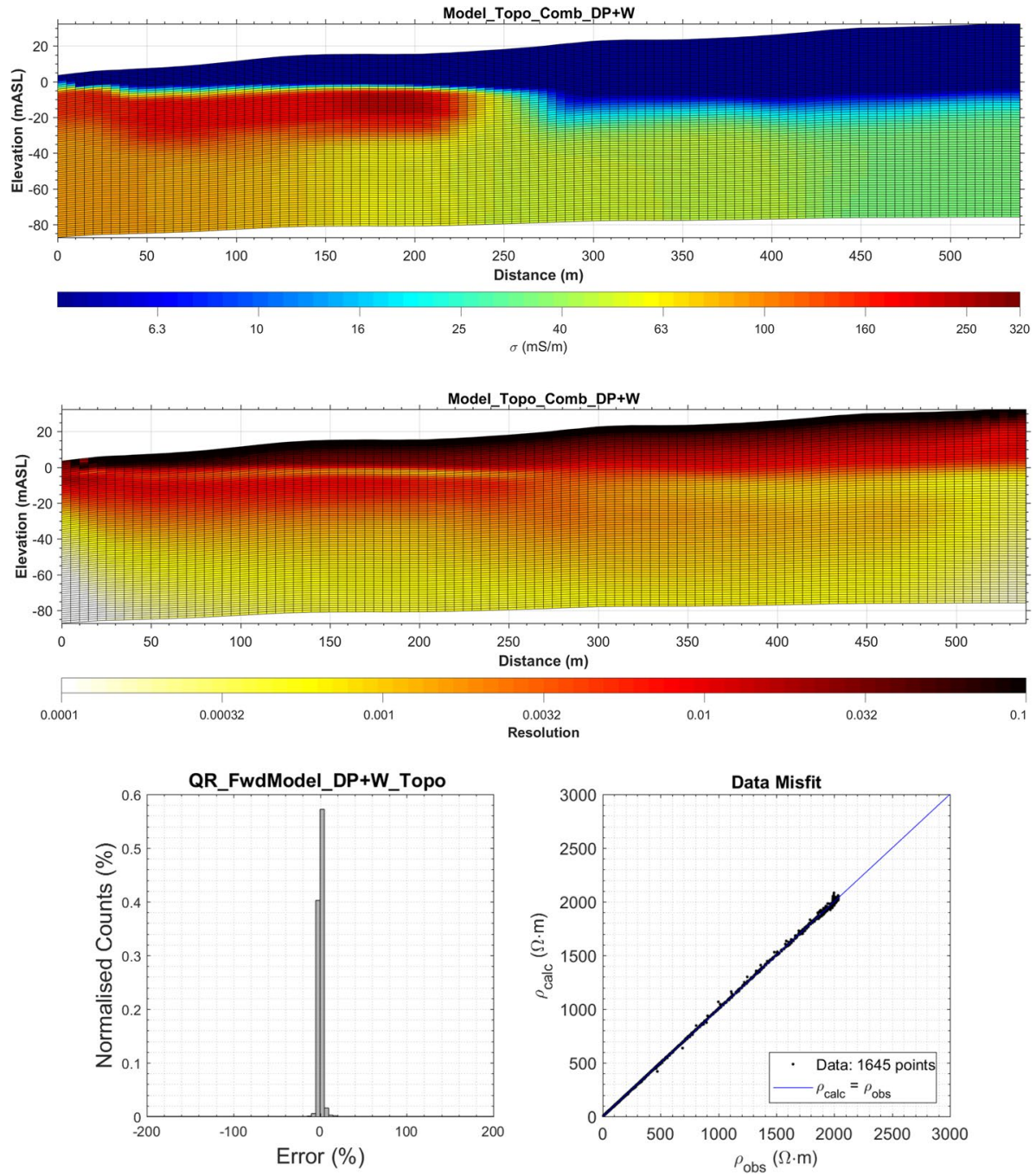

Fig. 39 Inverted conductivity distribution (top), distribution of resolution (middle), and error distribution and statistics (bottom) for the synthetic model of a seawater interface including topographic relief. This example uses the combined Wenner and dipole-dipole configuration 

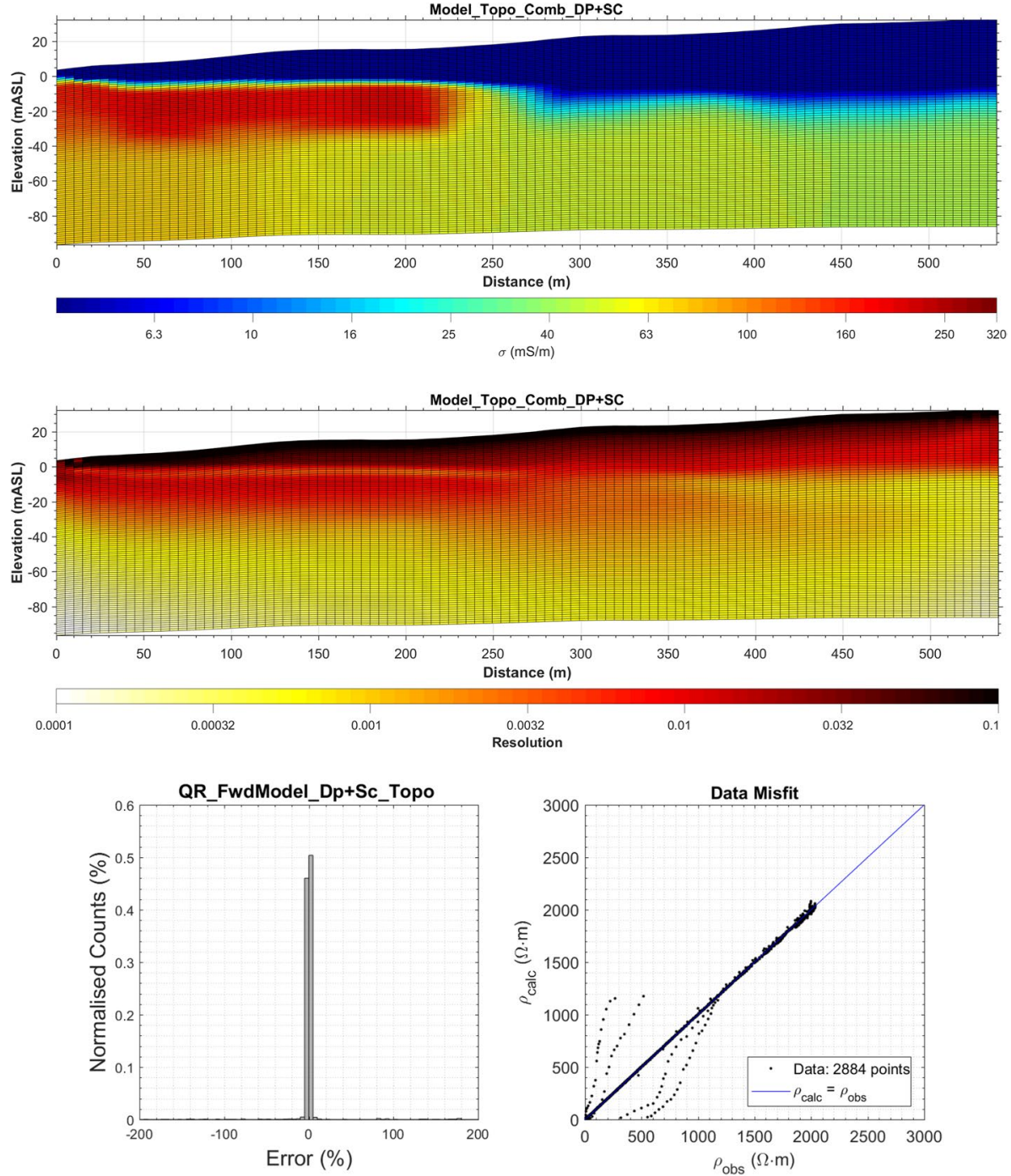

Fig. 40 Inverted conductivity distribution (top), distribution of resolution (middle), and error distribution and statistics (bottom) for the synthetic model of a seawater interface including topographic relief. This example uses the combined dipole-dipole and Schlumberger configuration 

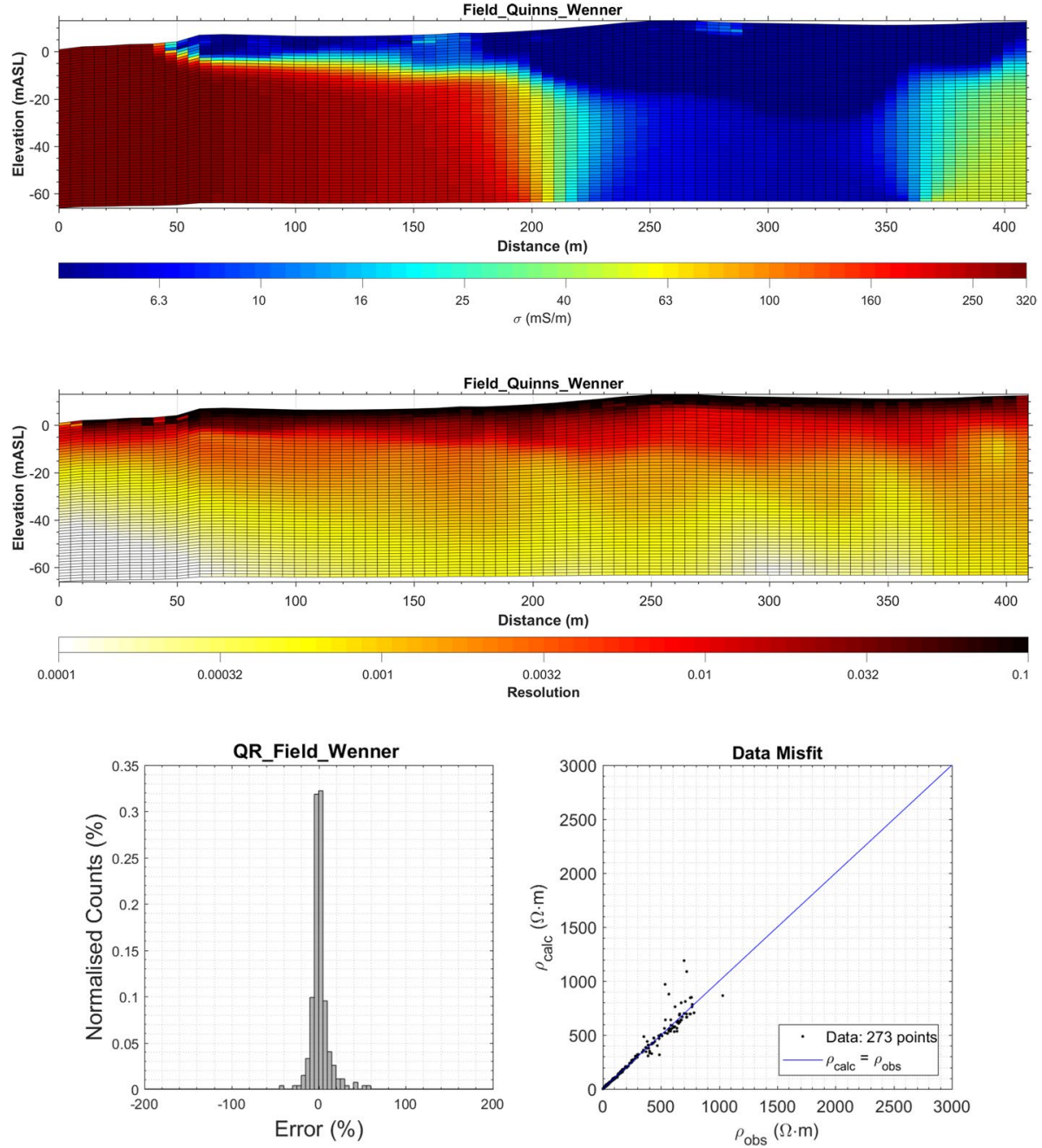

Fig. 41 Inverted conductivity distribution (top), distribution of resolution (middle), and error distribution and statistics (bottom) for the field data at the Quinns Rocks calibration site. This example uses the Wenner configuration 

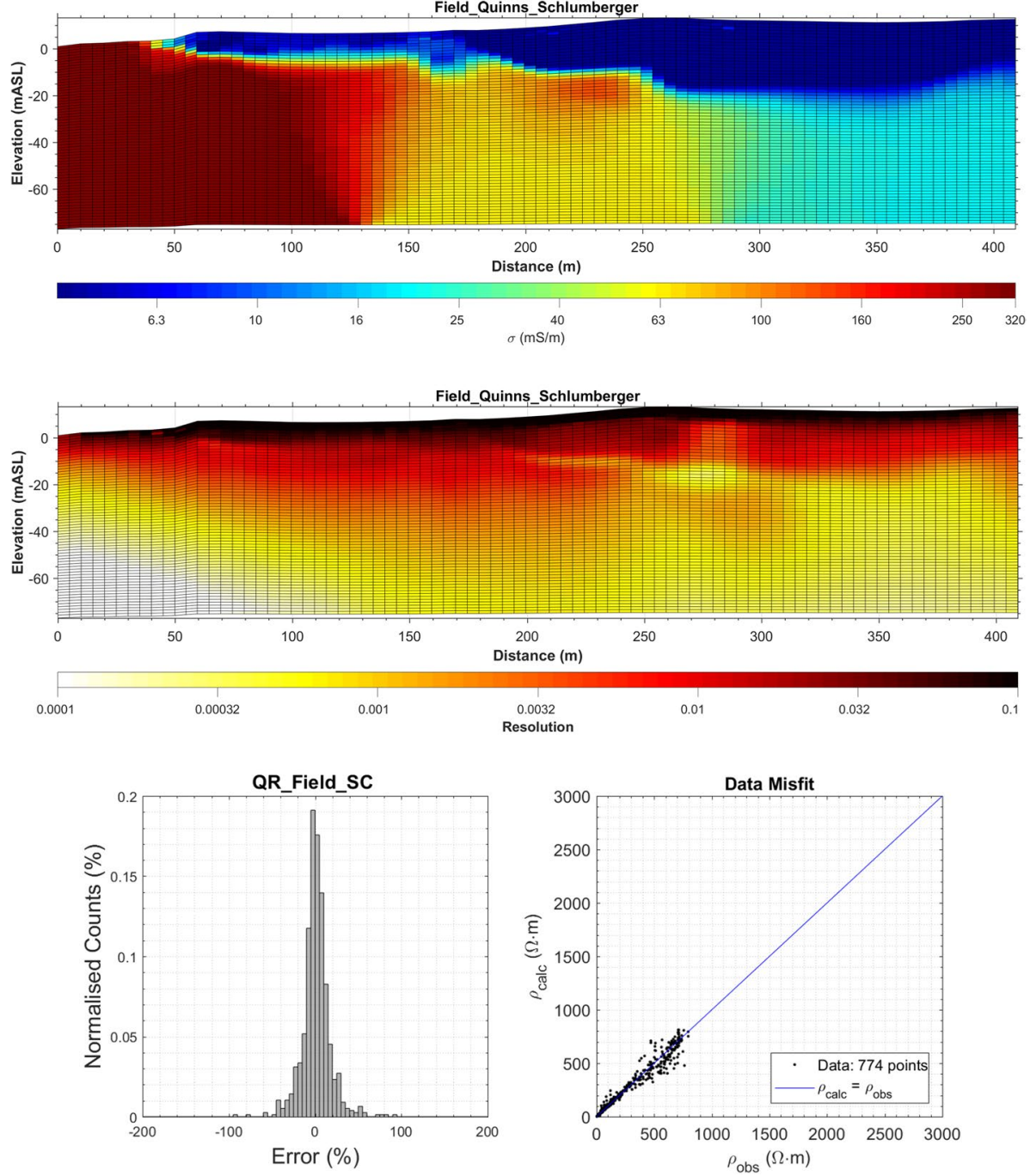

Fig. 42 Inverted conductivity distribution (top), distribution of resolution (middle), and error distribution and statistics (bottom) for the field data at the Quinns Rocks calibration site. This example uses the Schlumberger configuration 

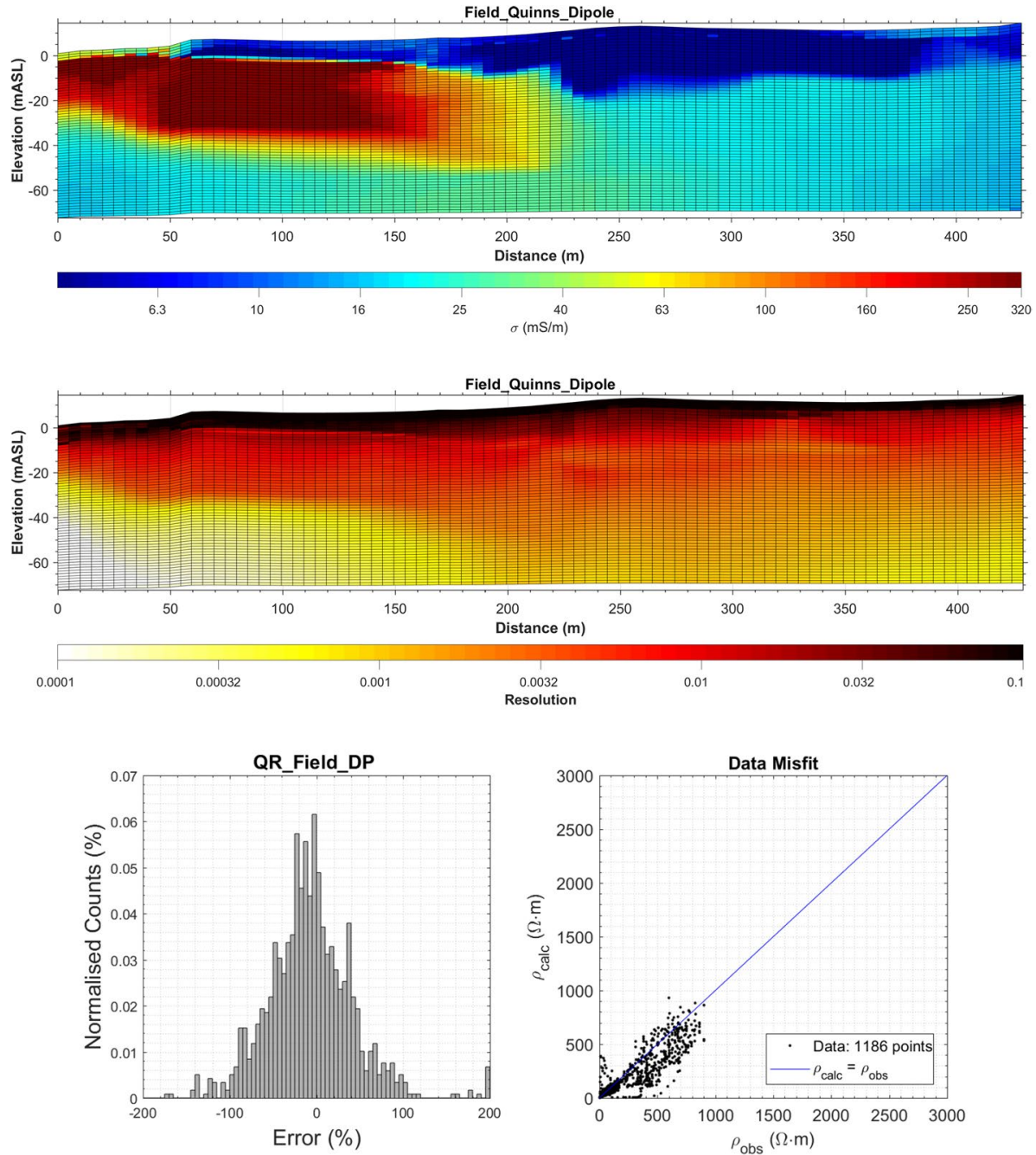

Fig. 43 Inverted conductivity distribution (top), distribution of resolution (middle), and error distribution and statistics (bottom) for the field data at the Quinns Rocks calibration site. This example uses the dipoledipole configuration 

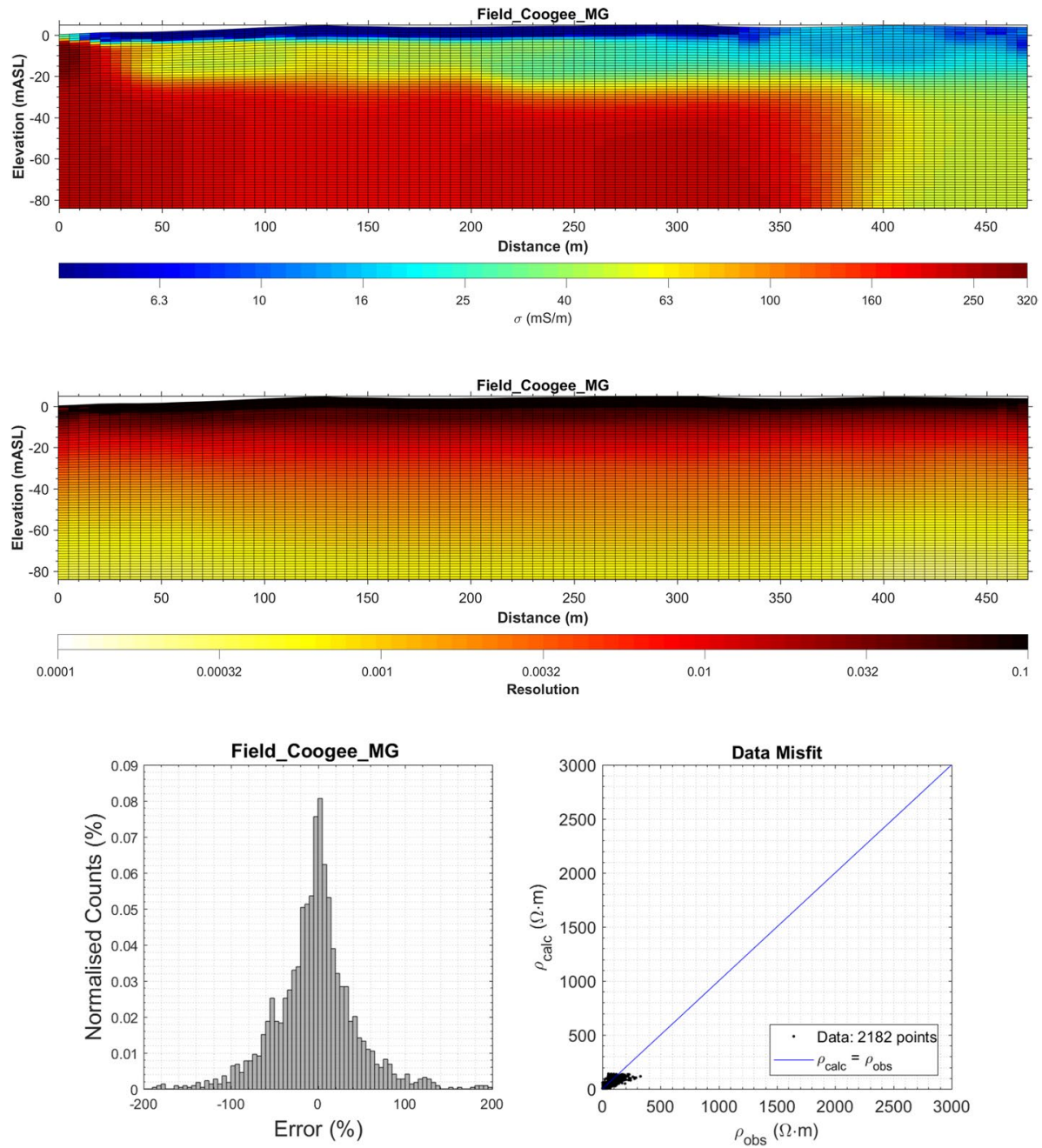

Fig. 44 Inverted conductivity distribution (top), distribution of resolution (middle), and error distribution and statistics (bottom) for the field data at the Coogee site. This example uses the multiple-gradient configuration 

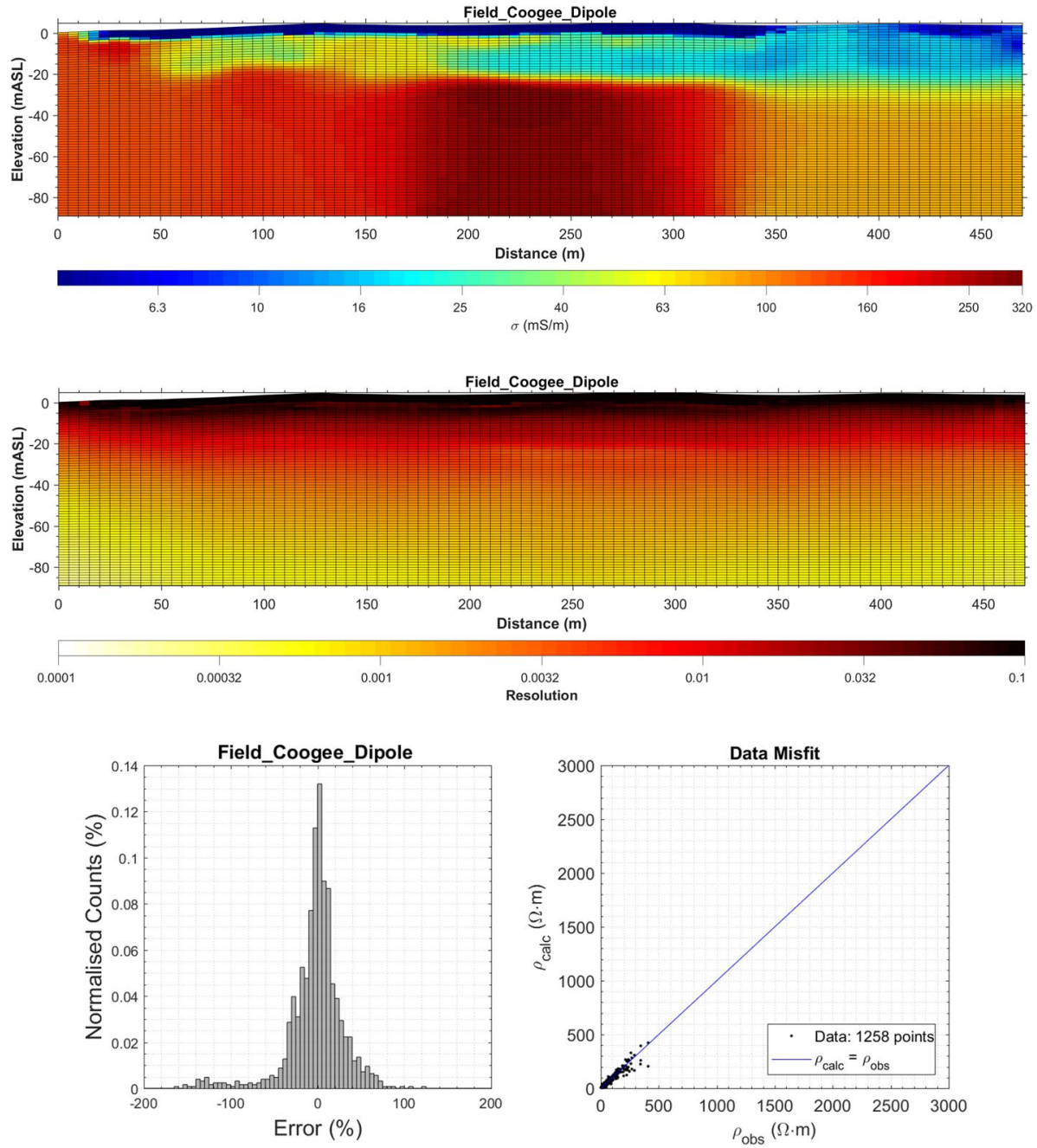

Fig. 45 Inverted conductivity distribution (top), distribution of resolution (middle), and error distribution and statistics (bottom) for the field data at the Coogee site. This example uses the dipole-dipole configuration 

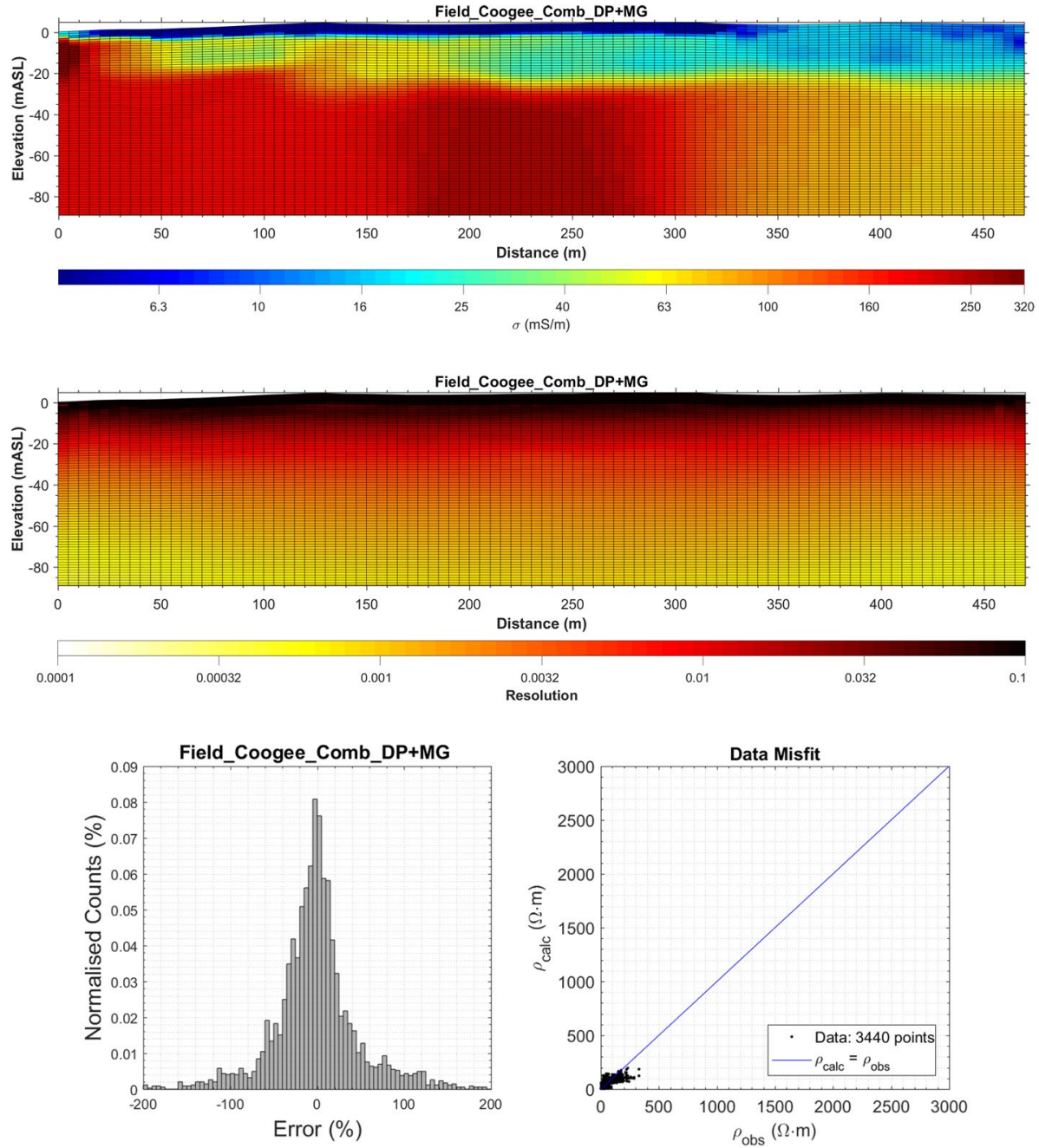

Fig. 46 Inverted conductivity distribution (top), distribution of resolution (middle), and error distribution and statistics (bottom) for the field data at the Coogee site. This example uses the combined dipole-dipole and multiple-gradient configuration 

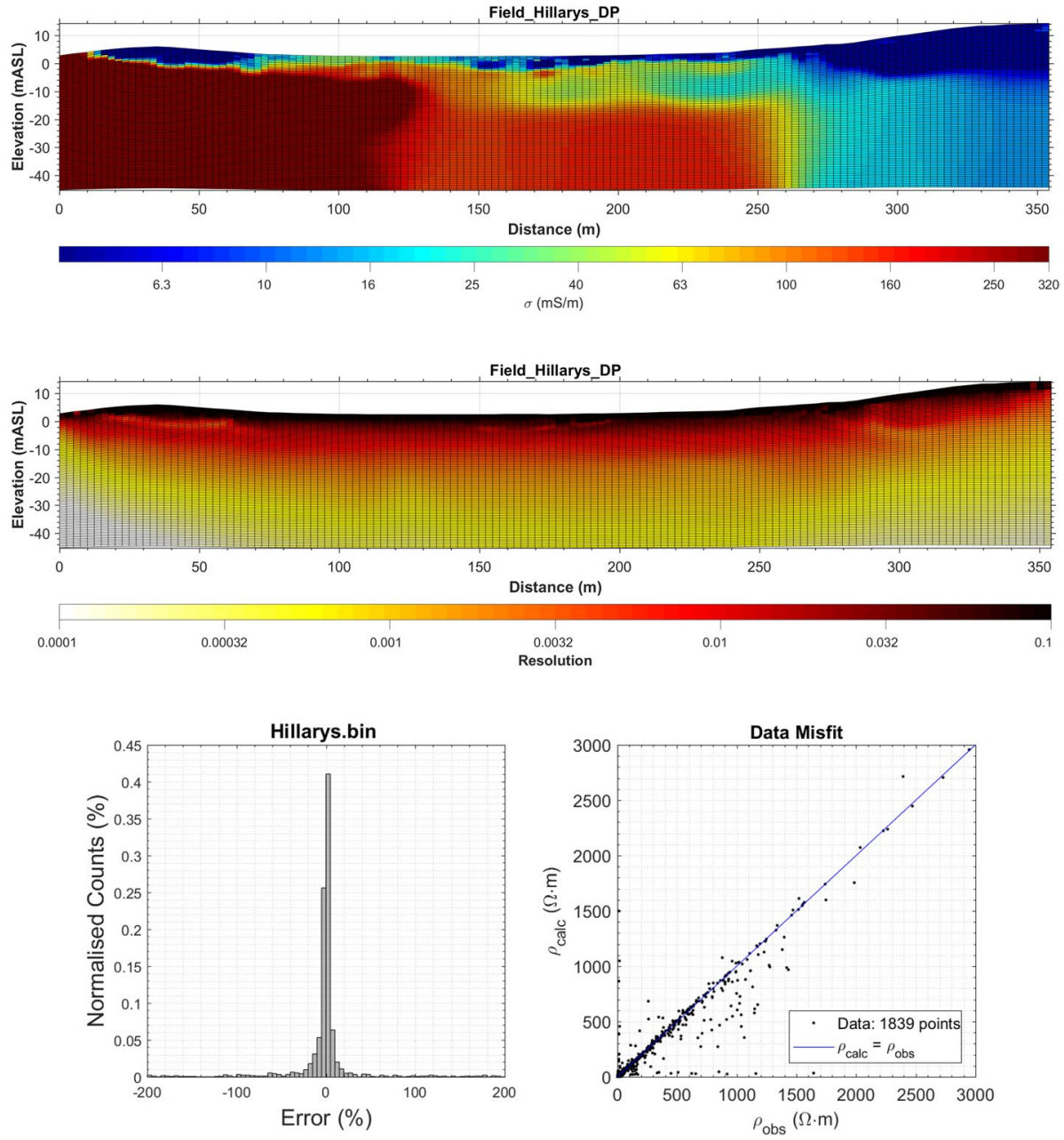

Fig. 47 Inverted conductivity distribution (top), distribution of resolution (middle), and error distribution and statistics (bottom) for the field data at the Hillarys site. This example uses the dipole-dipole configuration 

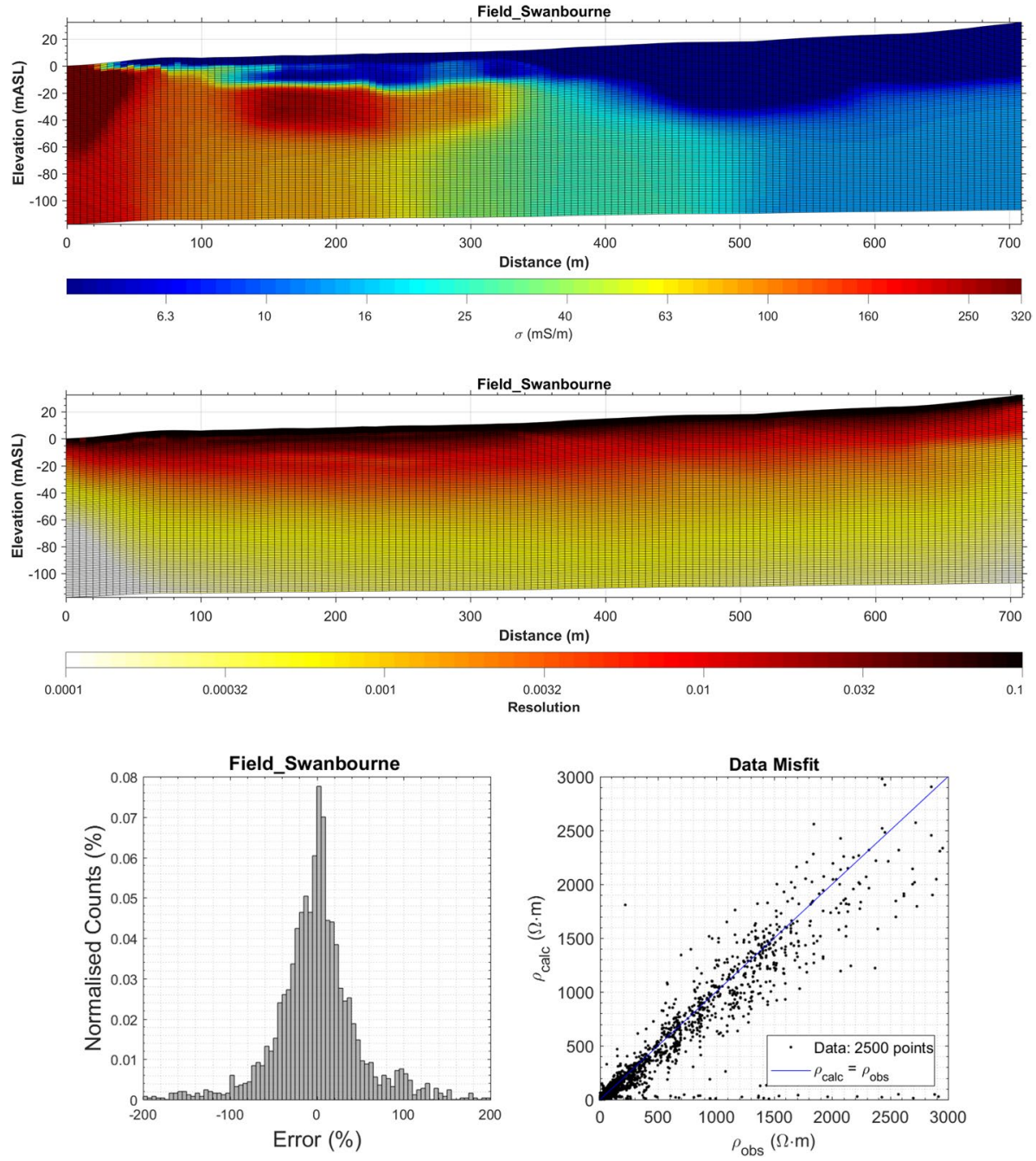

Fig. 48 Inverted conductivity distribution (top), distribution of resolution (middle), and error distribution and statistics (bottom) for the field data at the Swanbourne site. This example uses the dipole-dipole configuration 

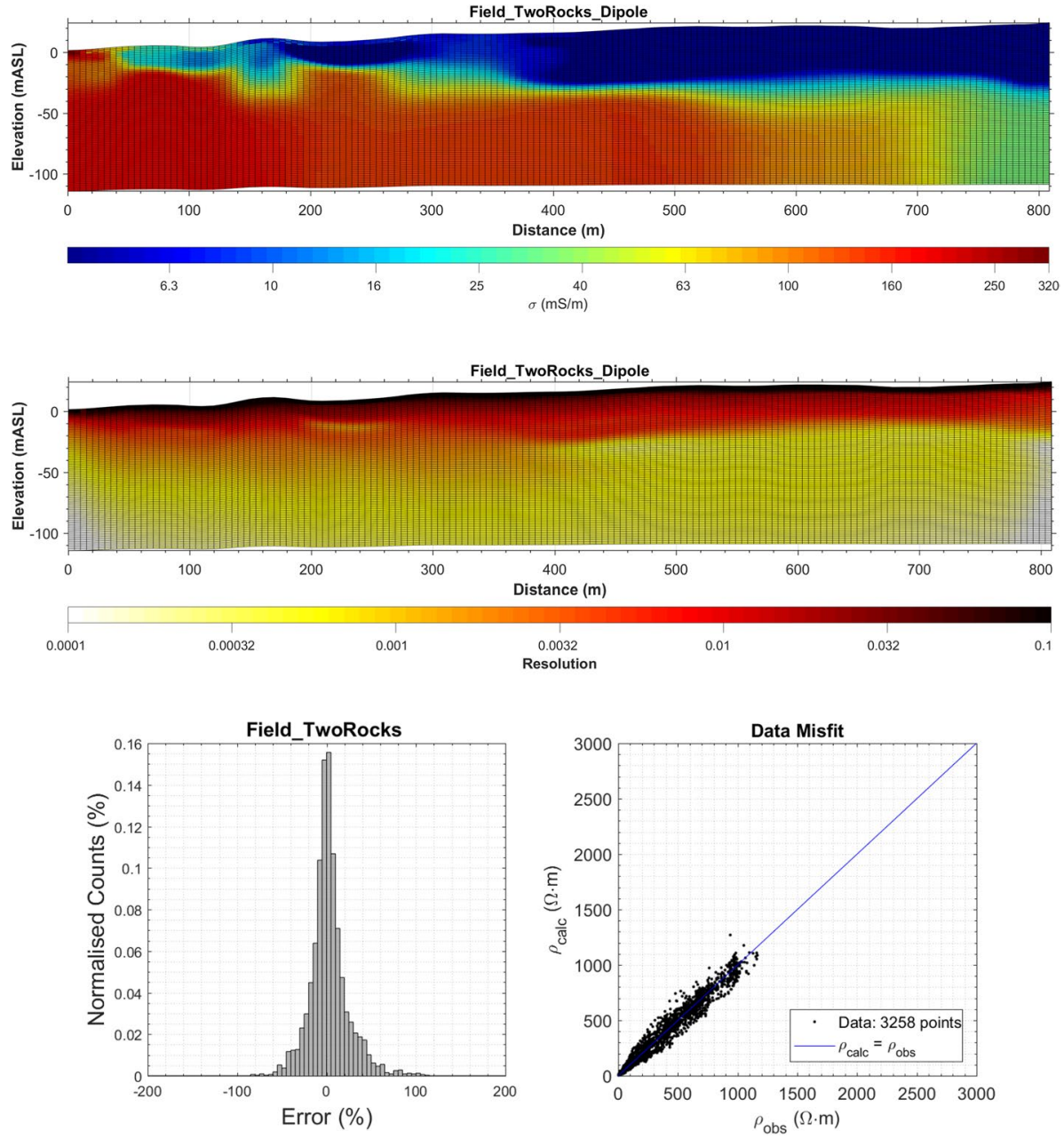

Fig. 49 Inverted conductivity distribution (top), distribution of resolution (middle), and error distribution and statistics (bottom) for the field data at the Two Rocks site. This example uses the multiple-gradient configuration

\section{References}

Abarca E, Clement TP (2009) A novel approach for characterizing the mixing zone of a saltwater wedge. Geophys Res Lett. https://doi.org/10.1029/2008g1036995

Abdul Nassir SS, Loke MH, Lee CY, Nawawi MNM (2000) Salt-water intrusion mapping by geoelectrical imaging surveys. Geophys Prospect 48:647-661. https://doi.org/10.1046/j.1365-2478.2000.00209 .x

Athanasiou EN, Tsourlos PI, Papazachos CB, Tsokas GN (2007) Combined weighted inversion of electrical resistivity data arising from different array types. J Appl Geophys 62:124-140. https://doi. org/10.1016/j.jappgeo.2006.09.003

Australian Bureau of Statistics (2006) Regional population growth, Australia and New Zealand, vol 3218.0. Australian Bureau of Statistics, Canberra

Australian Bureau of Statistics (2018) Estimated residence population (ERP) by statistical area 2 (Sa2), 1991 to 2014. Australian Bureau of Statistics, Canberra 
Beaujean J, Nguyen F, Kemna A, Antonsson A, Engesgaard P (2014) Calibration of seawater intrusion models: inverse parameter estimation using surface electrical resistivity tomography and borehole data. Water Resour Res 50:6828-6849. https://doi.org/10.1002/2013wr014020

Binley A, Hubbard SS, Huisman JA, Revil A, Robinson DA, Singha K, Slater LD (2015) The emergence of hydrogeophysics for improved understanding of subsurface processes over multiple scales. Water Resour Res 51:3837-3866. https://doi.org/10.1002/2015WR017016

Carriere SD, Chalikakis K, Senechal G, Danquigny C, Emblanch C (2013) Combining electrical resistivity tomography and ground penetrating radar to study geological structuring of karst unsaturated zone. J Appl Geophys 94:31-41. https://doi.org/10.1016/j.jappgeo.2013.03.014

Chai T, Draxler RR (2014) Root mean square error (RMSE) or mean absolute error (MAE)?-Arguments against avoiding RMSE in the literature. Geosci Model Develop 7:1247-1250. https://doi. org/10.5194/gmd-7-1247-2014

Christiansen AV, Auken E (2012) A global measure for depth of investigation. Geophysics 77:WB171WB177. https://doi.org/10.1190/geo2011-0393.1

CIESIN (2016) Gridded population of the world, version 4 (GPWv4): UN-adjusted population count. Center for International Earth Science Information Network. Accessed 16 Nov 2016

Claerbout JF, Muir F (1973) Robust modeling with erratic data. Geophysics 38:826-844. https://doi. org/10.1190/1.1440378

Constable SC, Parker RL, Constable CG (1987) Occam's inversion: a practical algorithm for generating smooth models from electromagnetic sounding data. Geophysics 52:289-300. https://doi. org/10.1190/1.1442303

Crook N, Binley A, Knight R, Robinson DA, Zarnetske J, Haggerty R (2008) Electrical resistivity imaging of the architecture of substream sediments. Water Resour Res. https://doi.org/10.1029/2008W R006968

Dahlin T (2001) The development of DC resistivity imaging techniques. Comput Geosci 27:1019-1029. https://doi.org/10.1016/S0098-3004(00)00160-6

Dahlin T, Zhou B (2004) A numerical comparison of 2D resistivity imaging with 10 electrode arrays. Geophys Prospect 52:379-398. https://doi.org/10.1111/j.1365-2478.2004.00423.x

Dahlin T, Zhou B (2006) Multiple-gradient array measurements for multichannel 2D resistivity imaging. Near Surf Geophys 4:113-123. https://doi.org/10.3997/1873-0604.2005037

Davidson WA (1995) Hydrogeology and groundwater resources of the Perth Region, Western Australia, vol 142. Geological Survey of WA

Davidson WA, Yu X (2008) Perth regional aquifer modelling system (PRAMS) model development: hydrogeology and groundwater modelling. Department of Water

de Franco R et al (2009) Monitoring the saltwater intrusion by time lapse electrical resistivity tomography: the Chioggia test site (Venice Lagoon, Italy). J Appl Geophys 69:117-130. https://doi.org/10.1016/j. jappgeo.2009.08.004

Department of Water WA (2015) Gnangara evaluation statement 2011-2014

Diersch H-JG (2014) Feflow: finite element modeling of flow, mass and heat transport in porous and fractured media. Springer, New York. https://doi.org/10.1007/978-3-642-38739-5

Ecoscape Australia Pty Ltd (2004) Foreshore management plan mindarie-Quinns rocks. Ecoscape (Australia) Pty Ltd, City of Wanneroo

Edwards L (1977) A modified pseudosection for resistivity and IP. Geophysics 42:1020-1036. https:// doi.org/10.1190/1.1440762

Ekblom H (1974) L p-methods for robust regression BIT. Numer Math 14:22-32. https://doi. org/10.1007/bf01933114

Farquharson CG (2007) Constructing piecewise-constant models in multidimensional minimum-structure inversions. Geophysics 73:K1-K9. https://doi.org/10.1190/1.2816650

Farquharson CG, Oldenburg DW (1998) Non-linear inversion using general measures of data misfit and model structure. Geophys J Int 134:213-227. https://doi.org/10.1046/j.1365-246x.1998.00555.x

Fox RC, Hohmann GW, Killpack TJ, Rijo L (1980) Topographic effects in resistivity and induced-polarization surveys. Geophysics 45:75-93. https://doi.org/10.1190/1.1441041

Gallardo LA, Meju MA (2007) Joint two-dimensional cross-gradient imaging of magnetotelluric and seismic traveltime data for structural and lithological classification. Geophys J Int 169:1261-1272. https://doi.org/10.1111/j.1365-246X.2007.03366.x

Gallardo LA, Meju MA (2011) Structure-coupled multiphysics imaging in geophysical sciences. Rev Geophys. https://doi.org/10.1029/2010rg000330

Geoscience Australia (2017) ELVIS—elevation information systsm. http://www.ga.gov.au/elvis/\#/

Gozzard JR (2007) Geology and landforms of the Perth Region. Geological Survey of Western Australia 
Günther T (2004) Inversion methods and resolution analysis for the 2D/3D reconstruction of resistivity structures from DC measurements. Dissertation

Hamdan HA, Vafidis A (2013) Joint inversion of 2D resistivity and seismic travel time data to image saltwater intrusion over karstic areas. Environ Earth Sci 68:1877-1885. https://doi.org/10.1007/s12665-012-1875-9

Heen ZHA, Muhsen SA (2017) Electrical resistivity tomography for coastal sea water intrusion characterization along Rafah Area, South of Gaza Strip, Palestine. IUG J Nat Stud

Henderson RD, Day-Lewis FD, Abarca E, Harvey CF, Karam HN, Liu L, Lane JW (2010) Marine electrical resistivity imaging of submarine groundwater discharge: sensitivity analysis and application in Waquoit Bay, Massachusetts, USA. Hydrogeol J 18:173-185. https://doi.org/10.1007/s1004 0-009-0498-Z

Herman R (2001) An introduction to electrical resistivity in geophysics. Am J Phys 69:943-952. https:// doi.org/10.1119/1.1378013

Hermans T, Vandenbohede A, Lebbe L, Martin R, Kemna A, Beaujean J, Nguyen F (2012) Imaging artificial salt water infiltration using electrical resistivity tomography constrained by geostatistical data. J Hydrol 438:168-180. https://doi.org/10.1016/j.jhydrol.2012.03.021

Igroufa S, Hashim R, Taib S (2010) Mapping of salt-water intrusion by geoelectrical imaging in Carey Islands

Imperial College London (2015) Salt water intrusion in Bangladesh. https://www.imperial.ac.uk/grant ham/our-work/impacts-and-adaptation/ipcc-working-group-ii/sea-level-rise/

Ishola KS, Nawawi MNM, Abdullah K (2015) Combining multiple electrode arrays for two-dimensional electrical resistivity imaging using the unsupervised classification technique. Pure Appl Geophys 172:1615-1642. https://doi.org/10.1007/s00024-014-1007-4

Ivkovic K et al (2012) National-scale vulnerability assessment of seawater intrusion: summary report. Australian Government National Water Commission waterlines report series no. 85

Johnson TC, Versteeg RJ, Ward A, Day-Lewis FD, Revil A (2010) Improved hydrogeophysical characterization and monitoring through parallel modeling and inversion of time-domain resistivity andinducedpolarization data. Geophysics 75:WA27-WA41. https://doi.org/10.1190/1.3475513

Karaoulis M, Tsourlos P, Kim JH, Revil A (2014) 4D time-lapse ERT inversion: introducing combined time and space constraints. Near Surf Geophys 12:25-34. https://doi.org/10.3997/1873-0604.2013004

Koukadaki MA, Karatzas GP, Papadopoulou MP, Vafidis A (2007) Identification of the saline zone in a coastal aquifer using electrical tomography data and simulation. Water Resour Manag 21:1881-1898. https://doi.org/10.1007/s11269-006-9135-y

Kretschmer P, Degens B (2012) Review of available groundwater in the superficial aquifer for the Yanchep, Eglinton and Quinns groundwater subareas. Hydrogeological report series

Krishnaraj S, Balasubramanian M, Gopinath S, Saravanan K, Prakash R, Ravindran A, Sarma V (2014) Evaluation of estuarine impact on groundwater salinization in Pondicherry coastal aquifers using electrical resistivity imagine techniques. J Coast Sci. https://doi.org/10.6084/m9.figshare.1206337

Le CVA, Harris BD, Pethick AM, Takougang EMT, Howe B (2016) Semiautomatic and automatic cooperative inversion of seismic and magnetotelluric data. Surv Geophys 37:845-896. https://doi. org/10.1007/s10712-016-9377-z

Legates DR, McCabe GJ (1999) Evaluating the use of "goodness-of-fit" measures in hydrologic and hydroclimatic model validation. Water Resour Res 35:233-241. https://doi.org/10.1029/1998W R900018

Leyland LA (2011) Hydrogeology of the Leederville Aquifer, Central Perth Basin. University of Western Australia, Crawley

Leyland LA (2012) Reinterpretation of the hydrogeology of the Leederville aquifer: Gnangara groundwater system/by La Leyland. Hydrogeological record series; $\mathrm{Hg} 59$, Accessed from http://nla.gov.au/nla.catvn6101223. Deparment of Water, Perth, WA

Loke M (2003) Rapid 2D resistivity \& IP inversion using the least-squares method geotomo software, manual 122

Loke M (2016a) Tutorial: 2D and 3D electrical imaging surveys. Universiti Sains Malaysia, Penang

Loke MH (2016b) RES2DINVx64 ver. 4.05 with multi-core and 64-bit support

Loke MH (2016c) Res2DMod

Loke MH, Lane JW (2004) Inversion of data from electrical imaging surveys in water-covered areas. In: ASEG extended abstracts 2004: 17th geophysical conference, pp 1-4. https://doi.org/10.1071/ASEG2 004ab091

Loke M, Alfouzan FA, Nawawi M (2007) Optimisation of electrode arrays used in 2D resistivity imaging surveys. In: ASEG extended abstracts 2007. Australian Society of Exploration Geophysicists (ASEG), pp 1-4. https://doi.org/10.1071/ASEG2007ab002 
Loke MH, Chambers JE, Rucker DF, Kuras O, Wilkinson PB (2013) Recent developments in the directcurrent geoelectrical imaging method. J Appl Geophys 95:135-156. https://doi.org/10.1016/j. jappgeo.2013.02.017

Loke MH, Wilkinson PB, Chambers JE, Strutt M (2014a) Optimized arrays for 2D cross-borehole electrical tomography surveys. Geophys Prospect 62:172-189. https://doi.org/10.1111/1365-2478.12072

Loke MH, Wilkinson PB, Uhlemann SS, Chambers JE, Oxby LS (2014b) Computation of optimized arrays for 3-D electrical imaging surveys. Geophys J Int 199:1751-1764. https://doi.org/10.1093/ gji/ggu 357

Loke M, Kiflu H, Wilkinson P, Harro D, Kruse S (2015a) Optimized arrays for 2D resistivity surveys with combined surface and buried arrays. Near Surf Geophys 13:505-517. https://doi.org/10.3997/18730604.2015038

Loke MH, Wilkinson PB, Chambers JE, Uhlemann SS, Sorensen JPR (2015b) Optimized arrays for 2-D resistivity survey lines with a large number of electrodes. J Appl Geophys 112:136-146. https://doi. org/10.1016/j.jappgeo.2014.11.011

Lu C (2011) Mixing in complex coastal hydrogeologic systems. Thesis, Georgia Institute of Technology

Lu CH, Chen YM, Zhang C, Luo J (2013) Steady-state freshwater-seawater mixing zone in stratified coastal aquifers. J Hydrol 505:24-34. https://doi.org/10.1016/j.jhydrol.2013.09.017

Marker PA, Foged N, He X, Christiansen AV, Refsgaard JC, Auken E, Bauer-Gottwein P (2015) Performance evaluation of groundwater model hydrostratigraphy from airborne electromagnetic data and lithological borehole logs. Hydrol Earth Syst Sci 19:3875-3890. https://doi.org/10.5194/ hess-19-3875-2015

Martorana R, Fiandaca G, Ponsati AC, Cosentino PL (2009) Comparative tests on different multielectrode arrays using models in near-surface geophysics. J Geophys Eng 6:1-20. https://doi. org/10.1088/1742-2132/6/1/001

Menke W (2012) Chapter 4-solution of the linear, gaussian inverse problem, viewpoint 2: generalized inverses. In: Geophysical data analysis: discrete inverse theory, 3rd edn. Academic Press, Boston, pp 69-88. https://doi.org/10.1016/B978-0-12-397160-9.00004-7

National Water Commission (2012) National-scale vulnerability assessment of seawater intrusion: coastal aquifer typology. Geoscience Australia, Canberra, and National Centre for Groundwater Research and Training, Adelaide

Nguyen F et al (2009) Characterization of seawater intrusion using 2D electrical imaging. Near Surf Geophys 7:377-390. https://doi.org/10.3997/1873-0604.2009025

Noel M, Xu B (1991) Archaeological investigation by electrical resistivity tomography: a preliminary study. Geophys J Int 107:95-102. https://doi.org/10.1111/j.1365-246X.1991.tb01159.x

O'Callaghan J, Pattiaratchi C, Hamilton D (2007) The response of circulation and salinity in a micro-tidal estuary to sub-tidal oscillations in coastal sea surface elevation. Cont Shelf Res 27:1947-1965. https ://doi.org/10.1016/j.csr.2007.04.004

Ogilvy R et al (2009) Automated monitoring of coastal aquifers with electrical resistivity tomography. Near Surf Geophys 7:367-375. https://doi.org/10.3997/1873-0604.2009027

Oldenburg DW, Li YG (1999) Estimating depth of investigation in dc resistivity and IP surveys. Geophysics 64:403-416. https://doi.org/10.1190/1.1444545

Paster A, Dagan G, Guttman J (2006) The salt-water body in the Northern part of Yarkon-Taninim aquifer: field data analysis, conceptual model and prediction. J Hydrol 323:154-167. https://doi. org/10.1016/j.jhydrol.2005.08.018

Pazdirek O, Blaha V (1996) Examples of resistivity imaging using ME-100 resistivity field acquisition system. In: 58th EAGE conference and exhibition. https://doi.org/10.3997/2214-4609.201408817

Pidlisecky A, Moran T, Hansen B, Knight R (2016) Electrical resistivity imaging of seawater intrusion into the Monterey Bay aquifer system. Ground Water 54:255-261. https://doi.org/10.1111/ gwat. 12351

Pollock D, Smith A, Trefry M, Davis G, Johnston C, Gardiner A (2006) Status of groundwater quality in the cockburn sound catchment

Pool M, Carrera J (2011) A correction factor to account for mixing in Ghyben-Herzberg and critical pumping rate approximations of seawater intrusion in coastal aquifers. Water Resour Res. https://doi. org/10.1029/2010wr010256

Post VE, Groen J, Kooi H, Person M, Ge S, Edmunds WM (2013) Offshore fresh groundwater reserves as a global phenomenon. Nature 504:71-78. https://doi.org/10.1038/nature12858

Price RM, Top Z, Happell JD, Swart PK (2003) Use of tritium and helium to define groundwater flow conditions in Everglades National Park. Water Resour Res. https://doi.org/10.1029/2002wr001929 
Ronczka M, Voss T, Gunther T (2015) Cost-efficient imaging and monitoring of saltwater in a shallow aquifer by using long electrode ERT. J Appl Geophys 122:202-209. https://doi.org/10.1016/j.jappg eo.2015.08.014

Roy A, Apparao A (1971) Depth of investigation in direct current methods. Geophysics 36:943-959. https:// doi.org/10.1190/1.1440226

Rücker C, Günther T, Spitzer K (2006) Three-dimensional modelling and inversion of dc resistivity data incorporating topography-I. Modelling. Geophys J Int 166:495-505. https://doi.org/10.1111/j.1365246X.2006.03010.x

Samouëlian A, Cousin I, Tabbagh A, Bruand A, Richard G (2005) Electrical resistivity survey in soil science: a review. Soil Tillage Res 83:173-193. https://doi.org/10.1016/j.still.2004.10.004

Schwarz J, Bear J, Dagan G (2016) Groundwater development in Israel. Groundwater 54:143-148. https:// doi.org/10.1111/gwat.12384

Small C, Nicholls RJ (2003) A global analysis of human settlement in coastal zones. J Coast Res 19:584599. http://www.jstor.org/stable/4299200

Smith AJ, Hick WP (2001) Hydrogeology and aquifer tidal propagation in Cockburn Sound, Western Australia. CSIRO Land and Water. https://doi.org/10.4225/08/58791689a6f92

Smith A, Massuel S, Pollock D (2012a) Geohydrology of the Tamala Limestone Formation in the Perth Region: origin and role of secondary porosity. CSIRO: Water for a Healthy Country National Research Flagship, Perth. https://doi.org/10.4225/08/599dd0fd98a44

Smith A et al (2012b) Final summary report-hydrological controls on MAR in Perth's coastal aquifer. https ://doi.org/10.5072/83/5849a0859f360

Sonenshein RS (1995) Delineation of saltwater intrusion in the Biscayne Aquifer, Eastern Dade County, Florida. USGS. http://fl.water.usgs.gov/Miami/online_reports/wri964285/

Soueid Ahmed A, Zhou J, Jardani A, Revil A, Dupont JP (2015) Image-guided inversion in steady-state hydraulic tomography. Adv Water Resour 82:83-97. https://doi.org/10.1016/j.advwatres.2015.04.001

Steklova K, Haber E (2017) Joint hydrogeophysical inversion: state estimation for seawater intrusion models in 3D. Comput Geosci 21:75-94. https://doi.org/10.1007/s10596-016-9595-y

Stummer P, Maurer H, Horstmeyer H, Green AG (2002) Optimization of DC resistivity data acquisition: real-time experimental design and a new multielectrode system. IEEE Trans Geosci Remote Sens 40:2727-2735. https://doi.org/10.1109/TGRS.2002.807015

Szalai S, Novák A, Szarka L (2009) Depth of investigation and vertical resolution of surface geoelectric arrays. J Environ Eng Geophys 14:15-23. https://doi.org/10.2113/JEEG14.1.15

Szalai S, Koppán A, Szokoli K, Szarka LC (2013) Geoelectric imaging properties of traditional arrays and of the optimized Stummer configuration. Near Surf Geophys 11:51-62. https://doi.org/10.3997/18730604.2012058

Takam Takougang EM, Harris B, Kepic A, Le CV (2015) Cooperative joint inversion of 3D seismic and magnetotelluric data: with application in a mineral province. Geophysics 80:R175-R187. https://doi. org/10.1190/GEO2014-0252.1

Tsourlos PI, Szymanski JE, Tsokas GN (1999) The effect of terrain topography on commonly used resistivity arrays. Geophysics 64:1357-1363. https://doi.org/10.1190/1.1444640

Uhlemann SS et al (2016) Integrated time-lapse geoelectrical imaging of wetland hydrological processes. Water Resour Res 52:1607-1625. https://doi.org/10.1002/2015WR017932

Van Weert F, van der Gun J, Reckman J (2009) Global overview of saline groundwater occurrence and genesis. International Groundwater Resources Assessment Centre, Delft

Verruijt A (1968) A note on the Ghyben-Herzberg formula. Hydrol Sci J 13:43-46. https://doi. org/10.1080/02626666809493624

Vorosmarty CJ, Green P, Salisbury J, Lammers RB (2000) Global water resources: vulnerability from climate change and population growth. Science 289:284-288. https://doi.org/10.1126/scien ce. 289.5477 .284

Water Corporation (2016) Perth groundwater replenishment scheme. Water Corp. http://www.watercorpo ration.com.au/water-supply-and-services/ongoing-works/groundwater-replenishment-scheme, 2018

Water-Technology (2016) Groundwater replenishment system (GWRS), Orange County, California, United States of America. Water-Technology.net. http://www.water-technology.net/projects/groundwaterrepl enish/

Water Information Reporting Database (2015) W.A Department of Water, W.A Department of Regional Development. http://wir.water.wa.gov.au

Weisstein EW (2017) Absolute error. http://mathworld.wolfram.com/AbsoluteError.html

Wentworth CK (1947) Factors in the behavior of ground water in a Ghyben-Herzberg system. http://hdl. handle.net/10125/12855 
Werner AD et al (2013) Seawater intrusion processes, investigation and management: recent advances and future challenges. Adv Water Resour 51:3-26. https://doi.org/10.1016/j.advwatres.2012.03.004

Wilkinson PB, Loke MH, Meldrum PI, Chambers JE, Kuras O, Gunn DA, Ogilvy RD (2012) Practical aspects of applied optimized survey design for electrical resistivity tomography. Geophys J Int 189:428-440. https://doi.org/10.1111/j.1365-246X.2012.05372.x

Wilkinson PB, Meldrum PI, Chambers JE, Kuras O, Ogilvy RD (2006) Improved strategies for the automatic selection of optimized sets of electrical resistivity tomography measurement configurations. Geophys J Int 167:1119-1126. https://doi.org/10.1111/j.1365-246X.2006.03196.x

Willmott CJ, Matsuura K (2005) Advantages of the mean absolute error (MAE) over the root mean square error (RMSE) in assessing average model performance. Clim Res 30:79-82. https://doi.org/10.3354/ cr030079

Willmott CJ, Matsuura K, Robeson SM (2009) Ambiguities inherent in sums-of-squares-based error statistics. Atmos Environ 43:749-752. https://doi.org/10.1016/j.atmosenv.2008.10.005

Wilson SR, Ingham M, McConchie JA (2006) The applicability of earth resistivity methods for saline interface definition. J Hydrol 316:301-312. https://doi.org/10.1016/j.jhydrol.2005.05.004

Wu JC, Xue YQ, Liu PM, Wang JJ, Jiang QB, Shi HW (1993) Sea-water intrusion in the coastal area of Laizhou Bay, China. 2. Sea-water intrusion monitoring. Groundwater 31:740-745. https://doi. org/10.1111/j.1745-6584.1993.tb00845.x

Zhou J (2015) Structure-constrained image-guided inversion of geophysical data. Thesis, Colorado School of Mines

Zhou J, Revil A, Karaoulis M, Hale D, Doetsch J, Cuttler S (2014) Image-guided inversion of electrical resistivity data. Geophys J Int 197:292-309. https://doi.org/10.1093/gji/ggu001 